\title{
Safety System Status Monitoring
}

Prepared by J. R. Lewis, M. H. Morgenstern, T. H. Rideout, P. J. Cowley

Pacific Northwest Laboratory

Operated by

Battelle Memorial Institute

Prepared for

U.S. Nuclear Regulatory

Commission 


\section{NOTICE}

This report was prepared as an account of work sponsored by an agency of the United States Government. Neither the United States Government nor any agency thereof, or any of their employees, makes any warranty, expressed or implied, or assumes any legal liability of responsibility for any third party's use, or the results of such use, of any information, apparatus, product or process disclosed in this report, or represents that its use by such third party would not infringe privately owned rights.

\section{Availability of Reference Materials Cited in NRC Publications}

Most documents cited in NRC publications will be available from one of the following sources:

1. The NRC Public Document Room, 1717 H Street, N.W. Washington, DC 20555

2. The NRC/GPO Sales Program, U.S. Nuciear Regulatory Commission, Washington, DC 20555

3. The National Technical Information Service, Springfield, VA 22161

Although the listing that follows represents the majority of documents eited in NRC publications, it is not intended to be exhaustive.

Referenced documents available for inspection and copying for a fee from the NRC Public Document Room include NRC correspondence and ir,ternal NRC memoranda; NRC Office of Inspection and Enforcement bulletins, circulars, information notices, inspection and investigation notices; Licensee Event Reports; vendor reports and correspondence; Commission papers; and applicant and licensee documents and correspondence.

The following documents in the NUREG series are available for purchase from the NRC/GPO Sales Program: formal NRC staff and contractor reports, NRC-sponsored conference proceedings, and NRC booklets and brochures. Also available are Regulatory Guides, NAC regulations in the Code of Federal Regulations, and Nuclear Regulatory Commission Issuances.

Documents available from the National Technical Information Service include NUREG series reports and technical reports prepared by other federal agencies and reports prepared by the Atomic Energy Commission, forerunner agency to the Nuclear Regulatory Commission.

Documents available from public and special technical libraries include all open literature iterns, such as books, journal and periodical articles, and transactions. Federal Register notices, federai and state legislation, and congressional reports can usually be obtained from these libraries.

Documents such as theses, dissertations, foreign reports and translations, and non-NAC conference proceedings are available for purchase from the organization sponsoring the publication cited.

Single copies of NRC draft reports are available free upon written request to the Division of Technical Information and Document Control, U.S. Nuclear Regulatory Commission, Washington, DC 20555.

Copies of industry codes and standards used in a substantive manner in the NAC regulatory process are maintained at the NRC Library, 7920 Norfolk Avenue, Bethesda, Maryland, and are available there for reference use by the public. Codes and standards are usually copyrighted and may be purchased from the originating organization or, if they are American National Standards, from the American National Standards Institute, 1430 Broadway, New York, NY 10018. 


\section{Safety System Status Monitoring}

Manuscript Completed: September 1993

Date Published: March 1984

\section{Prepared by}

J. R. Lewis, M. H. Morgenstern, T. H. Rideout, P. J. Cowley

Pacific Northwest Laboratory

Richland, WA 99352

Prepered for

Division of Human Factors Safety

Office of Nuclear Reactor Regulation

U.S. Nuclear Regulatory Commission

Washington, D.C. 20555

NRC FIN B2360 

The Pacific Northwest Laboratory has studied the safety aspects of monitoring the preoperational status of safety systems in nuclear power plants. The goals of the study were to assess for the NRC the effectiveness of current monitoring systems and procedures, to develop acceptance criteria by which the adequacy of safety status monitoring systems can be evaluated, to develop nearterm guidelines for reducing human errors associated with monitoring safety system status, and to recommend a regulatory position on this issue. A review of safety system status monitoring practices indicated that current systems and procedures do not adequately aid control room operators in monitoring safety system status. This is true even of some systems and procedures installed to meet existing regulatory guidelines (Regulatory Guide 1.47). In consequence, this report suggests acceptance criteria for meeting the functional requirements of an adequate system for monitoring safety system status. Also suggested are near-term guidelines that could reduce the likelihood of human errors in specific, high-priority status monitoring tasks. It is our recommendation that 1) Regulatory Guide 1.47 be revised to address these acceptance criteria, and 2) the revised Regulatory Guide 1.47 be applied to all plants, including those built since the issuance of the original Regulatory Guide. 



\section{SAFETY SYSTEM STATUS MONITORING}

\section{SUMMARY}

Certain safety-related systems or components of a nuclear power plant are routinely bypassed or made inoperable during periodic tests or maintenance. The control room operator must monitor the status of these safety systems so that he can make knowledgable decisions about their availability to respond to accident conditions. The Pacific Northwest Laboratory (PNL) has studied the safety aspects of monitoring the preoperational status of these safety systems and components. The goals of the study were:

1) to assess for the NRC the effectiveness of current monitoring systems and procedures,

2) to develop near-term guidelines for reducing human errors associated with monitoring safety system status,

3) to develop acceptance criteria by which the adequacy of safety status monitoring systems can be evaluated, and

4) to recommend a regulatory position on this issue.

The assessment of current systems and procedures involved three main stages: a) a survey of current industry practices, b) identification of tasks in safety system status monitoring, c) evaluation of how well current practices aid the control room operator in doing these tasks.

The survey of current industry practices included data gathered through iiterature searches, site visits to seven utility power plants, and interviews with utility personnel, reactor operators, vendors, design engineers, and industry groups. Six classes of status verification systems, some in use and some proposed, were identified. The survey also identified a special problem: some instrumentation and control valves are not monitored by control room operators but are capable of affecting power plant safety systems.

A representative set of plant administrative procedures was reviewed to obtain a listing of tasks in the monitoring of safety system status (Appendix A). Control room operations personnel and four NRC-certified 1 icensee examiners reviewed the task selection. A data flow analysis of safety system status monitoring was used to refine and validate the task listing. Each task was rated for its importance to verification of safety systems status and for its potential for human error. The result was the identification of 38 highpriority tasks (Appendix A).

The current practices identified in the survey were then evaluated for their effectiveness in reducing the likelihood of errors in the high-priority 
tasks of safety system status monitoring. None of the status verification systems or procedure strategies covered all the high-priority tasks. Several of the high-priority tasks are not aided by any of the verification systems described in this report. It was concluded that current industry practices do not adequately help the control room operator to monitor the status of safety systems. This is true even of some systems and procedures installed to meet the guidelines of Regulatory Guide 1.47 - "Bypassed and Inoperable Status Indication for Nuclear Power Plant Safety Systems."

Based on an analysis of the needs of control room operators as they monitor the status of safety systems, functional requirements and acceptance criteria were developed for a status verification system that would effectively aid operators in this task. Anong the assumptions underlying the criteria are that 1) retrofitting of instrumentation to all non-instrumented components is impractical, and 2) some procedures will be used to monitor safety system status, even in plants that install automated systems. A system that is designed to meet these acceptance criteria should reduce the likelihood of errors associated with tasks in the monitoring of safety system status.

Considering the effectiveness of current industry practices in monitoring the status of safety systems, PNL has developed some guidelines for improvements that could be implemented in the near term with relatively low cost and impact on plant activities. The improvements include:

- improved procedures

- more effective methods for independent verification of equipment status

- effective use of labels and placards on plant equipment

- clear visual indications of valve status

- identification of the safety-related components for each safety system

- display of safety system and component status

- increased management and training emphasis on the importance of maintaining a knowledge of safety system status

- improved access to engineering information

The suggested guidelines do not address all of the acceptance criteria for a status verification system. A companion to this report will be published to detail longer-term improvements needed to satisfy the general acceptance criteria.

Regulatory Guide 1.47 does not address most of the acceptance criteria developed in this project. Of the plants visited during this study, those with 
status verification systems installed to meet the intent of Regulatory Guide 1.47 were not significantly improved over plants that did not have such systems. The chief reasons for this were that Regulatory Guide 1.47 does not adequately address either the monitoring of non-instrumented components or the operator's need for a way to determine how the removal of a component will affect safety systems. It is our recommendation that 1) Regulatory Guide 1.47 be revised to adequately address the acceptance criteria contained in this report and 2) the revised Regulatory Guide 1.47 be applied to all plants, including those built since the original Regulatory Guide was issued. 

NOMENCLATURE AND GLOSSARY

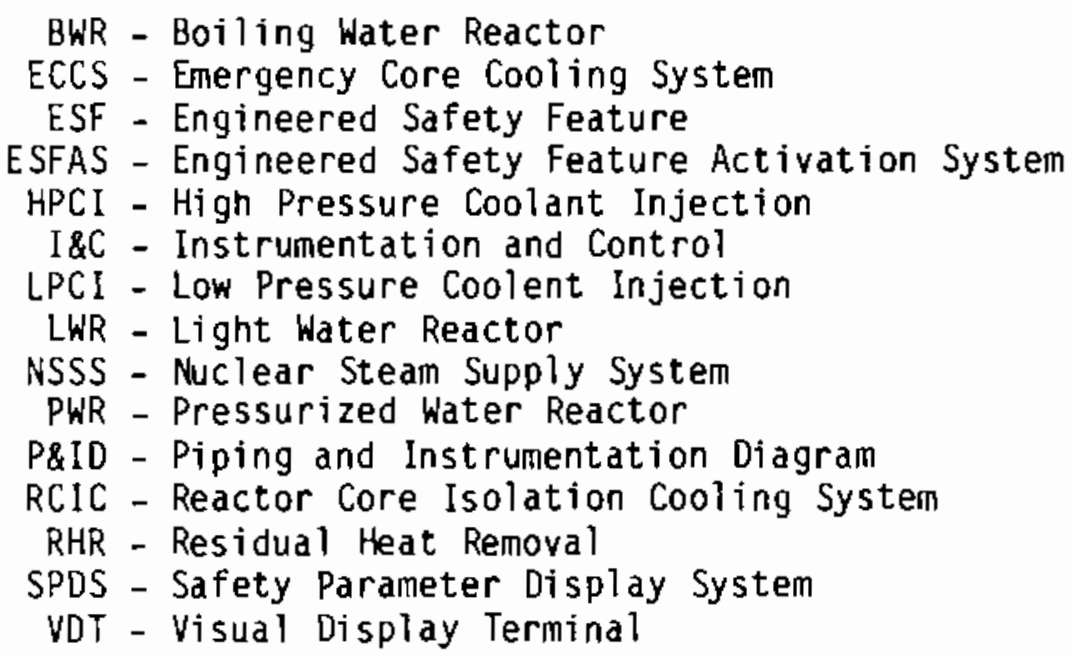

displays - all sources of information including VDTs, control panels, log books, charts, graphs, etc.

hardwired - directly connected either mechanically or electrically. For example, a valve may be hardwired to an indicator light on the control room panel, giving the operator an indication that is dependent on valve status. The vaive is then said to be hardwired.

man-machine interface - those system components which act to connect human components with machine components in a man-machine system

mimic - a simplified diagram intended to show only the major components of a complex system

safety system component - any component within safety-related systems or trains and any component of an auxiliary or support system that has the potential to degrade or make a safety system inoperable. These include those components which provide actuation signals to safety systems, such as I\&C assemblies.

\section{Status Types}

preoperational status - the status of safety systems during routine plant operations. The operator must monitor and verify the status of safety systems that are in a standby mode or are aligned to perform other plant functions.

postoperational status - the status of safety systems during abnormal and emergency events. The operator must monitor the status of safety systems that have been brought into operation to mitigate the emergency event. 


\section{System Types}

manual - system in which people provide both the power and the control. semiautomatic - system in which machines provide the power and people provide the control.

automatic - system in which machines do both the sensing and controlling in normal operation. The operator is a monitor who enters the loop to override the automatic system and enter new data where needed. 


\section{ACKNOWLEDGMENTS}

This report could not have been completed without the cooperation and assistance of many people in numerous organizations. The authors wish to extend their appreciation to the personnel at utility headquarters and power plants who so willingly assisted us in this endeavor. We thank the personnel of the various vendor and architect-engineer firms who took time out from their busy schedules to discuss their views on the subject of this study. Finally, we extend our gratitude to our Battelle colleagues who helped us in innumerable ways, from technical analyses to manuscript preparation. All these contributions have made this document a better product than it otherwise would have been. However, the authors take full responsibility for the content of this report. 



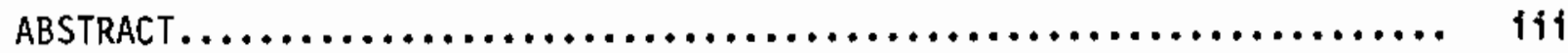

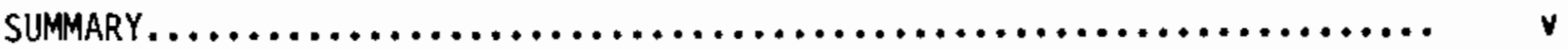

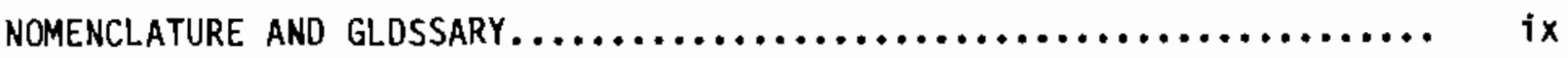

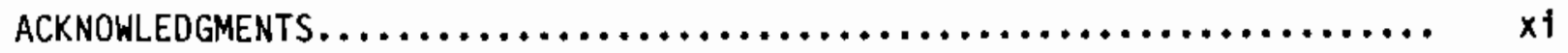

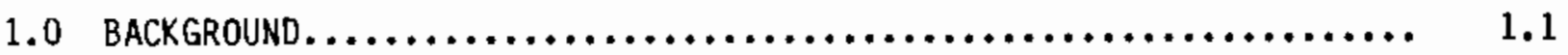

1.1 NATURE OF THE PROBLEM................................ 1.1

1.2 REgUlatory REQUiREMENTS AND GU1DELINES................. 1.2

1.3 APPROACH. $\ldots \ldots \ldots \ldots \ldots \ldots \ldots \ldots \ldots \ldots \ldots \ldots \ldots \ldots \ldots \ldots \ldots \ldots \ldots \ldots \ldots, 1.4$

2.0 SURVEY OF CURRENT INDUSTRY PRACTICES...................... 2.1

2.1 SURYEY METHODOLOGY $, \ldots \ldots \ldots \ldots \ldots \ldots \ldots \ldots \ldots \ldots \ldots \ldots, 2.1$

2.2 SURVEY RESULTS. $\ldots \ldots \ldots \ldots \ldots \ldots \ldots \ldots \ldots \ldots \ldots \ldots \ldots \ldots, 2.2$

2.2.1 Domestic Systems and Practices................. 2.2

2.2.1.1 Domestic Plant Visits................... 2.2

2.2.1.2 Instrumentation and Control Valve Issues....... 2.13

2.2.1.3 Vendor Visits.......................... 2.14

2.2.1.4 Summary of System Classes................ 2.17

2.2.1.5 Design Philosophies and Opinions Regarding
Status Monitoring Systems................... 2.17

2.2.1.6 Survey of Safety Monitor Consoles for SPDSs.... 2.22

2.2.2. Foreign Experience.......................... 2.23

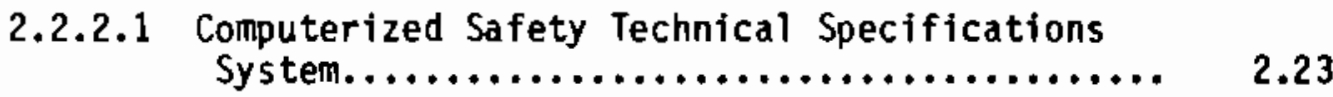

2.2.2.2 Computerized Operations Manual............. 2.24

2.2.2.3 Disturbance Analysis and Surveillance System... 2.24

2.2.2.4 Computer-Based Al arm Handling System......... 2.26 
2.3 POTENTIAL PROBLEMS IN CURRENT INDUSTRY PRACTICE............ 2.27

2.3.1 Status of Non-Instrumented Components............. 2.28

2.3.2 Surveillance Testing and Maintenance............... 2.29

2.3 .3 I \& $C$ Val ves................................ 2.29

2.3.4 Control Panel Indications $. . \ldots \ldots \ldots \ldots \ldots \ldots \ldots \ldots . .2 .29$

2.3.5 Information Processing Requirements.............. 2.30

3.0 effectiveness of CurRent Practices........................ 3.1

3.1 approach to effectiveness evaluation.................... 3.1

3.1.1 Selection of a Model of the Man-Machine Interface..... 3.1

3.1 .2 Error Taxonomy.............................. 3.3

3.1 .2 .1 Encoding $. . \ldots \ldots \ldots \ldots \ldots \ldots \ldots \ldots \ldots \ldots \ldots, \quad 3.3$

3.1.2.2 Menory $\ldots \ldots \ldots \ldots \ldots \ldots \ldots \ldots \ldots \ldots \ldots \ldots, \quad 3.3$

3.1.2.3 Information Processing and Decision Making..... 3.4

3.1.2.4 Response............................. 3.4

3.1.2.5 Motivation $. \ldots \ldots \ldots \ldots \ldots \ldots \ldots \ldots \ldots \ldots \ldots, \quad 3.5$

3.1.3 Methods for Identifying Error-Susceptible Tasks....... 3.5

3.1.3.1 Initial Task Identification............... 3.5

3.1.3.2 Data Flow Analysis..................... 3.6

3.1.3.3 Identification of High-Priority Tasks........ 3.6

3.2 RESULTS $. . \ldots \ldots \ldots \ldots \ldots \ldots \ldots \ldots \ldots \ldots \ldots \ldots \ldots \ldots \ldots \ldots, 3.7$

3.2.1 Effectiveness of Status Verification Systems......... 3.8

3.2.1.1 Conclusions - Effectiveness of Status

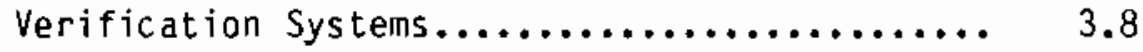

3.2.1.2 Discussion - Factors that Limit the Effectiveness of Automated Status Verification

systems................................ $\quad 3.10$

3.2.2 Effectiveness of Procedures.................... 3.11 
3.2.2.1 General Conclusions About Procedures.......... 3.13

3.2.2.2 Conclusions Specific to Verification Tasks..... 3.13

3.2.2.3 Discussion - Effectiveness of Procedures...... 3.14

4.0 SYSTEM ACCEPTANCE CRITERIA............................... 4.1

4.1 ASSUMPTIONS....................................... 4.1

4.2 FUnCTIONAL REQUIREMENTS $\ldots \ldots \ldots \ldots \ldots \ldots \ldots \ldots \ldots \ldots \ldots \ldots, 4.1$

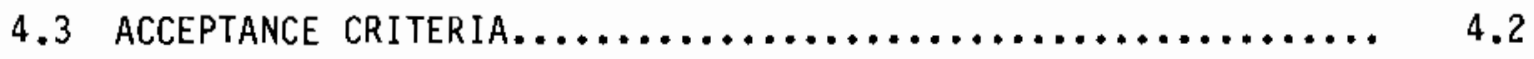

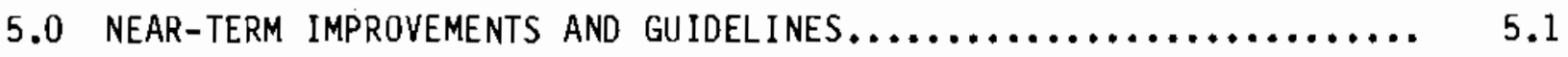

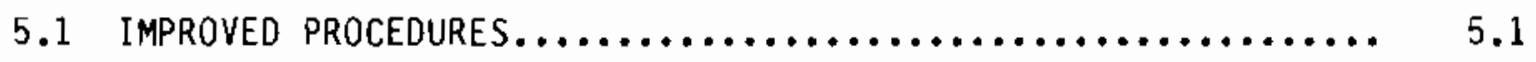

5.2 MORE EFFECTIVE METHODS FOR INDEPENDENT VERIFICATION......... 5.3

5.3 Effective use of labels and Placards................. 5.3

5.4 valve Status indications $\ldots \ldots \ldots \ldots \ldots \ldots \ldots \ldots \ldots \ldots \ldots \ldots \ldots \ldots, 5.4$

5.5 IDENTIFICATION OF SAFETY SYSTEM COMPONENTS $\ldots \ldots \ldots \ldots \ldots \ldots \ldots .5 .5$

5.6 DISPLAY OF SYSTEM AND COMPONENT STATUS................. 5.5

5.7 management and training emphas $15, \ldots \ldots \ldots \ldots \ldots \ldots \ldots \ldots \ldots, 5.7$

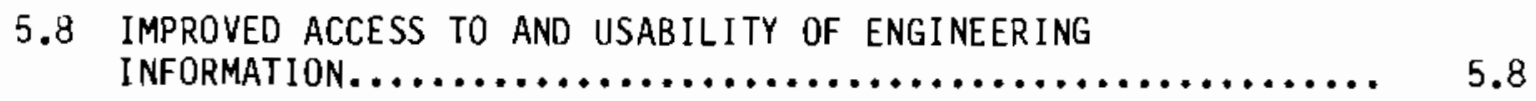

5.9 DISCUSSION - NEAR-TERM IMPROVEMENTS.................. 5.8

6.0 RECUMMENDED REgULATORY POSITION.......................... 6.1

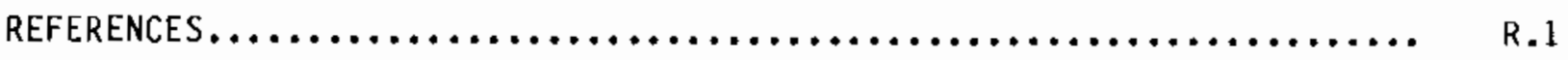

APPENDIX A - DETAILED TASK LISTING AND RATINGS FOR TASKS............ A.1

APPENDIX B - DATA FLOW DIAGRAM AND DESCRIPTION OF EACH FUNCTION........ B.

APPENDIX C - EFFECTIVENESS OF STATUS MONITORING SYSTEMS IN REDUCING THE LIKELIHOOD OF ERRORS IN HIGH-PRIORITY TASKS.......... C.

APPENDIX D - EFFECTIVENESS OF PROCEDURES IN REDUCING THE LIKELIHOOD OF ERRORS IN HIGH-PRIORITY TASKS..................... 0.1

APPENDIX E - GUIDELINES FOR EFFECTIVE PROCEDURES $\ldots \ldots \ldots \ldots \ldots \ldots \ldots \ldots$ E.I

APPENOIX F - GUIDELINES FOR LABELS AND PLACARDS................. F.1 



\section{FIGURES}

3.1 Semiautomatic System Model $\ldots \ldots \ldots \ldots \ldots \ldots \ldots \ldots \ldots \ldots \ldots \ldots \ldots, \quad 3.1$

3.2 Interactions During Safety System Status Monitoring............ 3.2

3.3 Top-Level Data Flow Diagram for Safety System Status

Monitoring................................................ 3.7

\section{TABLES}

2.1 Classes of Status Monitoring Systems and Their Characteristics.... 2.18

3.1 Effectiveness of Procedures.............................. 3.12

5.1 Relation of Near-Term Guidel ines to Acceptance Criteria for Safety System Monitoring.................................. 5.9

A.1 Detailed Task Listing and Ratings for Tasks.................... A.1

B.1 Top-Level Data Flow Diagram for Safety System Status Monitoring.............................................. B.

B.2 Data Flow for 1.0 - Prepare for Tagout....................... B.

B.3 Data Flow for 2.0 - Al ign Systems and Tag Equipment............. B.4

B.4 Data Flow for 4.0 - Perform Maintenance Task................... B.4

B.5 Data Flow for 5.D - Remove Tags and Real ign Systems............ B. 5

C.1 Classes of Status Monitoring Systems and Their Characteristics.... C.2

C.2 Task Matrix.......................................... c.3

D.1 Procedures Effectiveness Ratings.......................... 0.2 



\section{SAFETY SYSTEM STATUS MONITORING}

\subsection{BACKGROUND}

Presented here are an introduction to the problem of safety system status monitoring in nuclear power plants, a summary of currently applicable regulations, and the approach of this project in the development of guidelines for improving the situation.

\subsection{NATURE OF THE PROBLEM}

Certain safety-related systems or components of a nuclear power plant are routinely bypassed or made inoperable during periodic tests or maintenance. The status of these systems or components, which are specifically designed to respond to accident conditions, must be monitored by the operator in the control room. Operators monitor safety systems and their components using the annunciator system, indicator lights, oral and written communications, audible alarms, equipment tags, and system or component displays on visual display terminals (VDTs). The operator relies on his knowledge of the status of these safety systems to make decisions about their availability before an off-normal event and about their performance during an event.

The Three Mile Island, Unit 2 (TMI-2) incident is an example of how important it is that the operator monitor safety system components and know which components or systems are bypassed or inoperable. Following the incident, two major committees were appointed: the Nuclear Regulatory Commission (NRC) Special Inquiry Group and the President's Commission on the Accident at Three Mile Island. Their reports cite missing or inaccurate status information as a contributing factor (Rogovin, 1980; Kemeny, 1979). A human factors review of the accident identified a design deficiency that adversely contributed to operator performance during the accident (Malone, 1980):

"There is no displayed indication or alarm to indicate that the emergency feedwater systern is in misaligned or inoperative condition. The operator must visually inspect pump status and valve alignment to confirm that the system is functioning properly."

The key issue involves the operator's knowledge of the readiness of the safety systems to respond correctly when called upon to mitigate an incident. The operator must be fully aware of the state of the systems to determine whether the safety systems can respond to these demands. Because of the complex nature of these systems, the number of components involved, and the lack of monitoring instrumentation on many safety-related components, the task of monitoring the status of the systems becomes a complex information search and processing problem for the control room operator. During the stress of an incident, such as that at TMI-2, the problem may be overwhelming. 
Other more recent studies confirm that human errors associated with the operation and monitoring of the reactor safety systems are not uncommon. A study recently completed for the NRC by Brookhaven National Laboratory (NUREG/ CR-2417) involved a review of Licensee Event Reports (LERs) to develop a data base of human error associated with the operation, testing, and maintenance of reactor safety pumps and valves in licensed nuclear power plants. Of the 3,054 LERs describing pump and valve events occurring within the critical (i.e., safety-related) systems, 279 valve-related events and 195 pump-related events were identified as resulting from human error. It is generally acknowledged that reporting systems such as LERs tend to underestimate human error.

A 1981 study of critical operator decisions performed by Bolt Beranek \& Newman, Inc., for the Electric Power Research Institute (EPRI) involved an indepth review of four events that have occurred in nuclear power plants (Pew, Miller, and Feeher, 1981). The selection of these events was based on the following four criteria:

1. A potential threat to the safety of the public existed at one or more times during the course of the event.

2. Actions taken by one or more operators played a critical role in the evolution of consequences of the event.

3. Documentation in the form of Licensee Event Reports and/or manufacturer reports were available and contained sufficient information to provide an initial understanding of the time course of the event, the control actions of the operators, and the behavior of critical plant parameters.

4. Members of the control room crew on duty at the time of the event were available and willing to be interviewed.

Of the four events, three involved errors in safety system monitoring.

These two studies indicate that in safety system status monitoring a potential exists for errors which have an impact on public health and safety.

In recognition of this potential risk, the U.S. Nuclear Regulatory Commission Division of Human Factors Safety (DHFS) has contracted with Pacific Northwest Laboratory (PNL) to aid the NRC in reviewing current industry practice and in developing guidelines for the improvement of safety system status monitoring.

\subsection{REGULATORY REQUIREMENTS AND GUIDELINES}

This report was written in response to TMI Action Plan (TAP) Item I.C.6 (Procedures for Verification of Correct Performance of Operating Activities) and TAP Item I.D.3 (Safety System Status Monitoring) (NUREG-0660). 
TMI Action Plant Item 1.C.6 requires that 1 icensees' procedures be reviewed and revised as necessary to assure that an effective system of verifying the correct performance of operating activities is provided as a means of reducing human errors and improving the quality of normal operations. Such a verification system may include automatic system status monitoring and human verification of operations and maintenance activities.

TMI Action Plan I.D.3 states that the Office of Nuclear Reactor Regulation (NRR) will study the need for all licenses and applicants to monitor and verify operations, testing, and maintenance activities by means of an automatic status monitoring system. This applies only to licensees and applicants not presently cominitted to the requirements of Regulatory Guide 1.47, "Bypassed and Inoperable Status Indication for Nuclear Power Plant Safety Systems," which describes such an automatic status monitoring system. The study was to be performed following a review of procedures and other nonautomatic actions to verify these activities, as required in Item I.C.6, and following installation of the safety monitor console (Item I.D.2). Consideration was also to be given to the impact of other control room modifications on the need for automatic monitoring (Item I.D.1).

Regulatory Guide 1.47 was issued in 1973 and is applicable to plants with construction permits docketed after issuance of the guide. Section 4.13 of IEEE Standard 279-1971, "Criteria for Protection Systems for Nuclear Power Generating Stations," requires the following: "If the protective action of some part of the protection system has been bypassed or made inoperable for any purpose, this fact shall be continuously indicated in the control room." The regulatory position stated in Regulatory Guide 1.47 Section $C$ is as follows:

"The following comprises an acceptable method for implementing the requirements of Section 4.13 of IEEE Standard 279-1971 and criterion $X I V$ of Appendix $B$ to 10 CFR Part 50 with respect to indicating the bypass or inoperable status of portions of the protection system, systems actuated or controlled by the protection system, and auxiliary or supporting systems that must be operable for the protection system and the system it actuates to perform their safety-related functions:

1) Administrative procedures should be supplemented by a system that automatically indicates at the system level the bypass or deliberately induced inoperability of the protection system and the systems actuated or controlled by the protection system.

2) The indicating system of $\mathcal{C} .1$ above should also be activated automatically by the bypassing or deliberately induced inoperability of any auxiliary or supporting system that effectively bypasses or renders inoperable the protection system and the systems actuated or controlled by the protection system. 
3) Automatic indication in accordance with $C .1$ and $C .2$ above should be provided in the control room for each bypass or deliberately induced inoperable status that meets all of the following conditions:

a. Renders inoperable any redundant portion of the protection system, systems actuated or controlled by the protection system, and auxiliary or supporting systems that must be operable for the protection system and the systems it actuates to perform their safety-related functions;

b. Is expected to occur more frequently than once per year;

c. Is expected to occur when the affected system is normally required to be operable.

4. Manual capability should exist in the control room to activate each system-level indicator provided in accordance with C.l above."

\subsection{APPROACH}

The goals of this project were:

- to obtain information on current safety system status monitoring practices, and to study the safety aspects of these practices in order to provide the NRC with an assessment of effectiveness of current systems and procedures;

- to develop guidelines for reducing human errors associated with safety system status monitoring, and

- to recommend a regulatory position concerning this issue.

To achieve these goals, a multiphase approach was taken. Phase I involved a survey of current industry practices, domestic and foreign. Data was gathered through literature searches, site visits, and interviews with utility personnel, NSSS vendors, architect and engineering (A\&E) staff, consultants, and industry groups.

The emphasis in Phase II was on determining the effectiveness of current practices. This was done by identifying and defining the tasks involved in safety system status monitoring, prioritizing tasks by their importance and error potential, and then reviewing current practices to see how well they did or did not aid the operator in performing important, error-susceptible tasks. Phase II also included further site visits and interviews to confirm the validity of the task descriptions. 
The activities of Phase II generated a basis from which functional requirements and general acceptance criteria were developed in Phase III.

Phase IV, the development of guidelines for improvement of safety system status monitoring, is in progress. The current plan is to provide near-term guidelines in this report and longer-term guidelines in a subsequent report. The near-term guidelines represent improvements that can be implemented almost immediately at little or no cost. Longer-term guidelines may involve a greater investment of time and money. To appropriately satisfy the general acceptance criteria, it is envisioned that most utilities would address issues involved in both sets of guidelines, near-term and long-term.

Section 2 of this report covers the survey of current industry practices (Phase I). Section 3 evaluates the effectiveness of current practices (Phase II). Section 4 reports the functional requirements and acceptance criteria developed to describe an acceptable system for monitoring the status of safety systems (Phase III). Section 5 presents the near-term guidelines for improvement of safety system status monitoring. Based on the data and experience gathered during the course of this project, a recommendation for a regulatory position was developed and is included in this report in Section 6 . 



\subsection{SURVEY OF CURRENT INDUSTRY PRACTICES}

This review of current practices in monftoring the status of safety systems included a survey of domestic commercial LWR industry practices, systems currently being developed and implemented to aid the operator in monitoring the status of the safety systems, and some practices of the foreign nuclear industry.

This section of the report describes the initial review of safety system status monitoring obtained through interviews during site visits, vendor and utility visits, and review of documents concerning foreign experience. Discussions of the survey methodology and findings are provided in Section 2.1 and 2.2. Based on the survey findings, potential problems in current industry practice are discussed in Section 2.3.

\subsection{SURYEY METHODOLDGY}

Phase I of the project included visits to U.S. comercial nuclear power plants. The purpose of the site visits was to obtain information on the practices currently in use in the LWR industry for verifying safety system status; these practices include administrative procedures and automated systems. Visits to the plants included discussions with operations supervisors, reactor operators, and design engineers. At two of the sites, discussions were held with operator trainers. Personnel at the sites were very cooperative and attempted to provide access to operations personnel and to the control room.

The sites were selected to obtain a representative view of current industry practices. The seven site visits can be classified as follows:

Nuclear Steam Supply System Vendors

1 - General Electric

3 - Westinghouse

2 - Babcock and Wilcox

1 - Combustion Engineering

Age of Unit

1 - Near Term Operating Licensee

3 - 1970-1973 startup

3 - 1974-1975 startup

After the initial seven sites were visited, it was determined that further information was needed concerning instrumentation and control ( $1 \& C$ ) valves that were not monitored by control room personnel. To obtain this information, interviews were held with personnel at five additional plants in conjunction with site visits that were held for another study PNL is performing for the NRC. 
In addition to utility plant visits, vendors in the nuclear industry were also visited. Vendors and utilities are designing and implementing systems to aid the operator in monitoring the status of the safety systems. The four Nuclear Steam System System (NSSS) vendors were contacted and their systems or proposed systems were reviewed. Also, information was obtained on systems under development by two other vendors and one utility. These systems were reviewed to identify the types of components they monitored, the information available to the operator, and the method by which the operator must interact with the system. Vendors' plans for Safety Parameter Display Systems (SPDSs) were also reviewed to determine their applicability to safety system status monitoring.

In addition to a review of the U.S. commercial industry, this phase of the project included a review of a sample of foreign commercial experience related to safety system status monitoring.

\subsection{SURVEY RESULTS}

The survey results for domestic systems and practices are based on the site visits and interviews. The review of foreign experience is based on a search of the literature.

\subsubsection{Domestic Systems and Practices}

In addition to summarizing the domestic plant and vendor visits, this section lists basic characteristics of six status monitoring systems (both installed and proposed). A special subsection presents some design philosophies and opinions of engineers and designers involved with safety system status monitoring.

\subsubsection{Domestic Plant Visits}

At each site visited, the operators used a combination of documented records and control panel displays to determine the standby or preoperational status of the safety systems. At one plant a computer-based VDT was dedicated to safety system status monitoring. However, this display was not used by the operators because incorrect information on component status was often displayed. Another plant had a hardwired safety system panel that displayed the preoperational status of components of the safety systems and provided indications of correct operation and alignment of safety systems once they were actuated. Four other plants also had a display that provided the operator with an indication of the postactivation status of the safety systems.

At every plant there were components of the safety systems that were not instrumented. Administrative controls and procedures were used to maintain 
records of the status of these components. In all cases the operator was required to be aware of these records and to mentally integrate this information into the data from the control panel displays.

Provided below are detailed descriptions of the plant visits and findings.

Plant 1

General Description: The plant is an example of one where the operator must determine the status of the safety systems from component-level indications on the control panel and documented records of components that are not instrumented. In addition to the conventional controls and indicators for safety system components, the control panel contains a display from which the operator can determine the operability of a safety system once the system is activated.

Control Room 0isplays: The control room does not have an automated system for monitoring the bypassed and inoperable status of the safety systems. The operators must receive input solely from administrative procedures, manual logs, and component indicator lights on the control panel to determine the preoperational status of the systems.

The control room does, however, contain a Safety Injection Panel, a Containment Isolation Panel, and a Containment Spray Panel. Located on boards above the controls for the associated systems, these panels indicate to the operator whether all vaives are properly aligned for the operation of the safety system once the system has been actuated. The Safety Injection Panel also contains pump status indicators. As the pumps come on, a light illuminates on the panel to indicate the pump has started. The Safety Injection Panel is also used as a display to indicate a change in valve alignment from hot phase recirculation to cold phase recirculation. Once an actuation signal has been sent to one of these safety systems, the operator can quickly scan the panel and determine whether the safety system is operating correctly (all lights on). Thus, if the system is working correctly, very little information retrieval and information processing is required of the operator. If any of the indicators are not lit, the operator must use the indicators on the control panels and documented records on components to diagnose the cause of the problem.

Although this system aids the operator, the use of a "lights out" condition to signal a specific condition is not a recominended human factors practice.

Operator Tasks and Procedures: At this plant the operator uses a locked valve list to determine which valve, if it were mispositioned, would affect a safety system. During start-up or after maintenance, the normal valve lineups are performed. Following this, an operator is sent out to verify the lineup. For any valve on the locked valve list, another operator is sent out to verify independently the valve lineup. Whenever a locked valve is repositioned, this double verification process occurs. 
The maintenance procedures at the plant require that a $\log$ book be maintained. This book contains a sheet for each maintenance request that has not been completed. The sheets are color-coded: white for components not safetyrelated; red for safety-related components from train $A$; and blue for safetyrelated components from train $B$. The operator can look at the book and quickly see if any safety system component is out for maintenance by the appearance of a colored sheet. The operator should never see both blue and red sheets at the same time, since this would indicate that both trains of a safety component are out of service. Any maintenance on safety-related components must have approval of the operations supervisor before the component can be released for maintenance. (We were told this by the operations supervisor. However, the maintenance procedures do not state that this approval must be obtained.)

The procedures for tagging equipment require the operator to tag the control panel and then tag the equipment. Then the individual performing maintenance is required to put another tag on the equipment and to make sure that there is already an operator's tag on the piece of equipment. The operations supervisor who was interviewed felt this was more effective than dual tagging by the operators.

There are three types of tags on the control panel. A rectangular manila tag indicates that a problem exists but maintenance has not been started. A yellow tag (caution) indicates that equipment can be used but is not to be used unless absolutely necessary. An orange tag (danger) indicates equipment that is not available. These tags are of a size and shape that does not obstruct labels or indicators. Only one tag is placed on the control itself.

Shift turnover procedures state that all safety systems components that are out for maintenance must be entered on the shift turnover checkoff list at every shift change. In addition, the maintenance book must be reviewed at shift change by the oncoming shift supervisor to ensure that the supervisor knows about any safety-related components that are out for maintenance.

In summary, this plant does not have any specific display for helping the operator to determine the preoperational status of the safety systems. Thus, in order to sense information regarding preoperational status, the operator must scan several parts of the control panel and must rely heavily on documented records. On the other hand, several displays are available to help the operator quickly assess the status of these systems in their postactivation phase.

\section{Plant 2}

General Description: This plant is another example of a control room that contains a display from which the operator can determine the operability of a safety system once the system has been activated. The preoperational status of the safety system is determined wholly through the use of procedures.

Control Room Displays: Plant 2 does not have an automated system for monitoring the bypassed and inoperable status of the safety systems. The 
operators must receive input solely from administrative procedures, manual logs, and tags and component indicator lights on the control panel to determine the status of the systems.

The control room contains an integrated control and indicator panel for the four safety systems composing the Emergency Core Cooling System (ECCS). This panel consists of pushbutton control/indicator lights grouped by safety system and by reactor unit. The indicator lights are arranged such that for a particular unit and safety system, proper alignment of each component is indicated by a white light in horizontal alignment with the rest of the indicators for that system. When the system is activated, all of the white indicator lights should illuminate, enabling the operator to determine, with few information processing and information retrieval requirements, that the system has responded properly to the safety injection signal.

A11 components of the safety systems are either displayed on control room indicators or are on a locked valve list. The plant plans to install sensors on manually operated valves as part of the Plant Integrated Computer System during their 1985 scheduled outage.

The personnel interviewed indicated that the only safety system monitoring problem that misled operators was caused by a failed instrumentation power source.

Operator Tasks and Procedures: Each safety system at Plant 2 is covered by at least one Surveillance Procedure (SP). SPs are step-by-step procedural lists containing instructions to be performed, verified and checked of $f$. A Surveillance Operating Procedure (SOP), one type of SP, is followed to verify safety system component status. This involves a visual inspection of each component and a comparison against a lineup list for each train in each plant condition. Manual valves are specified in the SOP as open, closed, locked open, or locked closed. In addition, breakers for motor-operated valves, pumps, and power sources are specified as open, closed, racked in, or racked out. The SOP may refer to other SOPS for other related systems; for example, the SOP that is followed to insure that High-Pressure Injection Train A is properly aligned for ESFAS Standby refers to another SOP that verifies that Nuclear Service Raw Water System A is also properly aligned for ESFAS Standby. Locked valves are physically sealed and tagged with valve identification. Each lineup list is verified after shutdown. SOPs for safety systems are performed to verify lineup lists following maintenance or testing on that system. This verification must be performed by two operators/technicians sequentially, each independent of the other. Following performance and verification of a set of SOPs related to a safety system, the filled-out SOP form(s) represent documented records of the safety system's operability.

From a maintenance standpoint, each component can be in one of three states and is tagged as such.

- Green tag (or no tag) means component is in service and operable.

- Red tag means component is inoperable. 
- Yellow tag means "Caution: don't use unless necessary."

At shift turnover, the departing shift supervisor and the oncoming shift supervisor walk the control panel together and fill out a shift turnover log which contains all of the instrumented components for the safety systems. The purpose of this $\log$ is to ensure that the oncoming operators are aware of the status of the safety systems.

In summary, Plant 2 is much like Plant 1 with regard to safety system status monitoring. That is, no automated systems are available for preoperational verification, but an automated system is available for quickly verifying postactivation response.

\section{Plant 3}

General Description: The plant is a third example of a control room that contains a display from which the operator can determine the operability of a safety system once the system has been activated. The operator must determine all preoperational status of the safety system through the use of documented records and conventional control panel displays for those components that are instrumented. All information from this plant was obtained by a PNL employee who was at the plant for reasons other than this project. The input is based upon observation and not on a detailed interview with operations personnel.

Control Room Displays: The plant does not have a system for determining the preoperational status of the safety systems. However, there is a lighted status board in the control room where each component that is activated by an Engineered Safeguards Actuation Signal (ESAS) is represented. On this panel a red light means that the breaker is closed or a valve is open, and a green light means that a breaker is open or a valve is closed. The operator determines that the item of concern is in a safety status after engineered safeguards actuation by comparing the color of the light with the color of the component label plate. Thus, compared to Plants 1 and 2 this system requires more sensing, information retrieval, and information processing on the part of the operator.

In agreement with this conclusion, the observer noted that the status panel seems to be very "busy," "cluttered," and "confusing." It was the opinion of the observer that no one could look at it and in a glance verify that proper ESAS is occurring. While an operator with good integrated system knowledge could combine knowledge of the status panel and other indications to find a problem, he would have to devote considerable attention to detail. Again, this panel gives the operator no indication of a bypassed or inoperable status prior to an ESAS.

Operator Tasks and Procedures: All of the information concerning procedures was obtained from formal documentation rather than discussion with the operations staff. 
A station $\log$ is maintained in the control room. This $\log$ must include any change of status of safety systems and associated Technical Specifications limitations and action requirements. Some changes in safety system status require detailed documentation of the circumstances of the change. Some examples include:

(1) A safety system or component fails its surveillance test or is otherwise determined to be inoperable during routine operation.

(2) The system or component is removed from service for preventative maintenance, adjustment, modification, or repair.

(3) The system's or component's control or actuation is bypassed or otherwise overridden.

(4) Components within the system are in an "off-normal" mode requiring special operating considerations, such as automatic valves secured in their actuated position.

In addition to entry of this information on the station log, an entry must al so be made to the safety system status board.

The latest system lineup sheets and applicable valve breaker lineup exception sheets, which reflect system configuration, are maintained in the control room in the master valve breaker lineup book.

Maintenance procedures require that whenever a component is released for maintenance, its release is entered on the HOLD card/CAUTION card log book and a tag is placed on the control panel indicator for that component. An independent verification of the HOLD card request sheet must be conducted for components of safety systems. The purpose of this verification is to additionally assure that operability requirements for redundant systems are not violated and to assure that technical specifications governing the Limiting Conditions for Operation are not being violated.

Any valves that are classified as part of the safety systems must be identified and logged whenever they are manipulated and must be reverified, repositioned, and locked in their required position after completion of the maintenance task. The operators are responsible for independently verifying system realignment following removal of HOLD cards and system restoration. They are also responsible for double verification of realignment and locked status of any safety system values.

Shift turnover procedures require the shift supervisor to review the HOLD card/CAUTION card $\log$ book each shift to reassess the status of equipment which is out of service. The shift supervisor must inform the oncoming shift supervisor of HOLD cards and CAUTION cards issued and still outstanding. A shift turnover checklist provides the component positions for safeguards alignment, and the list must be checked at each shift turnover. 
This plant, incidentally, had no explicit means for defining whether a component was safety-related or not.

Thus, as with Plants 1 and 2 , this plant has no automated system for determining safety system status, although it does use an extensive set of procedures for determining this status. As with Plants 1 and 2, this plant does have an automated system for verifying postactivation status, al though the system for Plant 3 appears to place more of a load on the operator's information sensing, retrieval, and processing capacities.

\section{Plant 4}

General Description: The plant is an example of one in which a control panel was retrofitted to include a completely manual status board, providing the operator with the status of the safety systems and some of the components in those systems.

Control Room Displays: At this plant, preoperational or standby safety system status is indicated on an "Equipment Status Display." The purpose of the board is to provide the operator with one location that he can scan to determine the status of the system or components of the system. This is a manually operated status board consisting of small backlighted pushbutton controls that are labeled with component and systern names le.g., LPCI, RHR PUMP1A, and HPCI). The operator is required to update the status board manually by depressing the appropriate pushbutton controls whenever a component of the safety system is removed for maintenance. Because this is a manual system, it is still the operators' responsibility to determine if a system is operable whenever its components are bypassed or made inoperable. The operator has the responsibility for updating the board each time the status of a component changes. This board is a recent addition, and the operator interviewed believed that it helped the operations staff remain aware of the current status of the safety systems.

The controls for the safety systems are functionally grouped by system. Indicator lights associated with the controls are red and green. As in most plants, red indicates flow or power applied and green indicates no flow or no power applied. As an aid to the operator in determining whether open or closed valve status is correct, a small colored dot has been placed above the control for each component. If the dot is red, then the red light should be on when the system is activated; if the dot is green, the green light should be on when the system is activated. In order to verify that the system is functioning properly once it has been activated, the operator must visually match the color of each indicator light with the associated colored dot.

A few of the manually operated valves had limit switch indicator lights on the control panel. These indicators had been backfitted to the control panel because the utility felt they were important enough that an indication of their position was needed in the control room. The valves that were indicated were the manual valves in the main trains of the RHR, HPCI, and RCIC systems. 
Operator Tasks and Procedures: The plant has recently implemented the use of a comprehensive shift turnover checklist that is used to verify the status of components of the safety systems. The relieving senior operator walks the control panel with the senior operator who was on duty and verifies the alignment of the safety systems at each shift change. All of the components of the safety systems that have indicator lights in the control room are listed on the checklist and must be individually checked off as to their status. In addition, at each shift change the positions of all valves appearing on the locked valve list are visually verified by use of a checklist, and a second independent verification is performed by operations personnel.

Unlike previous plants, Plant 4 has a method for determining both preoperational and postactivation status of the safety systems. White the preoperational status board involves exclusive use of manual data entry, the operators believed it to be a useful method of maintaining awareness of current safety system status; i.e., it reduced operator sensing, information storage, and information processing requirements. Because of the "red-green valve openclosed" concept used on the postactivation status board, the operators are required to carry out a paired comparison visual scanning task. However, the information is easy to sense and the task requires little information storage, so the potential for error is lessened.

\section{Plant 5}

General Description: The plant is an operating license applicant. Many of the procedures are currently being written, so information on procedures was incomplete. The control room has been completed and at one time had a VDT dedicated to safety system status information. This system has been removed for reasons that are explained below.

Control Room Displays: This plant had at one time a computer-based system for monitoring the status of the safety systems. A color VDT was used to display the status. The operator could call up one of about 12 systems (not all of them were safety systems) and the screen would show a schematic of valve lineup. In addition the system would give alarms and grace times (based upon technical specifications).

This system was not liked by anyone at the plant. There were a few basic problems with it. First of all, because of hardware and software design, the system was too slow. The system could not keep up with the status of the plant. In addition, there was no continuity of software personnel that designed and maintained the system. The software was being continually upgraded and was never stabilized to the point where the valve position indication on the VDT agreed completely with the indications on the control panel.

The system has been removed and the hardware is being used for spare parts for an identical system in operation at Plant 6 . The utility is currently in the process of designing a new bypassed and inoperable status indication system. The design philosophy of this system is discussed later. 
One of the panels in the control room has five sets of system status lights (exclusive of the ones associated with reactor trips). The stated purpose of these lights is to indicate, once a safety actuation signal has been sent, whether all components of a safety system assume their proper alignment. If a component is properly aligned, in most cases the window will be lit. If the window is in a group demarcated by black tape, then proper alignment is indicated by an unlit window.

Our immediate observation was that there were very many more status indicator windows than we had observed at plants that had similar status panels. The reason for this was that many of the indicators were for components of nonsafety-related systems, e.g., the Reactor Coolant System (RCS). These indicators were interspersed among safety-related system component status indicators on the same panel. These indicators are not grouped by system. Rather, they are grouped and labeled simply as "Monitoring Group A," "Monitoring Group B," etc. The operator stated his dissatisfaction with this grouping, indicating that it resulted in an indicator often being quite a distance from its associated control.

When a safety actuation signal is received and the operator observes that a component did not align properly, he must associate the indicator, which signals misalignment, with the appropriate control. This process would require less sensing, information storage, and information processing and would be less stress-provoking if the indicators and their associated controls were located together.

The operator also expressed extreme concern that controls for aligning systems for testing were grouped with safety-related controls. He felt that this arrangement greatly increases operator response time.

Operator Tasks and Procedures: At the time of our visit, some of the procedures were being finalized for this plant, so the information obtained on procedures is incomplete. The control room maintains a System Status File for each safety system. This file contains a valve checklist with the latest valve alignments. In addition, a configuration $\log$ is kept in the control room. This is a $\log$ of short-term changes in safety system component status. They keep the latest valve checklist (which is a Quality Assurance document) in the control room in the system status file. Any time a valve is set to an abnormal position, this fact is documented either in the status file or in the configuration log. Ouring each shift turnover, the alignment of the safety systems is verified and checked off.

Every morning the operations personnel receive a copy of the computerized printout of equipment out for maintenance. During the day they maintain a carbon copy of any additional maintenance requests received that day.

This plant intends to have a preoperational safety system status panel. In the meantime, status is maintained in a $\log$ and verified manually. The plant does have a postactivation status panel. While the necessary information 
is provided to the operator regarding postoperational status, the design of the status panel appears to place more of a load than necessary on operator sensing, information storage, information processing, and action functions.

\section{Plant 6}

General Description: This was the only plant that had an automated status monitoring system. However, in spite of the fact that the system was operational, it was never used by the operators. The plant uses procedures extensively for monitoring the status of the safety systems.

Control Room Displays: The control room at this plant was basically identical to the one at Plant 5. The operators determine the status of the safety systems by the same process that was described for Plant 5 .

The Status System Monitor display, which was operational at this plant, is a computer-based system with a VDT dedicated to system status monitoring. For each system the operator can call up a piping diagram and get a picture of the status of the valves and pumps in that system. A set of hardwired lights that display the status at a system level are located at the side of the VDT screen.

Although the concept is sound, the operators do not use the system at all. Besides being slow to respond, the system provides conflicting and erroneous information. An operator pointed out multiple instances where the display showed a valve in one position and the control panel showed the valve in the opposite position. The operator said they always assume that the control panel indications are correct. Besides being unreliable, the operator felt that the display only provided him with information that he could already obtain from the control panel. None of the non-instrumented valves are displayed in the diagrams on the screen.

The operator believed that if the status monitoring system were accurate and reliable and had the capability for entering manual valve status, then it might be helpful.

Operator Tasks and Procedures: A status file is maintained for each safety system. This file contains a sheet for the approved valve alignment. Attached to the valve alignment list is a Preferred Status Deviation List. This sheet contains any approved deviations from the original valve alignment. Also, the operators maintain a configuration $\log$. The $\log$ is organized by system and contains an entry for every valve for which a temporary change in alignment has been performed.

One operator stated that he would iike a system in which he could manually enter any change in the position of a valve and would receive a printed listing of the system(s) affected and the valve alignments of that system(s). He felt that it is important for the operator to have the paper listing to use while working in the control room. This type of system would act as a procedural aid and would eliminate the paperwork involved with filling out and keeping track 
of the configuration logs. Because this would be an easier process, the operator believed this would eliminate some of the tendency to "forget" to $10 \mathrm{~g}$.

Thus, this plant had a preoperational safety systems status system that was not used by the operators because it was unreliable.

Plant 7

General Description: This plant is an example of a control room that had a hardwired panel for displaying the status of the safety systems. This panel is used to depict preoperational status of the safety systems as well as proper functioning or alignment once the systems have been activated.

Control Room Displays: The control panels are mimicked to depict flow through the pumps and valves. They also have a hardwired panel for indicating status of the safety systems. The panels are divided by train and by system within the train. A white light indicates that a component is not available. A blue light indicates that a component is in correct postactivation status (i.e., a valve is aligned properly or a pump started). An indicator that is not lit signifies the component is available but has not been actuated. The operator can scan the board and quickly determine if any instrumented components are inoperable by the presence of a white light. Once the activation signal is sent to the safety system, the operator can determine if the instrumented components are aligned properly by scanning to determine whether all of the blue lights are lit. Theoretically, the operator can also scan the board and note that a lack of lights indicates that all the systems are ready to respond. However, since the lack of a signal could also be due to a burned out bulb, this scan is only correct if preceded by a bulb status check. That is why the absence of a signal to indicate status is not considered good human factors practice.

Operator Tasks and Procedures: Administrative procedures require a monthly check of valve alignment for the manual valves. In addition, for the auxiliary feedwater system only, there is a double verification of valve alignment. The administrative procedures were in the process of being changed, however, and a double verification of all manual valves was planned. This change was initiated because of several instances in which valves were discovered to be out of position. When the operator was asked why there were problems with valve alignments, he said it was a matter of an operator just forgetting a valve or missing a valve thought to have been checked. Also, sometimes it is not even an operator who does the checking.

An example of a problem in monitoring the status of manual valves surfaced on this trip. Instrumentation and control (I\&C) engineers have their own valves downstream of root stop valves. These valves are not on P\&IDs and do not have identification numbers on them. I\&C is responsible for these valves and for realigning them after they have completed their work. The I\&C valves are not on the operators' valve lineup sheets. At this plant, they have put color codes on the valves so the I\&C people know which position to put them in 
after they are done with their work. In some cases, if these valves are misaligned, control room indications will be incorrect and/or actuating signals for safety systems may be compromised.

At shift turnover the operators check the status of the control panel. They are required to enter onto the shift turnover log any safety system components that are out for service.

As in many of the other plants, preoperational status of the manual valves in the safety systems is verified through the use of a checklist. Past problems regarding wrong information being placed on the checklist have led to a double verification format. Preoperational status and postactivation status of instrumented valves is indicated on a safety systems panel. Although this system appears to provide relevant information quickly to the operators, the use of a "light out" condition to indicate status means that the information is partially ambiguous in the "system ready" condition.

\subsubsection{Instrumentation and Control Valve Issues}

The visit to Plant 7 made us aware of a potential safety problem: instrumentation and control (I\&C) valves that are not monitored by the control room operator. This appeared to be a serious enough problem to warrant further study to determine 1) the extent to which these valves may present safetyrelated problems and 2) the potential safety impact if these valves are misaligned.

The valves that were selected for further study were safety-related system I \&C valves for transmitters, for switches, and for pressure, flow, and level indicators. These valves are "hidden" except to I\&C technicians who must manipulate them in order to block out the transmitters, switches, and indicators for surveillance testing or maintenance.

Licensee Event Reports (LERs) covering events from $6 / 01 / 81$ to $12 / 17 / 82$ were reviewed to determine if any errors involved valves of the type described above. Of the 321 LERs reviewed, 14 involved valves of this type. The immediate consequences of misaligned valves to indicators, transmitters, or switches were:

- A reactor protection system subchannel was inoperable.

- An emergency diesel generator was inoperable.

- A remote containment pressure monitoring channel was inoperable.

- A steam generator pressure indication was inoperable.

- A main steam line hi-flow trip was inoperable.

- A HPCS auto-initiation on reactor level-low was inoperable. 
- A loss of auto-initiation of ECCS on drywell hi-pressure occurred and this presented a threat to containment integrity.

The conditions just described could affect safety. If one of these valves were to be inadvertently left misaligned on the redundant train of a system where one train is already unavailable due to maintenance, the general design criterion of redundancy might be violated. Another possibility is the inadvertent disabling of an instrument that should automatically actuate a safety system in an emergency.

Operations staff at five plants were interviewed to evaluate the extent of the problem and the steps utilities might be taking to solve the problem. Events associated with misalignment of these types of valves were noted in four of the five plants visited. At all five plants administrative procedures have been implemented, or are being implemented, to reduce the likelihood that these misalignment errors will occur. The procedures vary in the way that valve alignment is verified and controlled:

- The valve alignment is verified by I\&C technicians and the valve listing is not sent to the control room.

- The valve alignment is verified by I\&C technicians and the valve listing is sent to the control room.

- Prior approval of the control room supervisor is required to initiate work and system testing is required when the component is returned to service. The valve alignment is doubly verified by I\&C technicians.

At one plant, even though double verification was performed, an incorrect valve status was reported.

\section{2 .1 .3 Vendor Visits}

Vendors and utilities in the nuclear industry are designing and implementing systems to help the operator monitor the status of the safety systems. The four NSSS vendors were contacted and their systems or proposed systems were reviewed. Also, information was obtained on systems under development by two other vendors and one utility.

These systems were categorized into three classes (A, B, C) based upon their functional characteristics. These three classes are described below.

\section{Computer System Type A}

One system under development is a Safety Parameter Display System (SPDS) that supports safety system status monitoring. The displays for the safety system status monitoring portion are separate from the other SPDS displays. Currently there are ten display formats: 
- a summary display of the readiness status of the safety systems

- display (one for each of six safety systems) that provides messages whenever a component of a system is not available -- If a component is part of two or more systems, this fact will be indicated on the display.

- one piping and instrumentation drawing for the high-pressure injection system

- a mimic of the $480-V$ essential bus

- one display for prediction capability.

The system does not allow manual input for non-instrumented components. It does, however, have a hypothetical "what-if" capability. The operator can enter an instrumented component identifier, and the system will provide an assessment of the effect that the removal of this component will have on all of the safety systems.

\section{Computer System Type B}

A second system currently under development is a computer-based system that uses a color VDT and a keyboard that has dedicated function keys for display selection. There are three levels of display in a hierarchical structure:

(1) The top-level alphanumeric display is used to indicate the status of each of a preselected number of safety systems. The display page consists of the name of the system, the train (if applicable), and the words "operable" or "inoperable." If a system is inoperable, the line indicating that system will be displayed in black lettering on a red background.

(2) The second-level alphanumeric display is organized in the same way as the first level, but it shows subsystems that compose a particular top-level system.

(3) The third-level alphanumeric display is like the other two except that it shows component-level information.

The system status level display will be on the screen until the operator requests a lower-level display. This is accomplished by moving the cursor on the screen until it is positioned over the system for which more detailed information is desired. Then the operator pushes a special function key ("display page") on the keyboard, and the next-level display will appear.

The operator has the option of entering a technical specification time limitation for any system that is inoperable. The status indication system will then count down and provide a pre-warning and warning alarm as the technical specification time limitation is approached and reached. 
The operator has the capability to enter the status of non-instrumented components in the safety systems. The fact that the data on a particular component was entered manualiy will appear on the display whenever that component's status appears on the display.

This system also has a hypothetical mode. Whenever the operator requests this mode, the system captures a snapshot of the current plant state. The operator can then hypothetically change the state of any valve or pump by entering the appropriate information into the system. The system will determine the overall effect of these changes to the safety systems, and the displays will reflect this effect. Whenever the operator has the system in a hypothetical mode, the displays are identified as hypothetical.

\section{Computer System Type C}

A third type of computer system is being developed to provide improved monitoring of critical equipment in nuclear facilities. The system components include a minicomputer, an operator work station, and a data collection subsystem. All of the equipment in the plant that is to be monitored is affixed with permanent bar-coded equipment tags. During the monitoring process, an individual walks the plant with a hand-held terminal and bar-code reader. The equipment is identified by use of the bar-code reader, and the operator keys in the component status. The data is transmitted to the minicomputer via radio base stations. In addition to the data channel, the terminals contain a voice channel for communication with the control room personnel.

The data base for the system consists of:

- equipment identification, location, and normal status

- blocking sequences and permits

- piping and instrumentation diagrams (P\&IDs)

- transaction logs.

Using this data base, the system has the capability to produce items such as checklists for valve alignment verification, bar-coded tags, blocking sequences for maintenance and testing activities, survey lists of equipment, and historical studies of transactions.

The operator workstation consists of a text VDT, a graphics VDT, and a graphics tablet (a light-pen-sensitive board used for operator interaction with the graphics display). The text VDT is used for displaying menus, messages, and tabular reports. The graphics VDT is used to display digitized piping and instrumentation diagrams. The diagrams are overlayed with component status information as it is transmitted to the computer. The system allows the operator to "point to" a portion of the P\&ID with a light pen and then provides a "zoomed-in" version of that section of the P\&ID on the screen. Once the display is on the screen, a hard copy can be printed directly from the screen.

For the initial installation of the system at the plant, all input to the data base will come from the hand-held terminals. Future expansions of the 
system could include the capability to pick up the signals from the existing hard-wired sensors and to update the recorded status from these signals.

\subsubsection{Summary of System Classes}

The systems described in the previous two sections are examples of those currently installed in the plants and those under development. The basic characteristics of these six systems are shown in Table 2.1.

\subsubsection{Design Philosophies and Opinions Regarding Status Monitoring Systems}

Discussions with the designers of the various safety system status monitoring systems, NSSS vendors, and architect engineer representatives revealed design philosophies that guided development of these systems. In some cases, designers had philosophies that contradicted those used by other designers. The ideas expressed by the individuals are important because they represent philosophies of individuals with a great deal of experience in the nuclear industry. These philosophies are grouped by subject. The opinions below are stated without evaluation by the authors.

1. Provision for operator input on the status of non-instrumented components:

- With manual input there are "so many ways to set yourself up for a big fall." Operators are not ready to use a system with manual input capabilities conscientiously. Because of the tendency towards overkill, use of manual input would end up being very informal and thus the reliability of the information presented by the system would be degraded.

- The capability for entering status on components manually is important, but this capability is useful only if it is used consistently and under strict administrative control.

- A manually updated, system-level status display for safety systems would be valuable if (and only if) it were to be implemented in a manner that the operators would accept, and if it were integrated into training programs and operating procedures.

- When considering manual input of status information to a status indication system, one must ask oneself "what have you really done for the operations staff except give them something else to worry about?"

2. Use of piping diagrams on displays:

- P\&ID mimics on the screen are an advantage to a system of this type if they are carefully formatted and updated to agree with the actual P\&IDs (although they may contain less detail). They should only show the actual status of the system, not alarins. In other words, 
TABLE 2.1. Classes of Status Monitoring Systems and Their Characteristics

I. Push-Button Status Panel

- No readings from instrumented components

- Manual input capability

- Selected number of components on the display

II. Conventional Control Panel

- Displays consist of only the normal control panel display of each component.

- These displays may or may not be grouped by safety system.

III. Control Panel Indicator Lights Specifically for Safety Systems

- Display is grouped by safety system.

- Lights give status of safety system components once the system has been activated.

- Only a selected number of system components are displayed.

- Some systems of this type have a limited capability to change component status indication if equipment is out of service, thus giving limited preoperational status.

IV. Computer-Based System A

- Obtains input only from instrumented components

- No capability for manual input

- Displays system and component status on a CRT

- Limited graphic diagram of systems

v. Computer-Based System B

- Obtains input from instrumented components

- Capability for manual input

- Displays system and component status on CRT

- Hypothetical capabilities

- No graphics capabilities for P\&IDs for system mimics

VI. Computer-Based System C

- Does not obtain input from instrumented components

- Capability for manual input

- Positive identification of equipment by bar code reader

- Communication from balance of plant to control room

- No hypothetical capabilities

- Extensive P\&ID graphic displays with real-time updating of data 
no determination of what is normal and what is off-normal should appear on the P\&ID display. The alarming display function should be associated with the other displays generated by the system.

- It is not necessary for a bypassed and inoperable status indicator system to display P\&IDs.

3. Backfitting of Instrumentation:

- The answer is not to instrument every manual valve or to have administrative procedures that cover the verification of every noninstrumented valve on the safety systems. What is needed is an evaluation of the components that are important to the safe operation of the system. One way to do this is to perform a Probablistic Risk Assessment (PRA) similar to the one that was recently done for Zion. This would identify those valves that were important. After this is done it is important to retrofit instrumentation on those critical valves. An example of a typical valve that shows up on a PRA was provided. The Refueling Water Storage Tank (RWST) typically has one line as outlet from the tank. This line has a normally open de-energized instrumented valve. However, in addition to this valve, there are one or two manually operated locked chain valves with no instrumentation. These valves are normally open, but if they were to be left closed inadvertently and this condition remained undetected, there would be no source of water from the RWST.

- The overall effectiveness of Regulatory Guide 1.47 and the SPDS in the control room needs to be evaluated. One needs to take into consideration the role of computer systems in the rest of the control room as well. A system that monitors the bypassed and inoperable status of the safety systems is potentially as good as the degree of instrumentation in the plant.

- All of the valves cannot be monitored in any reasonable manner, but at least some of the key components should be monitored.

- Regulatory Guide 1.47 is "too big to Dackfit." Everyone is interpreting 1.47 as a mandate to instrument everything, and no one is doing any analysis on what should be monitored. The questions that should be asked are:

1. Where is the risk involved?

2. What should be monitored?

3. What should be tested?

The solution to 1.47 is to determine the key components that are not instrumented so that they can be highlighted in some manner with procedures. It is extremely important to define a manageable list of critical components. 
- If instrumentation is to be retrofitted for the purpose of implementing automatic systems for safety system status monitoring, a key issue is whether or not this instrumentation is to be qualified Class 1E. To build a reasonable automatic safety system status monitor would require non-Class $1 \mathrm{E}$ instrumentation. Just the paperwork associated with Class IE qualification would render the job impractical.

- A typical plant will have 16 to 24 main steam safety valves and eight turbine bypass valves that are not currently instrumented. It is important, from a safety standpoint, to instrument these particular components for automatic monitoring regardless of the cost and difficulty. The best way to do this is with sensors for presence and absence of flow.

- At one time, a plant was designed (and subsequently canceled) in which every manual valve's position was to be electrically monitored and fed into a multiplexer that was to drive a set of system-level status displays in the control room, one display for each valve train. The basis for this design was a strict post-TMI interpreta. tion of Regulatory Guide 1.47 . This was a reasonable thing to do during the original plant design phase, but to backfit such a system to an existing plant, particularly an older plant, would be economically out of the question.

- In considering retrofitting automatic status monitoring systems to most plants, the biggest engineering and implementation costs and problems come down to a matter of "real estate," $i . e .$, control room panel space.

- Consideration of VDTs for backfitting status indications in existing control rooms is premature in that not enough research has been done in the human factors area.

- Backfitting functions for bypassed and inoperable status indication on an existing dedicated turnkey computer systen that implements an SPDS is not a good idea. It would be better to implement the bypassed and inoperable status indication as a separate, dedicated turnkey system.

4. Use of procedures for monitoring:

- There has been overkill in some administrative procedures concerning the verification of valve line-up. The tendency of the utilities has been to put every manually operated valve on the valve line-up verification list. Thus it may become the policy to check 500 valves every day. When the operators are required to check that many valves they become sloppy and tend to think that the valve was in the correct alignment yesterday so I won't bother checking it today. An example was cited which occurred at a plant six months 
ago. A manually operated locked valve in the high pressure injection line was logged in as open but in fact was closed. When the system was actuated, it failed to work correctly because the valve was closed and the operators had no indication of its true status.

- Procedures can be effective for monitoring the status of the safety systems in those plants that do not currently have a high degree of instrumentation.

- Good procedures result in proper lineup and accurate verification of 1 ineup status. Procedures may, in fact, make improper assumptions, but the solution to this problem is to fix the procedures, not to retrofit instrumentation to augment or replace bad procedures.

5. Predictive or hypothetical capability:

- Hypothetical "what-if" capability is important if it is implemented properly. The predictive software must be able to identify interaction between systems. It is fairly obvious within each train what compromises the system, but when you get into components that support each train it is much harder for the operator to determine whether one or both of the trains will be compromised by the removal of a component. The logic must reflect what components you can have out of service and still meet limiting conditions for operation. Typical of those items that affect multiple systems or trains are: power supplies, essential bus power supplies, and three pumps supporting two trains. The LERs have identified quite a few times a year when certain combinations of components taken out of service have compromised both trains.

6. Operator input to design:

- Operator input during design and testing of any system that will be put in the control room is important.

- Operator input into the design and testing of systems of this type is extremely important. Operator training is a critical item and aids in their acceptance of the system. It is very important to phase a computer system into the control room. If the system has process information on it, the operator will use the system on a day-to-day basis and not just in an emergency. In this way the operator will be familiar with the system before it must be used in an emergency.

7. Other ideas:

- The system status monitoring information should be provided to the shift supervisor, who needs to sit back and get the "big picture" of what is going on in the plant. The operator doesn't need this information on a routine basis. 
- All parameter codes on VDT displays should be redundantly coded by color and shape. Thus, if the VDT loses its color the operator can still obtain the important information from the screen.

- Installation of TV cameras in control rooms for status monitoring, or any other purpose, may contribute to the problem of operator stress.

- More human factors research is needed to determine how to effectively design and implement control room alarms. Many human factors studies have just tended to knit-pick specific controls and indicators. What's needed is a systems approach to the issue of human factors in the control room. In particular, more research on the subject of Disturbance Analysis and Surveillance Systems should be done.

This ends the section on design philosophies and opinions regarding status monitoring systems.

\subsubsection{Survey of Safety Monitor Consoles for SPDSS}

TMI Action Plan Item I.D.2 states that the licensees and applicants will be required to install a Safety Parameter Display System (SPDS) that will display to operating personnel a minimum set of parameters that define the safety status of the plant. The SPDS is to provide a continuous indication of plant safety status during normal and abnormal operating conditions. The plant parameters to be monitored by the SPDS include a limited set of variables from which a primary display can be derived. This primary display shall indicate the status of the plant in terms of the following five functions las a minimum):

- reactivity control

- reactor core cooling and heat removal from primary system

- reactor coolant system integrity

- radioactivity control

- containment integrity.

The regulatory position and systems proposed by several vendors were reviewed to determine their applicability to safety system status monitoring. None of the proposed SPDSs really addressed the objectives of monitoring safety system status - nor were they intended to. An SPDS that meets the stated functional criteria may provide the control room operator with adequate information to determine that safety systems are functioning properly once they are activated. But it is not the intent of regulations, nor is it the posture of the nuclear industry, that the SPDS provide specific, component-level diagnostic information on components of safety systems. 


\subsubsection{Foreign Experience}

All information on foreign experience was obtained from reports that were available as of June 1981. No site visits were made. No personal interviews were conducted. The following sections summarize the results of the literature search.

\subsubsection{Computerized Safety Technical Specifications System}

Work is being done at the OECD Halden Reactor Project, in cooperation with Desterreichisches Forschungszentrum Seibersdorf, Austria, (Halden HWR-30) on a computerized operations manual for safety technical specifications. A pilot Computerized Safety Technical Specifications (CSTS) system was installed in the FORSMARK-1 Nuclear Power Plant in Sweden to test the main ideas of the computerized off-line system.

The basic function of the CSTS is to provide information on the status of components in a safety system. The operator will enter the changes in status of operation for components, and the system will provide operating restrictions, time limitations, and test requirements. In addition to the operational mode, the system has a hypothetical mode whereby the operator can enter a proposed component status change and determine the effect the proposed change would have on the safety system. This capability is useful in planning maintenance work.

The CSTS operates by having pertinent information from the technical specifications stored in the computer in the form of decision tables. Whenever an operator enters the identification for a component that has changed status, the CSTS can determine the status of the system of which this component is a part. The determination of status is affected by the mode of operation of the plant (e.g., cold shutdown, power mode, etc.). Other information that is displayed by the CSTS includes the time at which the change in the status of the component was reported, the time remaining before technical specifications are vio1 ated, and conditions and limitations for operations.

The CSTS is basically an operational aid. The displays are generated by software run on a minicomputer. The system is off-line; that is, it receives no input from sensors on the actual components. A11 input is provided by the operator at the keyboard as required by operating procedures. The CSTS aids the operator in record-keeping. The real power of this system is that the operator can determine the effect that the removal of a single component has on the entire safety system.

The system was experimentally operated from January to April 1981, and the operators experience and views were reported (Dah11, 1981b). The conclusions drawn from the questionnaires presented to the operators indicate that with the current implementation of CSTS the test mode of the system is the most useful function, and the system may be used often during maintenance planning. 0ahll concluded that a CSTS system will be a valuable tool if: 
- It is not a stand-alone system but an integrated part of the control room facilities.

- It is connected to a system for computerized handling of fault reports, etc.

- It is self explanatory and easy to use and understand.

- It has a high reliability and availability.

- It has a fairly short response time, which means that it should not share computing resources with programs having heavy computation.

We concluded that the CSTS project should be followed closely. Because a system of this type is relatively easy to develop and does not require instrumentation in the plant, it represents one possible technique for improving safety system status monitoring methods in the U.S. commercial nuclear power industry at fairly low cost.

\subsubsection{Computerized Operations Manual}

The concept of off-line computerized operation manuals (described above), has been expanded in other work being done in connection with the OECD Halden Reactor Project as reported in "Potentials of Computer-Assisted Operation Manuals" (Dah11, 1981a). The Computerized Operation Manual (COPMA) system, which was described in the Dahll report, would use information on plant status obtained by operator input or directly via the plant process computer. Based on this information the system would find the correct part(s) of the operation manual and present the contents to the operator. The emphasis in this project was on manuals that contain sequences of instructions that the operator must follow in various plant situations.

An important point of this report was the recognition that in operating the plant the operator does not stay in one location. Therefore, a VDT in a fixed location would necessitate the operator running to and from the screen whenever the instructions are presented and input has to be made. The solution to this problem, which was proposed in this study, was to give the operator a hand-held portable terminal that shows the instructions one by one. In addition, there would still be a fixed VDT display in a central location. The mimic system diagrams, which reflect changes resulting from operator actions, are presented on the VDT.

\subsubsection{Disturbance Analysis and Surveillance System}

Research is under way on Disturbance Analysis and Surveillance Systems (DASS). Their primary function is to aid the operator in analyzing any plant disturbance. One example of such a system, which has been under development in 
Gemany, is the STAR system(a). This system uses a logical and chronological combination of plant data and modeling techniques to perform its functions. The system associates actual signal patterns with the expected system pattern based on the mode1. A primary goal of the system is to present more useful information to the operator and present less nuisance information.

The functions of a DASS are to determine the cause of a disturbance, analyze and predict its development, present corrective actions, and provide general surveillance support. The specific functions performed by the STAR system include:

- status surveillance of the plant process during normal operations as well as disturbance analysis

- provision of information about the operability of automatic functions, control systems, etc., and about the availability of the safety and protection systems

- check of completeness of function sequences (post trip analysis)

- determination of the primary cause of a disturbance

- suppression of nuisance alarms, thereby reducing the amount of primary information

- provision of information about the expected propagation of the disturbance

- surveillance of mass, energy, and momentum balances to determine anomalous plant states

- surveillance of characteristic curves for components to obtain better information about the operation of the components

- prediction of the behavior of systems or components by means of simulation models

- consistency check of instrumentation

- provision of information about unanticipated disturbances

- support of the systems analysts in the construction of process models and cause-consequence descriptions.

(a) Dr. Raymond DiSalvo of the U.S. NRC provided information on the STAR DASS in a report of .regulatory review questions answered by $L$. Felkel of Gesellschaft fur Reaktorsicherheit $\mathrm{mbH}$, Garching. This document was distributed internally to the NRC and to NRC contractors in 1981. 
Experience with the STAR system has led its developers to believe that DASS improves the operators' capability to cope with more complex situations because they have access to more primary information. The operators' impressions of the system in Germany, where the plants already have a high degree of automation, are these:

- The system reduces the degree of boredom and might increase alertness as a result.

- The system introduces no additional operator responsibilities.

- The operators have to perform operational verification of the system after a disturbance.

- During a burst of alarms, operators should use the system to get a quick overview of the situation of the plant.

The STAR system is an example of how safety system status monitoring has been tied into other plant functions using one computer system. This is in contrast to the CSTS system which was an off-line, stand-alone system. The STAR system provides information on both preoperational and postactivation safety system status and does so in a way that makes the information easier for operators to sense and process.

\subsubsection{Computer-Based Alarm Handling System}

One of the systems under development at the Halden Project is the Handling of Alarms with Logic (HALO) system (Visuri, 1981a, 1981b).

The main functions of the HALO system are to:

- extract relevant alarms

- present these alarms to operators in a way that provides a clear overview of the process status

- perform a simple "safety check" during the first five minutes of a transient to make sure that proper automatic protective actions have taken place

- provide operators with the capability to list and sort the alarms in recent history.

HALO is a computerized system that processes signals with logic as they are received before generating alarms. The system generates alarms if some of the automatic functions are not carried out following a trip. The system also extracts relevant alarms from the large number of signals that would be presented as alarms in a conventional system. Tests of this system at a BWR power plant have shown that HALO is able to reduce the number of alarms by a factor of ten in some cases. 
The system provides three basic kinds of displays for presenting the alarms to an operator: overview picture, detailed alarm group pictures, and alarm texts. The overview picture is a schematic diagram that shows the subsystems of the whole process. Color is used to indicate alarms in a subsystem. If one or more alarms is received for any subsystem, the corresponding area on the schematic changes to the alarm color. The alarm group detail pictures are similar to the overview but display individual schematic diagrams of the subsystems. The alarm text displays are lists of alarm indications in the order that the alarms were tripped.

The HALO system does not provide capabilities for monitoring preactivation safety system status. However, it does alarm if these systems are not functioning properly after a trip. These alarms are in the form of schematic diagrams that aid the operator in determining the cause of the problem and the remedial action to be taken. The HALO system verifies postactivation operation through the absence of a signal.

\subsection{POTENTIAL PROBLEMS IN CURRENT INOUSTRY PRACTICE}

Conventional determination of safety system status presents several potential problems, which are summarized here and explained in more detail in the following subsections.

- The status monitoring of non-instrumented components (such as some valves) is dependent on record keeping, which is always subject to human error. In addition:

- Some of the valves that are manually checked are hard for operators to observe.

- Valve status is often hard to determine even if the valve can be easily observed.

- Frequent surveillance testing or inadequate maintenance planning can increase the chance of having a valve in a misaligned position.

- Operators are not even aware of some $1 \& \mathrm{C}$ valves that can affect operations.

- Control panel indications of valve status are often not conveniently grouped for a quick and easy assessment of system status.

- Some control panel indications do not signify actual valve position.

- The information processing requirements for determining the effects of removing a component or components are of ten quite difficult and can lead to error. 


\subsubsection{Status of Non-Instrumented Components}

The greatest difficulty in safety system status monitoring results from the fact that many of the components, most specifically valves, are not instrumented, and the operator must rely on documented records. The reliability of documented records is dependent on administrative procedures established to ensure that data are maintained and how well the procedures are followed by the operating personnel. Potential sources of error exist if records are not maintained for each non-instrumented component. If there are components for which there is no record maintained, the operator must be aware of this fact and must have knowledge of the relative importance of these components to the availability of the safety system.

A specific problem is the verification of valve alignment for noninstrumented valves. This is a manual process in most plants and requires a visual check of valve status. There are many types of human error associated with this task, including operator sensing, memory, and information processing. Several causes can be identified for failing to observe the valve. The valve may be inaccessible or nearly so, or the valve may be in a dark place and the operator may be unable or unwilling to illuminate it to obtain positive identification. The operator could observe the wrong valve because of lack of identification on the valve or in the procedure. Or the operator could become confused because of the physical location and orientation of the valve or because of its proximity to other valves. If a number of valves are being checked, the operator may inadvertantly skip one or more of them. Finally, the operator may not even attempt to observe a valve because he assumes that alignment is correct.

The operator may observe the correct valve but may incorrectly assess the valve's status. This could be caused by operator haste, but more often it is due to design problems. For instance, some valve handle designs are ambiguous as to open and closed positions, and the valve may be unusually or awkwardly oriented. Also, the valve handle could be assembled incorrectly so that it gives the reverse indication. At least one specific instance has occurred where containment spray header isolation valves were verified by visual inspection to be "locked open" when in fact they were closed (NUREG/BR-0051). This occurred because the valve stems were approximately six inches too long, thus giving a false indication that the valves were open. This design change was not indicated on the design drawings available to the licensee.

In an attempt to overcome some of these problems, many plants have moved to a double verification system; i.e., two people are used to check valve status. However, in none of the plants that we visited was this double verification truly independent. That is, either both people performed the verification walk-through together or the second individual used the checklist that was used by the first individual. A system in which the individuals used separate checklists and compared them after the walkthroughs would be preferable.

Another potential problem exists when documented records are not updated with complete and accurate information. Errors in recording information (for 
example, recording incorrect information or recording correct information in the wrong place) seriously degrade the value of the record.

\subsubsection{Surveillance Testing and Maintenance}

The problems with human error in manual checks of valve status are multiplied by the frequent surveillance testing of the safety systems. The requirements for testing for each plant are established during the 1 icensing phase. The adverse effects on plant safety that unnecessary reactor system challenges can have on the plant and equipment have been identified by others (Kohler, 1981). In this project we concentrated on the effect that frequent testing may have on the human part of status monitoring rather than on the equipment.

An example of a surveillance testing requirement at one plant involved a 31-day test cycle for safety injection pumps. Each time these pumps are tested, valve realignment occurs. For example, isolation valves may need to be closed and bypass valves open. Once the test is complete, the valves must be returned to their pretest alignment. As the number of surveillance tests increases, the opportunities for human error also increase. One operations supervisor said that the plant personnel carefully trace back any valve misalignments to determine the source of the problem. They have found that often the valve was left misaligned after a surveillance test. Other problems associated with frequent surveillance testing include an increase in the operators' workload and distraction of operator attention from plant operation.

Also, valves may be unnecessarily manipulated because of the lack of coordination and planning for maintenance. At some plants not enough care is exercised to ensure that all maintenance work is coordinated to minimize valve realignment.

\subsubsection{I \& C Valves}

Another potential problem is that there are $18 \mathrm{C}$ valves that are under control of the I\&C engineers. The responsibility for returning these valves to correct alignment lies solely with the engineers. In at least one plant, these valves are not even shown in the P\&IDs that the operator uses. This is a case where the operators lack critical information. In some cases if these valves are misaligned, control room indications will be incorrect and/or actuating signals for safety systems may be compromised.

\subsubsection{Control Panel Indications}

In plants that have no safety systems status panel, system valve indications are often displayed on different parts of the control panel. In order to determine safety system status, the operator either uses a checklist or memorizes correct positioning. Problems with a checklist or procedure are discussed above. However, reliance on long-term memory storage for such a task is even more prone to error. 
There are valve alignment errors that occur even when a valve is instrumented and its status is displayed in the control room. One problem is that sometimes the indication given in the control room is the status of the logic or control switch and not of actual valve position. In this case, operators often begin to accept the indication as the true status, rather than as an indirect indication of status that should be verified in a different manner. The TMI-2 accident is an example of this problem.

\subsubsection{Information Processing Requirements}

During the preoperational status check, the operator of ten has to decide what effects taking a component out of service will have on one or more safety systems. Because of the complexity of some of these systems, the operators may incorrectly process information, which can lead to a wrong decision and subsequent incorrect action. For instance, during the decision making process, the operator must rely on memory storage aids such as P\&IDs. There are problems associated with obtaining information from these drawings:

- The scale size of the P\&IDs results in readibility errors. Common errors include transposing piping 1 ines and incorrect interpretation of valve identification.

- The complexity of the system results in a comprehension problem for the reader of the diagrams.

- Lack of space in the control room to place the prints in order to look at them carefully may worsen the interpretation problem.

- Diagrams may not be up to date, or changes that refiect the current plant state may have been entered in an ambiguous or confusing manner.

In addition, many of the plants do not have easily accessible references that designate which components of which systems are safety related. This adds to the information processing problem for the operator. 


\subsection{EFFECTIVENESS OF CURRENT PRACTICES}

In Phase 1 of this project, information about system status monitoring was gathered from key personnel at both power plants and utilities. The information was therefore anecdotal, but it did show the kinds of problems faced by control room operators. The next step was to evaluate the effectiveness of the current practices. The chosen approach to this evaluation was to analyze the actual tasks performed by operators as part of safety system status monitoring. This approach is detailed in Section 3.1. The results of the evaluation, presented in Section 3.2, include the effectiveness of both status verification systems and procedures.

\subsection{APPROACH TO EFFECTIVENESS EVALUATION}

The analysis began with a man-machine interface model modified to describe safety system status monitoring. A functional analysis of the model identified four general categories within which operator errors could be classified. One error category outside the model was added to complete an error taxonomy. The tasks performed by plant personnel in monitoring safety systems were then identified and evaluated to determine their priority and potential for error. Using the tasks that were identified as high-priority or susceptible to error, current procedures and systems were evaluated to determine their effectiveness in reducing the likelihood of error in these tasks.

\subsubsection{Selection of a Model of the Man-Machine Interface}

A conceptual model of the man-machine interface (Figure 3.1) was adapted from Huchingson (Huchingson, 1981). This model was further modified to describe safety system monitoring (see Figure 3.2 ) and shows the man-machine system for verifying the status of safety systems. It also illustrates the three areas where man and machine interface--in sensing the information from the input displays, in manipulating (taking action with) the controls, and in updating documented records.

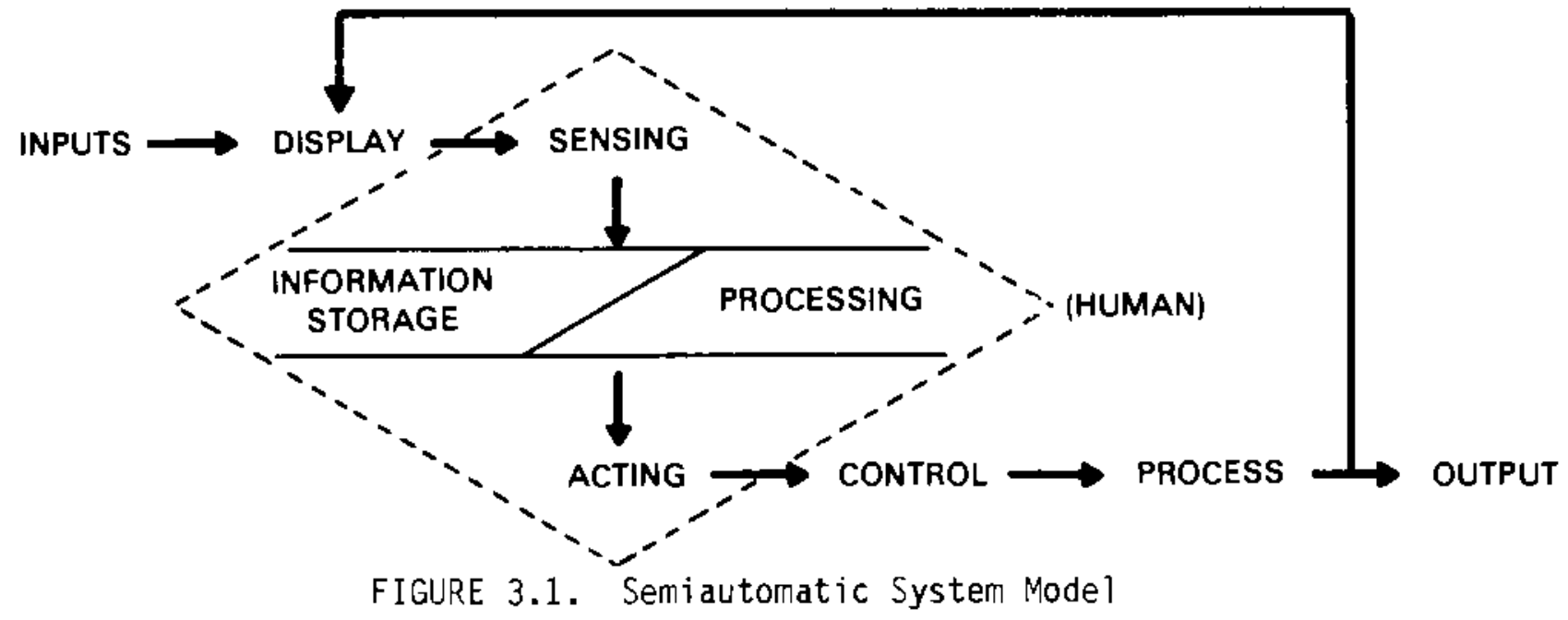


MAN-MACHINE INTERFACE

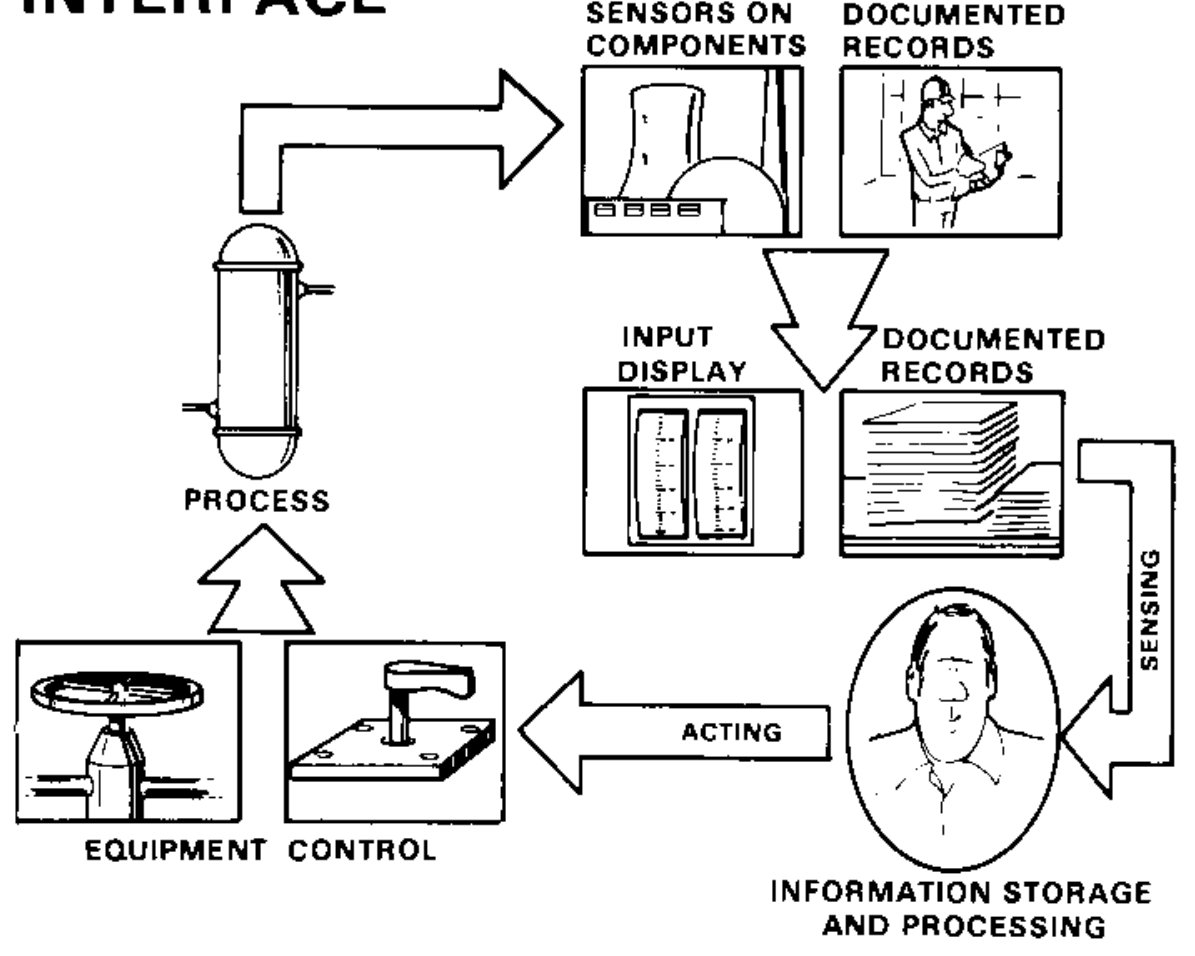

FIGURE 3.2. Interactions During Safety System Status Monitoring

Figure 3.2 illustrates the interaction that occurs in safety system status monitoring. First, inputs to the system come from sensors located on components and from human input in the form of documented records. Second, these inputs are displayed on control panel displays and in documented records (e.g., tags, logs, checklists and procedures). Third, this information is displayed to (i.e., interfaces with) the human operator.

The fourth aspect of the model is the set of equipment controls that the operator manipulates (e.g., the operator pushes a pushbutton control or turns a pistol-grip control). The operation of these controls can provide the operator with some immediate feedback (e.g., a "click" sounds and is felt as a control moves from detent to detent, or an indicator light changes to verify that the pushbutton is fully engaged). The fifth aspect of the model is actual changes in the process (e.g., a valve closing or a pump starting). These process changes can also provide feedback to the operator by affecting the sensors on components causing information to be displayed on the control panel and then sensed by the operator. Finally, the model indicates another feedback loop-operator action in updating documents that are then used as input display for subsequent action. Thus, the model identifies three man-machine interfaces:

- Viewing control panel displays and documented records. 
- Maniputating controls and receiving feedback from control manipulations.

- Updating documented records.

\subsubsection{Error Taxonomy}

An error taxonomy was developed from the model to facilitate categorizing potential human errors associated with operator tasks. Within the model, the operator carries out four kinds of tasks; errors may occur in any of the four categories:

1. Encoding--He must sense the input so that it can be brought into his short-term or working memory.

II. Memory--The operator must retrieve related information from memory or from documented records.

III. Information Processing and Decision Making--The operator processes the retrieved information and the newly-acquired (sensed) information and uses it to come to a decision.

IV. Response--The operator acts on his decision, carrying out specific behaviors.

These terms can refer to four types of errors that may occur during safety system status monitoring. A fifth category considers the effects that motivation can have on operator performance in status monitoring. These five categories are discussed in the following subsections.

\section{1 .2 .1 Encoding}

Errors in encoding arise from failures to sense information or from miscomprehension of sensed information. The way in which input displays (i.e., control room displays and documented records) and feedback are presented can greatly affect the probability of misperception or misinterpretation. Illegible or ambiguous information increases the likelihood of errors in encoding. Similarly, incomplete, inaccurate, unreliable, or noisy information will also degrade encoding.

\section{1 .2 .2 Memory}

Humans have a limited capacity to pick up and store information. The number of items a person can keep "in their head" at once (i.e., in short-term memory) typically cannot exceed about five without a serious degradation in reliability (recall). This holds for unrelated words, numbers, symbols, or what have been termed "chunks" of information. Furthermore, information in short-term memory (STM) cannot be sustained unless it is actively rehearsed or 
attended to in some manner. Interruptions requiring a diversion of attention from items in short-term memory will result in the loss (forgetting) of what had previously been stored in less than 20 seconds, sometimes immediately. Some information may be retained in a more permanent store (long-term memory) that is less susceptible to forgetting. Despite its relative permanence, longterm memory does not retain an accurate representation of the information. What is stored (and whether something is stored) depends greatly upon its organization, how it relates to previously stored information, and the context of information presentation. Errors in information storage include failing to store information and storing incorrect information. Similarly, errors in retrieval include forgetting and misremembering previously stored information.

\subsubsection{Information Processing and Decision Making}

This broad category of mental activity consists of manipulations of sensed or stored information. These mental activities can be simple and straightforward, as with comparison tasks (e.g., comparing one list of valves for correspondence with another), or may involve very complex reasoning steps (e.g., determining what effect the removal of a component has on a safety system). Comparison tasks may involve comparisons between various items of remembered information (mental comparison), written or spoken information (sensory comparison), or a combination of mental and physical sources (mixed comparisons). Many of the checking tasks in plant operations are comparison tasks (e.g., comparing a maintenance request sheet with a maintenance tag). The potential for error in these tasks involves errors both in encoding information, as described above, and in the comparison process itself.

Decision making and related high-level conceptual tasks are especially susceptible to error. Rules of logic used in reasoning may be misapplied or may require that an operator keep track of more things in his head than is possible without error. There is a propensity for error in integrating information from various sources since this requires simultaneous tracking of generalsystem and problem-specific information. Errors in information integration can degrade an operator's ability to determine what outcomes are likely from various interventions. Similarly, thinking through a cause-effect sequence for hypothetical actions is an error-prone process since it requires operators to manipulate and retain a large amount of information in short-term memory.

\subsubsection{Response}

The outputs of the human information processing subsystems are behavioral responses. Assuming that a "correct" or desirable response is attempted, there is still a possibility that this response will not be correctly executed (e.g., failing to completely close a valve). For physical manipulations, such as actuating controls, equipment design is important in minimizing response errors. Failure to take into account the physical characteristics of the operator (j.e., anthropometric data) results in increasing the likelihood of accidental or incorrect control activation. For both physical manipulations 
and communication responses, lack of adequate feedback about the adequacy or effects of the response can greatly increase the likelihood of error in this step.

\subsubsection{Motivation}

Motivation is an indirect, yet important, component in human performance. Motivation is not a step in human information processing but does affect all of the information processing functions described so far. Motivating influences such as the desire to do a good job, be a fast worker, avoid unpleasant interactions with other personnel, or avoid uninteresting work can have a profound and sometimes unexpected influence on task performance.

\subsubsection{Methods for Identifying Error-Susceptible Tasks}

Because of time and budget constraints associated with this study, it was not possible to perform detailed onsite task analyses. Alternatively, the approach used was to develop a generic task identification based on operating procedures from several plants. These administrative procedures covered tagging out equipment for maintenance, surveillance testing, shift turnover, control of locked valves, bypass of safety functions, and maintenance shift records. Then a data flow analysis was performed independently of the task identification. These were compared to identify missing or irrelevant tasks. Next, the tasks were further analyzed to generate a high-priority task listing.

\subsubsection{Initial Task Identification}

Administrative procedures of several plants were reviewed, and one representative set was selected in order to prepare the initial list of tasks. This plant was chosen because operator licensee examiners from PNL, who had a thorough knowledge of operations at that plant, judged the procedures to be especially well-written and complete.

Because the process of tagging equipment out for maintenance is representative of the steps that occur whenever a safety system or a component of a safety system is bypassed or made inoperable, the analys is is centered around this function. This sequence of tasks represents the most important aspects of the verification functions. In the course of performing these tasks, some or all of the status documentation affected by safety system components may be changed.

Each step in the task identification was reviewed by a panel of four individuals knowledgeable in plant operations and certified by the NRC as operating licensee examiners. In addition, the process was reviewed by two control room operations supervisors and members of their staff.

The detailed task listing is shown in a table of tasks provided in Appendix A. This table contains those tasks performed by operations staff in the control room and at remote locations. These tasks directly affect the contro? room operator's ability to monitor the status of the safety systems. The tasks 
were grouped into three major phases: preparing for tagout, maintaining status during the maintenance period, and returning equipment to service. During all three phases the operator must continually be aware of the status of the safety systems.

\subsubsection{Data Flow Analysis}

A data flow analysis was performed independently of the task identification. Data flow analysis is a technique used in computer system analysis and development. For any system, a data flow diagram can be derived that shows the major decomposition of functions and the information flow among these functions. This provides insight into the ways that different functions interact and the information required to perform each function. The plant administrative procedures that were used in the task identification were also used for the data flow analysis. After a careful review of the procedures, the following functions were identified:

- prepare for tagout

- align systems and tag equipment

- maintain status information

- perform maintenance or surveillance task

- remove tags and realign systems

- determine safety system status

These functions were then subdivided into more detailed functions. Once the flow model was derived, a narrative description of each of the detail functions was written. This narrative described the processing that occurs for each function. The top level of the data flow diagram is shown in Figure 3.3. The complete data flow analysis and a description of each function are presented in Appendix B.

The results of the data flow analysis and the task identification were then compared. This was done by attempting to fit each task into a function (shown as a node or "bubble" in the diagram). Instances where there were tasks that did not fit into one or more bubbles indicated that the information flow analysis was incomplete. If, on the other hand, there were bubbles that contained no tasks, that indicated that the task listing was incomplete. This provided a means of validating the task listing, refining it, and showing the way that the tasks are related.

\subsubsection{Identification of High-Priority Tasks}

Each task was next examined in detail to identify the importance of the task and assess the likelihood of human errors in the performance of the task. Each task was rated independently in two categories: 1) the importance of the task to verification of safety systems status and 2) the potential for human error. A five point rating scale was used for each category. An importance rating of one meant the task was relatively insignificant, while an error rating of one indicated that the task was not susceptible to error. An importance rating of five meant that the task was highly significant, and an error 


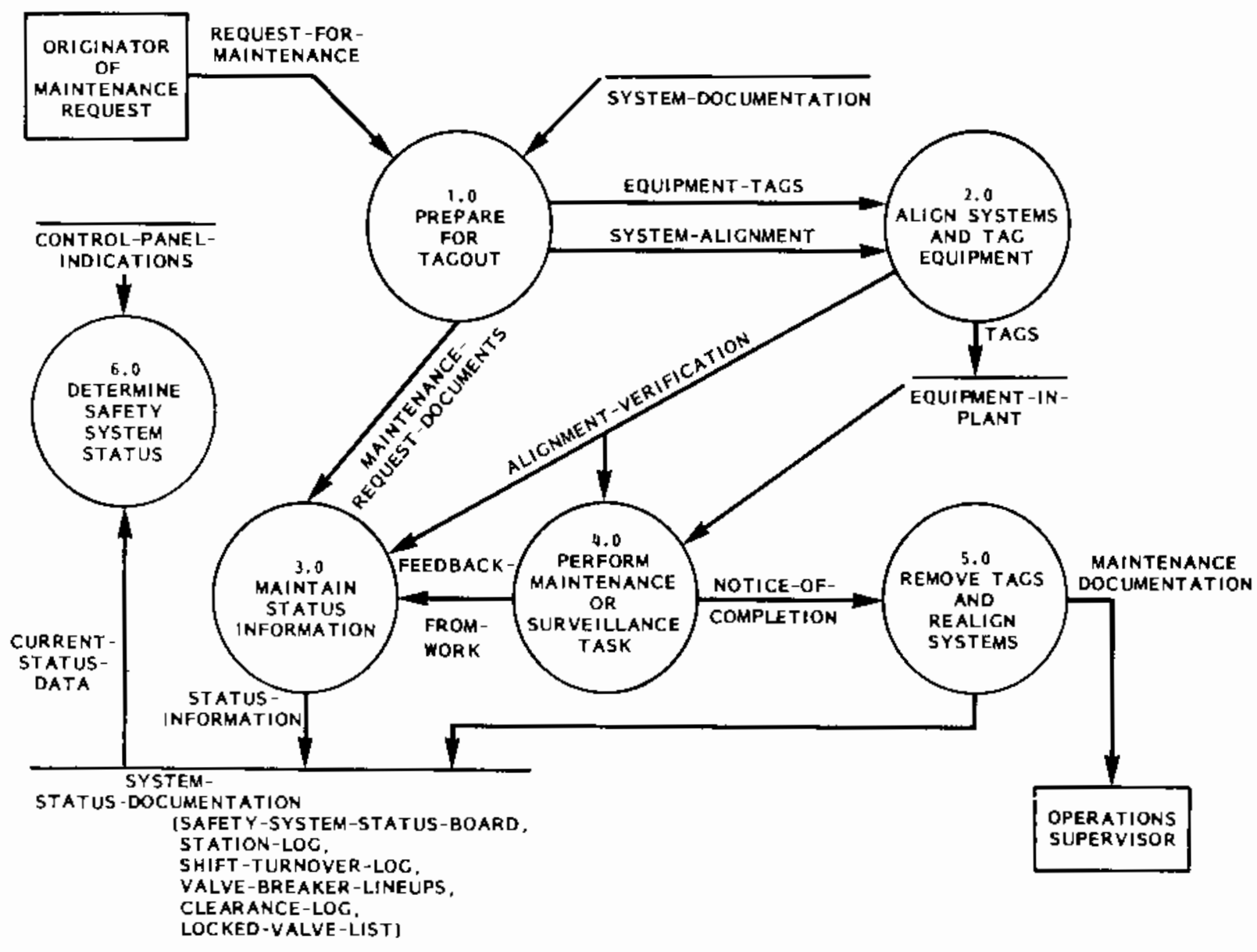

FIGURE 3.3. Top-Level Data Flow Diagram for Safety System Status Monitoring

rating of five indicated the task was judged to be very conducive to error. Those tasks whose importance rating was at least three and whose combined rating was at least six were selected as high-priority tasks. Of the original 54 tasks, 38 were identified as high-priority tasks for use in evaluating the effectiveness of systems. The ratings for all of the tasks are included with the task listings in Appendix A. The high-priority tasks are indicated by an asterisk, "k", following the ratings. As previously described, the tasks were independently rated by both operator licensing examiners and control room operations supervisors. The ratings were adjusted based on their review.

\subsection{RESULTS}

Once the tasks were defined and the error types were identified, the study addressed the effectiveness of 
1. automated and semi-automated status verification systems and

2. procedures

in helping operators to monitor the status of the safety systems.

\subsubsection{Effectiveness of Status Verification Systems}

Because the task of monitoring the status of the safety systems is a complicated information processing, storage, and retrieval task, semi-automated systems to aid the operator have been installed in plants, and automated systems are under development. Verification systems range from manual pushbutton controls on the control room vertical boards to computer-based systems that display system status via mimic system diagrams on a VDT. Six classes of verification systems were evaluated (see Section 2.2.1.4) by estimating the capability of each system to aid the operator in performing the high-priority tasks. Each high-priority task and its associated error types were then examined to determine if any or all of the systems would significantly aid in the performance of the task. The resulting matrix is shown in Appendix $C$. The high-priority tasks are listed in the leftmost column, and numbers representing the error types that are relevant to each task are listed next to each task description. The six types of verification systems are headings across the top of the matrix. An $X$ was placed in the column if the system was judged to significantly aid in a high-priority task and thereby reduce the likelihood of human error in the performance of that task.

As shown by the matrix, the most frequently cited error category was "Encoding", as might be expected because of the extensive documentation required by the "tagout" process. The push-button status panel of fers the least aid, while computer-based system $C$ aided in the most tasks. Computerbased system $C$ aided most in the tasks involving equipment identification in the plant. Computer-based systems $A$ and $B$ aided in high-level information processing tasks. The conventional control panel aided only in those tasks involving manipulation of instrumented components or where status could be inferred by flow or pressure indications.

\subsubsection{Conclusions - Effectiveness of Status Verification Systems}

Several conclusions were drawn from the analysis just described. These conclusions are based on an evaluation of the basic characteristics of each system. The final effectiveness of any system will depend on many factors, such as the way information is displayed on a screen or a control panel, the design of the user interface with the system, and the administrative controls governing the use of the system. The conclusions are:

1. Verifying safety system status for all modes of nuclear power plant operation is a complex psychological process. Several of the individual tasks in this process involve high-level conceptualization. 
2. The majority of the high-priority tasks had several types of errors associated with their performance. This is consistent with the conclusion that the likelihood of error during a task is partially determined by the number of opportunities for error inherent in the task.

3. All high-priority tasks were susceptible to error in the encoding of information. This stresses the importance of presenting information to operators in a legible and comprehensible format. Thus, systems that eliminate the need to obtain information from hard-to-read sources or that improve the readability of the sources help to mitigate errors in this area.

4. Those tasks involved in determining system status require integration of information from instrumented and non-instrumented components. Performance of these tasks has a high likelihood of error. Only those systems that have the capability of accepting input from both types of components provide sufficient help to the operator because they alleviate the need to assimilate the information from several sources. Only one of the systems reviewed (computer-based system B) had this capabitity.

5. The system incorporating a bar code reader for equipment identification was effective in aiding the control room operator in performing many of the tasks because it provided immediate feedback that the auxiliary operator was in the proper location in the plant, positively identified equipment, and aided in timely communication of equipment status to the control room.

6. The task of reviewing P\&IDs was rated as a very important and errorsusceptible task. Computer-based system $C$ displays the actual P\&ID on a graphics screen and overlays the diagram with status information on both the preferred valve alignment and the current valve alignment, aiding the operator in several ways. First, the ability to magnify a portion of the P\&ID improves readability by improving the identification of components and the ability to follow flow paths. Second, the overlay information on current and preferred line-ups simplifies the decision-making task by providing all relevant information in one location. Third, the use of color coding enhances the rapid identification of out-of-normal component status.

7. Computer-based systems $A$ and $B$ have a hypothetical "what-if" mode that may aid in complex decision making tasks because it allows the operator to predetermine the effect that component removal has on the safety systems. This is particularly significant when the operator is called upon to make decisions about nonstandard or infrequently used system alignments. This may occur while determining the operability of a redundant system or while determining the system alignment after maintenance has been completed. 
8. Several of the high-priority tasks are not aided by any of the verification systems described in this report. Most of these are implementation tasks that are accomplished once the operator has obtained all of the necessary information.

9. The conventional control panel shows open and closed positions of instrumented valves during both flow and no-flow conditions. Most of the displays on the conventional control panel provide information on status only in the "on" or "flow" position, while most ESF components are normally in the "off" or "no-flow" position. Therefore, conventional control room displays are of limited help to the operator in monitoring the readiness status of safety systems.

10. Some of the systems examined were designed specifically to meet the guidelines of Regulatory Guide 1.47. When these systems were evaluated against the tasks required for verifying the status of the safety systems, it was found that they did not aid the operator in several of the high-priority tasks.

\subsubsection{Discussion - Factors that Limit the Effectiveness of Automated Status Verification Systems}

The introduction of an automated system into a nuclear power plant can cause problems. Those problems must be carefully evaluated to determine the impact on the operator, and this impact must be weighed against the problems or errors that one hopes to alleviate by introducing the system. In the case of a nuclear power plant control room, this evaluation takes on more significance because of the potential impact on public safety. The purpose of the following discussion is to provide examples of the types of problems that may occur.

Some problems may arise when a new system of any kind is introduced into the control room. The operators must learn a new way of thinking about doing a task. Moreover, these problems tend to increase if the system being introduced is the operator's first exposure to a computer-driven VDT.

Operators may not be comfortable with a keyboard. Because most of them are not touch typists, they find it a difficult and slow process to communicate with the systems via the keyboard. These problems can be minimized with a good, human-factored design of the data entry portion of the system. The use of function keys, light pens, graphics pads, etc. may make the operators fee 1 more at ease with the computer-driven systen and may make it easier for the operator to learn to use the keyboard.

Operator acceptance can be enhanced if great care is taken in the design of the system. Human factors guidelines must be followed in the placement of VDTs and workspace layout in order to reduce glare on the screen and ensure a proper viewing angle so that fatigue is minimized. If a graphics display is used, the operator may be required to learn new symbols such as those used for 
pumps and valves. Also, the operator must be aware of the way color is used to depict change. These problems can be minimized by a careful design of the graphics package.

Operators tend to distrust any new system, especially a computerized one. In part, this is due to a time delay in getting data to the display. Some of this distrust can be reduced by good human factors design of the system itself. If there is a delay in obtaining data once it has been requested, the operator should be provided with positive feedback that the system is working.

Because a computerized system will not achieve $100 \%$ reliability, it may be necessary for the operator to use a backup method to obtain any time-critical information. Thus, the operator must be trained to perform the same function in two ways.

Although the introduction of computer-based systems may cause problems, these can be minimized by following some basic principles of system design. First, at least one of the operators should have meaningful involvement in the system design. This operator can then serve as a liaison with the rest of the operations staff and help educate them as to what to expect from the system. Second, the introduction of any new system should include a break-in or training period during which the operators can become familiar with the system. Such training time is very important in user acceptance of any system. Finally, it is extremely important that the operators know they can recommend beneficial changes to the system and have assurance that at least some of these changes will be made.

\subsubsection{Effectiveness of Procedures}

The evaluation of the effectiveness of procedures was based on a detailed review of procedures currently in use at three operating nuclear power plants. These plants were selected to represent different utilities, different nuclear steam supply system vendors, and different procedure types, formats, and writing styles. In evaluating the procedures we also used the considerable experience gained in other procedures work done by PNL for the NRC, including the evaluation of emergency procedures submitted by utilities as part of a new plant's licensing process. Although our analysis is limited to these typical written procedures, it is recognized that other procedure types and formats are possible; e.g., computerized procedures, compendia of decision aids, etc.

The procedures were examined in detail to determine how they aided the operator in monitoring the status of the safety systems. Extensive discussions were also held with operations personnel at seven plants to determine how they used procedures at their specific plant.

After the interviews were complete, two human factors specialists (one of whom was previously involved in procedures evaluations) examined each highpriority task and the error type associated with that task to determine if good procedures would significantly reduce the likelihood of error. The procedure 
was defined as the written information with which the operator is provided to do the task. If a form is to be filled out, this is considered to be part of the procedure. The following rating scheme was used:

0 - Use of procedures would not significantly reduce the error type.

1 - Good procedures would reduce the error type, but procedures currentiy do not exist or are inadequate as written.

2 - Good procedures would reduce the error type, and existing procedures are adequate as written.

The evaluation was repeated by an independent group of three human factors specialists (two of whom had been involved in the trips to the plants). Once the two groups had completed their evaluations, a comparison of the two independent evaluations was performed. Disagreements in the evaluations were resolved through a reexamination of the tasks and procedures. The majority of disagreements between the two groups occurred because one group felt that, for some of the tasks, a very detailed set of instructions would aid the operator in performing the task. However, during the resolution discussion the two groups concluded that it would be impossible to write the procedures in sufficient detail to cover every possible contingency. The complete set of ratings of the effectiveness of procedures for each high-priority task is included in Appendix D.

The results are summarized in Table 3.1. Procedures were judged unlikely to alleviate encoding errors in 31 of the 38 tasks, processing errors in 28 of 35 applicable tasks, response errors in 14 of 20 applicable tasks, and motivation-induced errors in 5 of 6 applicable tasks. Conversely, procedures were deemed at least potentially helpful in the alleviation of memory errors in 32

\section{TABLE 3.1. Effectiveness of Procedures}

\begin{tabular}{|c|c|c|c|c|}
\hline \multicolumn{2}{|c|}{ Error Type } & \multicolumn{3}{|c|}{ Applicability and Adequacy of Procedures } \\
\hline & & $\begin{array}{c}0 \\
\text { Inapplicable } \\
\end{array}$ & $\begin{array}{c}1 \\
\text { Applicable } \\
\text { but Inadequate } \\
\end{array}$ & $\begin{array}{c}2 \\
\text { Adequate } \\
\end{array}$ \\
\hline I. & Encoding & $31 / 38$ & $5 / 38$ & $2 / 38$ \\
\hline II. & Memory & $3 / 35$ & $20 / 35$ & $12 / 35$ \\
\hline III. & $\begin{array}{l}\text { Information } \\
\text { Processing }\end{array}$ & $28 / 35$ & $6 / 35$ & $1 / 35$ \\
\hline IV. & Response & $14 / 20$ & $6 / 20$ & $0 / 20$ \\
\hline V. & Motivation & $5 / 6$ & $1 / 6$ & $0 / 6$ \\
\hline
\end{tabular}


of the 35 applicable tasks. Procedures were found to be of no potential help in the reduction of any type of error in only four of the 38 high-priority tasks. Of the other 34 tasks judged capable of being improved by procedures, 15 were found to be currently performed according to an existing procedure that was judged to be adequate. Of these 15 tasks, the procedure was found to reduce memory errors in 12 cases, encoding errors in two cases, and processing errors in the remaining case. Although there were 15 cases in which better procedures could aid in task performance, in no case did procedures help all possible error types applicable to a given task.

\subsubsection{General Conclusions About Procedures}

In the course of the review of procedures from several different plants and from plant visits, it became clear that procedures contain a number of shortcomings:

1. In many cases all the instructions for one process are not included in one procedure. The user is therefore required to look in a number of places, thereby increasing the time and effort required to perform the task and reducing the likelihood of performing the task correctly.

2. Procedures frequently do not clearly state who is responsible for performing a particular task.

3. Procedures do not use consistent nomenclature.

4. Procedures contain faulty logic, logic dead ends, and do not give directions for all alternatives.

5. Procedures are poorly formatted. Poor organization, multiple tasks in single action steps, and improper numbering all contribute to this problem.

6. Procedures do not contain adequate information on how they relate to one another.

\subsubsection{Conclusions Specific to Verification Tasks}

In addition to these conclusions regarding the general adequacy of current procedures, there are several other conclusions relating to the specific role of procedures in monitoring safety system status. These latter conclusions are based on ratings of high-priority tasks and the potential effects of improving performance through enhanced procedures.

1. Control room operators need help in keeping track of safety systems status and in making decisions based upon system status. 
2. Current written procedures help primarily in aiding memory by

a) telling operators what tasks need to be accomplished and b) providing lists of information such as valve numbers.

3. For most of the high-priority tasks in which memory errors were possible, procedures could be improved to help reduce the chances of these errors.

4. Although procedures typically are not an effective motivating mechanism, the proper use of warnings and cautions may help operators understand the consequences of failure to follow procedures.

5. The procedures as they are currently written do not ensure that truly independent verification occurs when valve positions are being checked.

\subsubsection{Discussion - Effectiveness of Procedures}

Good procedures assist in minimizing operator error but are not in themselves a singular avenue to reliable and safe plant operation. No matter how well written any set of procedures may be, there are inherent limitations to the effectiveness of these procedures in alleviating operator error in tasks related to monitoring the status of safety systems. These limitations derive, in part, from the predisposition of the persons for whom the procedures are written, from mistrust of procedures, and from certain inherent characteristics of written procedures. Several limitations resulting from the inherent characteristics of written procedures are presented below:

Limitations in Scope: Some limitations of conventional procedures derive from the format of the procedures. Written procedures are static. They cannot change in content or emphasis as plant status changes except at the most general levels. For this reason procedures are restricted in their ability to provide detailed information or direction for novel and/or unanticipated situations. The scope of procedures is limited to information applicable to situations or tasks that may be treated generically, or to plant-specific situations that have been analyzed in advance.

Length Limitations: Procedures are restricted in length. There is a built-in tradeoff between the extensiveness of procedures and their usability. Although procedures must be sufficiently complete to be usable, too much information can degrade the usefulness of the procedures. Quick and effective use of procedures becomes more difficult as procedures become especially lengthy and/or complicated.

Other Limitations: The type of information that can be conveyed in procedures is necessarily limited. As a result, there are types of tasks for which a procedure is simply not an optimal tool. For example, procedures are not effective in motivating personnel; e.g., procedures cannot guarantee their own use. 
The effectiveness of written procedures may also vary with the nature of the task. The following is a summary of the limitations of procedures associated with typical verification tasks.

- Errors in Information Encoding Tasks: Procedures provide little assistance in ensuring that all information-conveying devices (labels, displays, etc.) are legible and comprehensive. Although procedures may direct personnel to obtain information from these sources, the displays themselves must be well designed and personnel sufficiently trained in their use if information is to be successfully conveyed to the operator.

- Errors in Comparison Tasks: Situations in which persons must compare one item of information with another (e.g., actual valve position with the position specified on a maintenance tag) are not easily helped by procedures. While procedures may sometimes direct a person to make a comparison, they seldom aid in the comparison process itself.

- Errors in Information Integration Tasks: Tasks requiring assimilation of much information can be aided by procedures (procedures may be thought of as memory aid), but procedures are not well suited to helping operators integrate this information and obtain an overall understanding of large sets of information.

- Errors in Periodic Monitoring Tasks: Procedures can inform the operator that an indicator should be monitored every 30 minutes, but they cannot remind the operator of this every 30 minutes. Procedures do not function well as an alerting mechanism.

- Errors in Complex Decision Making Tasks: Tasks requiring high-level mental processing (such as inference, deduction, etc.) are not easily assisted by procedures. Some procedures may include decision trees for some scenarios, but it is not feasible to include decision aids for all important decisions.

- Errors Resulting From Motivation Problems: Procedures are not effective in motivating personnel. Procedures cannot ensure their own use, nor can they guarantee that persons who use them will use them correctly. Procedures that are hard to use or outdated are not likely to be relied upon. 



\subsection{SYSTEM ACCEPTANCE CRITERIA}

The previous section of this report concluded that procedures are effective in reducing memory errors but they are not effective in reducing all errors associated with monitoring the status of the safety systems. Although existing systems did aid the operator, no system was effective in reducing error likelihood for all of the monitoring tasks. Based upon an analysis of the problems facing the operators as they monitor the status of the safety systems, this section defines a set of functional requirements that must be met by any system designed to effectively aid the operator in this task. The section then defines the acceptance criteria for a system that will meet those functional requirements.

\subsection{ASSUMPTIONS}

There are three assumptions underlying the following criteria. The first assumption is that improvements can be made to the methods used to monitor the status of the safety systems. The second assumption is that it is impractical to retrofit instrumentation to all of the non-instrumented components. The third assumption is that even if the plant installs an automated system, procedures will be used to some extent in monitoring the status of the safety systems.

\subsection{FUNCTIONAL REQUIREMENTS}

The goal of any system that monitors the status of the safety systems is to provide current and accurate status information, and to reduce the likelihood of error in all of the error-susceptible tasks involved. Previous sections of this report identified those tasks with a high likelihood of error and those that were judged to be important. Based on these results, four basic functional requirements were derived. These requirements should be met by any system that is used to monitor the status of the safety systems:

- The system should minimize the operators' need to search for taskrelevant information. The operator should have access to needed information without having to sift through irrelevant inputs or to obtain information from diverse locations.

- The system should facilitate component identification and minimize encoding errors. Errors in encoding arise from failures to sense information or from miscomprehension of sensed information. The data should be presented in a way that reduces the probability of misperception or misinterpretation. Illegible or ambiguous information increases the likelihood of errors in encoding. Similarly, incomplete, inaccurate, unreliable, or noisy information also degrades encoding. 
- The system should simplify the information processing tasks. There are two basic types of information processing tasks. The first is comparison tasks that may involve comparisons between various items of remembered information (mental comparison), written or spoken information (sensory comparison), or a combination of mental and sensory sources. Examples of these tasks are comparing one list of valves for correspondence with another, and comparing a maintenance request sheet with a maintenance tag. The second type of information processing tasks is those that involve complex reasoning steps. These tasks are especially susceptible to error. Examples of these tasks include determining system status based on component status data and determining the effect that the removal of a component will have on the system.

- The system should minimize the need for the operator to rely on memory. Humans have a limited capacity to pick up and store information. Errors in information storage include failing to store information and storing incorrect information. Similarly, errors in retrieval include forgetting and misremembering previously stored information.

These functional requirements describe in a general way the human interface considerations that should be addressed by a man-machine system designed to monitor the status of safety systems. Presented below are a set of acceptance criteria to help in evaluating a system to determine how well it meets the aforementioned functional requirements.

\subsection{ACCEPTANCE CRITERIA}

In order to ensure that a system meets the functional requirements defined above, the following set of acceptance criteria should be met:

1. A means should be provided to determine and display the status of each safety system during all modes of operation. The system should indicate at the system Tevel the bypass or deliberately induced inoperability of the safety system. For those systems with redundant trains, the system indication should be by train. The display should emphasize the effects that bypassing a component has on safety systems rather than the effects on auxiliary or supporting systems. The determination of system and availability should include non-instrumented as well as instrumented components.

2. A means should be provided to determine the status of each individual component within a safety system. Component status need not be displayed at all times. However, if a safety system is bypassed or inoperable, the operator should be able to quickly and reliably identify which individual component or components are bypassed or inoperable. The determination of component availability should include non-instrumented as well as instrumented components. 
3. A means should be provided to easily identify all of the components of each safety system and those components in auxiliary or supporting systems that must be operable for safety systems to perform their function. The operator should be able to obtain this listing Tor other type of display) by providing safety system identification. This listing should show the current status of each component if the operator requires that information. The noninstrumented components should be included.

4. A means should be provided to identify the system or systems of which any component is a part. The operator should be able to obtain this information by providing component identification.

5. A means should be provided to determine how the removal of a component or components affects a safety system or systems. Once the operator identifies the component(s), the system should then aid the operator in determining what effect the removal of the component(s) would have on the safety systems. Effects that are dependent on changes in plant mode should be included. The system should aid the operator in recognizing the effects of bypassing both: 1) components within safety-related systems or trains; and 2) any component of an auxiliary or support system that has the potential to degrade or make a safety system inoperable.

6. A means should be provided to ensure that all information on component or system status is valid, reliable, and timely. Changes in component status should be updated and communicated to control room operators as soon as possible. This criterion is extremely important for non-instrumented components.

7. A means should be provided to ensure positive identification of noninstrumented components. The system should aid the operator in identifying the correct component during the manual verification of its status.

8. A means should be provided to ensure positive identification of the status of the components.

9. The system should provide ready access to relevant engineering information (e.g., P\&ID's, E-Prints, and other technical data) in a simple and understandable format.

10. Displays should be designed for operator use and should contain only information relevant to the operator's task. The operator should not have to sift through irrelevant information.

11. Whenever procedures are used as part of the system, they should be tailored to the specific task type and should be written using a recognized procedures writing guide that incorporates both human factors and effective communications principles. 
12. Systems for monitoring safety systems status should follow accepted human factors standards and practices. These standards and practices should be applied to hardware, procedures, and training, as well as software, if a computer-based system is used.

A system that is designed to meet these acceptance criteria should reduce the likelihood of error associated with the tasks that occur in monitoring the status of the safety systems. 


\subsection{NEAR-TERM IMPROVEMENTS AND GUIDELINES}

This section describes suggested improvements that can be implemented in the near term at relatively low cost and with minimum impact on ongoing plant activities. These near-term improvements inciude:

- improved procedures

- more effective methods for independent verification of equipment status

- effective use of labels and placards on plant equipment

- clear visual indications of valve status

- identification of the safety-related components for each safety system

- display of safety system and component status

- increased management and training emphasis on the importance of maintaining a knowledge of safety system status

- improved access to engineering information.

The remainder of this section describes these improvements in further detail and provides guidelines for these improvements. These near-term improvements do not fully address all of the acceptance criteria outlined in the previous section. A subsequent report will be published to detail long-term improvements that are needed to fully satisfy the general acceptance criteria.

\subsection{IMPROVED PROCEDURES}

For proper operational awareness, control room operators need an indication of status for each of the safety systems. For plants without automated displays, operators obtain this information from a variety of logs and other records that are maintained in the control room. These logs and records are updated by the control room operator and other plant personnel during routine plant operations. In performing these operations, the operator uses several different procedures containing steps for:

- tagging equipment out for maintenance

- shift supervisor approval of maintenance activities

- locked manual valve logs and logs for jumpers and lifted leads 
- independent verification and double verification of component status following the completion of maintenance activities

- shift turnover procedures, especially the briefing to the oncoming shift on the status of safety-related components

- updates to station logs and status boards.

No specific procedure exists for monitoring the status of the safety systems. Rather, numerous procedures affect safety system status in a partial or incidental way. The operator needs the ability to access these diverse sources of information to determine system status. The list below provides guidelines for near-term improvements that will aid the operator in obtaining this information. Appendix E provides a more complete list of guidelines for the development of effective procedures.

- A job performance aid (JPA) should be provided to make the operator aware of all of the tasks and procedures that are important to safety system status monitoring. An example of such an aid is a flow diagram that depicts the flow of information concerning safety system component status. The JPA should:

- clearly identify persons responsible for the performance of each individual step or task.

- cross-reference for each of its elements and specific related procedures/documents in a manner that allows ready identification of and access to the procedure or document.

- include cross references to the location and content of documented records that reflect current status as altered during plant operation, e.g., locked-valve list, maintenance requests, shift turnover $\log$, etc.

- Any maintenance requests that involve safety system components should be clearly and easily distinguishable from other maintenance requests. The distinguishability of the maintenance requests should be intrinsic rather than derived from its surrounding. For example, putting safety system component maintenance requests on a uniquely colored form is preferable to filing them in a folder separate from maintenance requests involving components not in the safety system.

- Procedures should be modified to require physical interaction to verify component status in ambiguous situations where visual inspection alone may not be sufficient for status verification. For example, it may be necessary to move or attempt to move a handwheel on a valve in order to verify its status. 
- Procedures should be developed to assure that the control room operator is aware of the status of any components (for example, I\&C valve assemblies) that provide actuation signals to safety systems.

\subsection{MORE EFFECTIVE METHODS FOR INDEPENDENT VERIFICATION}

Utilities have attempted to improve human reliability for errorsusceptible tasks, or tasks in which errors cannot be tolerated (e.g., alignment of locked manual valves) by establishing a double verification system, i.e., two people checking the parameters of interest. This method of reducing unrecovered human errors could be improved by making the two checks truty independent. At present, both people usually perform the verification walk-through together, or the second individual uses the checklist filled out by the first individual. The co-presence of the checkers (or their checklist) creates a dependency between the checkers' behaviors: an error committed by one is less likely to be caught by the other than if the checks were truly independent. Regardless of the good intentions of the checkers, merely knowing what another checker has reported biases their expectations and reduces the reliability of the verification. The influence of contextually produced expectations on perception are well documented: information is typically perceived to be congruent with one's expectations whether those expectations are produced from prior experience (Pillsbury, 1897; Dember, 1964) or by a co-present person making the same judgment (Asch, 1951). Independent checks in which the first checker's report is not available to the second checker, and therefore does not bias the second checker's report, would improve reliability at minimal or no cost.

\subsection{EFFECTIVE USE OF LABELS AND PLACARDS}

Labels and placards on equipment in the plant reduce the probability of human error in the identification of components and the verification of their status. Key elements in effective manual verification systems are:

- labeling equipment such as valves, pumps, and motors so the operator will verify the status of the right item

- providing information to the operator out in the plant about now to verify the status of non-instrumented equipment.

The following guidelines should be followed for the design and placement of labels and placards on the equipment in the plant:

- Labels and placaras used in multi-unit plants should be sufficiently distinctive to prevent confusion of equipment from one unit to another.

- Label and tag notations should be consistent with system diagrams, schematics, and procedures. 
- Labels and placards should be designed to be read easily and accurately at the anticipated reading distances and environmental conditions (for example, illumination and vibration/motion).

- Each unit, assembly, subassembly, and part should be labeled with a clearly visible, legible, and meaningful name, number, code, mark, or symbol, as applicable.

- Labels should not be hidden by units and parts. For example, labels stamped on the chassis should not be placed under the parts which they identify.

- Labels should be clear and distinct, have high contrast, be mounted so as to minimize wear or obscurement by grease, grime, or dirt, and should remain legible for the overhaul interval of the equipment on which they are mounted.

- Label color should contrast with the equipment background.

Additional detailed guidelines on labels and placards are provided in Appendix F.

\subsection{VALVE STATUS INDICATIONS}

Most valves in a nuclear power plant are not instrumented. Knowledge of the status of valves that are part of a safety-related system is essential to status verification of that system. The following guidelines are intended to present a means of aiding the operator in determining the status of a noninstrumented valve.

- Alignment marks should be used to indicate open and closed status.

- The location and size of the alignment marks should consider the normal viewing distance, location, and ambient lighting.

- Alignment marks should show both the valve's fully open and fully closed positions. Each position should be labeled.

- Alignment marks should be located to minimize parallax error.

- In cases where the direction of rotation of a valve control wheel is not obvious, the direction of rotation for opening and closing should be indicated.

- Alignment marks should be precise enough that the observer can tell when a valve is fully opened or closed.

- For those valves where alignment marks would not be appropriate, consideration should be given to indicators that are activated by valve limit controls. 


\subsection{IDENTIFICATION OF SAFETY SYSTEM COMPONENTS}

To effectively maintain information on the status of the safety system, it is important that the operator has an easily accessible reference of the safety systems and all of the components within the safety systems. This reference is extremely important whenever the operator must make a decision about releasing an item of equipment for surveillance testing or maintenance. The following guidelines apply to this reference:

- The operator should be able to access the reference by system and obtain a listing of each component within the system, as well as components in auxiliary or supporting systems that must be operable for the safety system to perform its function.

- Any components that are a part of more than one system should be listed with each system, and this fact should be clearly indicated.

- Given a component identification, the operator should be able to use this reference to determine if the component is part of any safety system or part of a necessary supporting system and, if so, which safety system.

- The operator should be able to obtain needed information from this reference easily. Thus it may be necessary to use multiple indexing schemes so that retrieval of the information can be accomplished efficiently.

Additional enhancements to this reference could include the following:

- For each component, the reference could include information on component location in the plant and status during routine plant operation.

- If a component is identified by more than one identifier (manufacturer's part number, utility-assigned part number), then crossreferencing should be provided.

In addition to maintaining the list of components and supporting components for each safety system, the components should be identified as safety-related on documents, procedures, and information-handling systems used in the plant to control safety-related activities, including maintenance, surveillance testing, work orders, and replacement parts.

\subsection{DISPLAY OF SYSTEM AND COMPONENT STATUS}

The identification of the status of the components is necessary to maintain records of the status of the system level. A variety of methods are used 
to indicate this component status. Most of these methods involve the maintenance of logs; however, some plants use a manually updated status board. Effective use of status boards requires that all the needed status information is displayed in a manner that is easy to read and easy to update. Keeping status boards current may be the most important objective and the most difficult to accomplish. Current information is crucial because:

- Outdated information on status boards can lead to incorrect inferences regarding the status of systems.

- Continued failure to keep a status board current will lead to user rejection.

The updating problem is a difficult once because manual updating is necessary to reflect the effects of non-instrumented equipment on safety system availability. To promote prompt updating of status board information, the updating process must be an integral part of the procedures for the control of safety systems configuration.

Guidelines for status boards are given below:

- Before the removal or manipulation of a component that results in the unavailability of a safety system, procedures must ensure that the status board has been changed to show the affected system as unavailable. Provisions should be included to prevent work from proceeding until the status board has been updated.

- Status board updating should be included in a systematic documented system, similar to the document control system, so that updating is timely and the restoration to service is not complete until the status board has been updated.

- A desirable, but not necessary, provision is an "in process of change" indication for systems being removed or restored to service during the period the operations are actually being performed. These indications would alert operators to the potential availability of a safety system (depending on the progress of work), should a redundant system become inoperable in an emergency.

Information displayed on status boards should comply with good human factors practices in order to promote transfer of information between the display and the operator. Specific display requirements will depend on the type of display used (backlit tiles, placard-boards, indicator lights with text, etc.). However, regardless of display type, status boards should:

- Use simple alphanumeric characters readable from the intended viewing distance. 
- Use words, symbols, and abbreviations that are consistent with terms used in the rest of the plant; no special terms should be necessary for the status display.

- Make color coding (where used) consistent with color coding used el sewhere in the plant.

- Provide an easy way to update the status board; devices used for this purpose should conform to human factors guidelines for controls, where applicable.

- Be easily accessible for viewing by operators, although they need not be in the prime display areas since they do not require continuous monitoring. Placement should optimize ease of access for persons updating displays and ease of viewing for personnel reading the displays.

\subsection{MANAGEMENT AND TRAINING EMPHASIS}

A key element in effecting any of the improvements is increased management involvement. There is a positive relationship between a strong commitment on the part of management to enhancing plant monitoring of safety systems and the quality of procedures, and methods used to maintain the status. As evidence of this commitment, management should provide:

- adequate manpower and funds to ensure that procedures are well written and current

- the resources necessary to implement a well-designed training program that includes:

- systematic analysis and training of system status monitoring tasks

- identification of skills and knowledges required by operating and training personnel

- performance evaluation of status monitoring and valve alignment tasks.

- a system of rewards and sanctions associated with the goals of this program (for example, safety awards or incentive awards)

- a mechanism for the involvement of operation and maintenance personnel in meetings to improve communication and ensure employee involvement. 


\subsection{IMPROVED ACCESS TO AND USABILITY OF ENGINEERING INFORMATION}

The operator should have ready access to engineering information le.g., P\&IDs, E-Prints, and other technical data). The following guidelines present means for improving the usability of drawings, charts, prints, and other sources of engineering information:

- Quality of reproduction should be high, to improve readability.

- Readability should also be enhanced where possible through techniques such as enlargement, deletion of irrelevant items, or colorcoding.

- Engineering information in the control room should be up-to-date.

- Drawings should be properly indexed and filed.

- A well-lighted area in or near the control room should be provided where drawings and prints can be laid out for reading.

\subsection{DISCUSSION - NEAR-TERM IMPROVEMENTS}

The guidelines for near-term improvements are intended to meet the acceptance criteria as much as possible, at relatively low cost and with minimal or no interruption of plant operations. These guidelines do not address all of the acceptance criteria. A listing of the acceptance criteria and the degree to which the near-term guidelines satisfies each criterion is shown in Table 5.1. Those acceptance criteria that are not completely addressed in this report will be addressed in a subsequent document to be published in the future. This subsequent document will describe further, longer-term improvements to status monitoring. 
TABLE 5.1. Relation of Near-Term Guidelines to Acceptance

Criteria for Safety System Monitoring

\section{Acceptance Criteria}

1. Means must be provided to determine and display the status of each safety system.

2. Means must be provided to determine the status of each individual component within a safety system.

3. Means must be provided to determine and display all of the components of each safety system.

4. Means must be provided to determine the system or systems of which any component is a part.

5. Means must be provided to determine how the removal of a component or components affects a safety system or sys tems.

6. A means must be provided to insure that all information on component or system status is current.
As Addressed By

Reg. Guide 1.47 As Addressed by Near-Term Guidelines

Partially Determination of system status remains an error-susceptibie step.

No

Fulfills reliability provision through improved labeling and independent verification.

No

Fulfills provision for well designed lists of safety system components--The guidelines do not address providing component status information on this listing.

Fulfilled by provisions for listing of components

No significant improvements

No
Guidelines for independent verification and labeling improve reliability and validity--The provision for timely information is not completely satisfied. 
TABLE 5.1. (Contd)

Acceptance Criteria

7. A means must be provided to ensure positive identification of noninstrumented components.

8. A means must be provided to ensure positive identification of the status of components.

9. Means must be provided to display, in a highiy usable manner, engineering information needed by the operator.

10. Displays should contain only necessary information for the task and should be designed for the operators use.

11. Al1 displays and interactions with the user must follow accepted standards and practices of the human factors profession.

12. Whenever procedures are used as part of the system, they should be tailored to the specific task type and should be written using a recognized procedures writing guide that incorporates both human factors and effective communications prinicples.
As Addressed By

Reg. Guide 1.47 As Addressed by Near-Term Guidelines

Correct component identification may be improved in the near-term through improved component labels, placards and independent verification.

Valve status indications (alignment marks, etc.) should improve determination of status; further improvements would require valve instrumentation.

Some improvement in the usability of engineering data

The need to sort through irrelevant information is partially relieved through indexing schemes.

Near-term guidelines, including their applicable appendices and references, satisfy this criterion.
Overall, near-term guidelines partially fill this criterion. 


\subsection{RECOMMENDED REGULATORY POSITION}

TMI Action Plan Item I.C.6 (Procedures for Verification of Correct Performance of Operating Activities), requires that licensee procedures be reviewed and revised, as necessary, to assure that an effective system of verifying the correct performance of operating activities is provided as a means of reducing human errors and improving the quality of normal operations. TAP Item I.D. 3 (Safety System Status Monitoring) states, "NRR will study the need for licensees and applicants not presently committed to the requirements of Regulatory Guide 1.47, 'Bypassed and Inoperable Status Indication for Nuclear Power Plant Safety Systems,' to monitor and verify operations, test, and maintenance activities by means of an automatic status monitoring system, such as that described in Regulatory Guide 1.47."

Work described in this report addresses TAP Items I.C.6 and I.D.3. This involved a review of current industry practices, and of proposed practices and designs relating to system status verification. Information was also collected on foreign nuclear systems and practices. Preliminary measures of effectiveness were developed for assessing the comparative effectiveness of various automatic, semi-automatic, and manual verification/monitoring systems currently in use in the nuclear industry. This section presents the recommended regulatory position developed on the basis of this project.

The project has dealt with two issues concerning the recommended regulatory position:

- Should all plants be required to meet Regulatory Guide 1.47 ?

- If so, is Regulatory Guide 1.47 adequate as it is written?

As presented in Section 3, current industry practice (as represented by the survey sample) does not adequately aid control room operators in monitoring safety system status. Improvements are necessary if human errors in system monitoring are to be reduced.

The question now becomes one of whether Regulatory Guide 1.47 provides the vehicle for that improvement.

Of the seven plants visited, four of the plants had systems that were installed to meet the intent of Regulatory Guide 1.47. These systems, although they met the intent of 1.47 , provided no significant improvement over the plants that did not have systems for meeting 1.47 guidance. The reasons these systems provided little aid to the operator in the tasks of monitoring the status of the safety systems was because Regulatory Guide 1.47

1. does not adequately deal with the issue of entering the status of the non-instrumented components to ensure that their status is reflected in the overall safety system status. 
2. does not require that the system provide the capability to determine how the removal of a component or components affects a safety system or systems.

3. does not address the administrative procedures and controls that are necessary to assure non-instrumented component status is maintained in an accurate and timely manner.

The deficiencies summarized above were derived by examining whether each acceptance criterion (1isted in Section 4 of this report) was covered by Regulatory Guide 1.47. As summarized in Table 5.1, most of the acceptance criteria were not met. The acceptance criteria represent principles for reducing the likelihood of error associated with the tasks that occur in monitoring the status of the safety system. Because Regulatory Guide 1.47 does not adequately address these criteria, the current guidance cannot assure a reduction of the likelihood of error.

Since Regulatory Guide 1.47 seems to have resulted in little or no significant improvement in safety system status monitoring, it is our recomendation that: 1) Regulatory Guide 1.47 be revised to adequately address the acceptanca criteria contained in this report, and 2) that the revised Regulatory Guide 1.47 be applied to all plants, including those built since the issuance of the original Regulatory Guide. 


\section{REFERENCES}

Asch, S.E. 1951. "Effects of Group Pressure Upon the Modification and Distortion of Judgments," in Groups, Leadership and Men: Research In Human Relations, H. Guetzkow, Ed., Pittsburgh, PA, Carnegie Press, Pp. 177-190.

Dahl1, G., F. Dworzak, B. Karlsson and P. Visuri. 1981a. The Potentials of Computer Assisted Operation Manuals. Report HWR-280, OECD HaTden Reactor Project, Halden, Norway.

Dahll, G., F. Dworzak, B. Karlsen, B. Karlsson and G. Skjerve. 1981b. The Computerized Safety Technical Specifications (CSTS) System for the Forsmark-1 Nuclear Power Plant. Report HWR-234, OECD Haiden Reactor Project, Halden, Norway.

Dember, W.N. 1964. The Psychology of Perception. Holt, Reinhart and Winston, New York, New York.

Halden, 1981. Computerized Operation Manual for Safety Technical Specifications. Report HWR-30, OECD Halden Reactor Project, Halden, Norway.

Huchingson, R. D. 1981. New Horizons for Human Factors in Design. McGrawHill Book Company. New York, New York.

IEEE Standard 279. 1971. Criteria for Protection Systems for Nuclear Power Generating Standards.

Kemeny, J. G., Chairman, President's Commission on the accident at Three Mile Island. 1979. "The Need for Change: The LEgacy of TMI." Washington, D.C.

Kohler, J. E. 1981. "Plant Technical Specifications and Their Effect on Overall Plant Safety." Prepared for the 1981 ANS Winter Meeting.

Malone, T. B., et al. 1980. Human Factors Evaluation of Control Room Design and Operator Performance at Three Mile Is Tand-2." NUREG/CR-1270, Volume 1. Available for purchase from National Technical Information Service, Springfield, Virginia 22161.

U.S. Nuclear Regulatory Commission. 1980. NRC Action Plan Developed as a Result of the TMI-2 Accident. NUREG-0660. AvailabTe for purchase from National Technical Information Service, Springfield, Virginia 22161.

U.S. Nuclear Regulatory Commission. 1981. Guidelines for Control Room Design Reviews. NUREG-0700. Avajlable for purchase from National Technical Information Service, Springfield, Virginia 22161.

U.S. Nuclear Regulatory Commission. 1982. Power Reactor Events. NUREG/BR0051, Available for purchase from National Technical Information Service, Springfield, Virginia 22161. 
Brookhaven National Laboratory. 1982. Identification and Analysis of Human Errors Underlying Pump and Valve Related Events Reported by Nuclear Power Plant Licensees. NUREG/CR-2417, Brookhaven National Laboratory, Upton, New York.

Pew, R. W., D. C. Miller and C. E. Feeher. 1981. Evaluation of Proposed Control Room Improvements Through Analysis of Critical Operator Decisions. Prepared by Bolt Beranek \& Newman, Inc., Cambridge, Massachusetts for the Electric Power Research Institute, EPRI NP-1982.

Pillsbury, W. B. A Study in Apperception. American Journal of Psychology. 1897,8 , PP. 315-393.

Regulatory Guide 1.47. 1973. "Bypassed and Inoperable Status Indications for Nuclear Power Plant Safety Systems."

Rogovin, M., Director, Nuclear Regulatory Commission Special Inquiry Group. 1980. Three Mile Island: A Report to the Commissioners and to the Public. Volume I. U.S. Nuclear Regulatory Commission, Washington, D.C.

Visuri, P. J., and F. Owre. 1981a. A Candidate Approach to a Computer-Based Alarm Handling System (HALO) Functional Description. HWR-23, OECD Halden Reactor Project, Halden, Norway.

Visuri, P. J., B. B. Thomassen and F. A. Owre. 1981b. Handling of Alarms with Logic (HALO) and Other Operator Support Systems. HWR-24, OECD Ha7den Reactor Project, Halden, Norway. 
APPENDIX A

DETAILED TASK LISTING AND RATINGS FOR TASKS 
APPENDIX A

DETAILED TASK LISTING AND RATINGS FOR TASKS

\begin{tabular}{|c|c|c|c|c|}
\hline $\begin{array}{l}\text { TASK } \\
\text { NO } \\
\end{array}$ & TASK DESCRIPTION & $\begin{array}{l}\text { IMPORTANCE } \\
\text { RATING } \\
\end{array}$ & $\begin{array}{l}\text { HUMAN ERROR } \\
\text { RATING } \\
\end{array}$ & $\begin{array}{c}\text { HIGH } \\
\text { PRIORITY } \\
\end{array}$ \\
\hline \multicolumn{5}{|c|}{ Preparing for Tagout } \\
\hline 1. & Define Boundaries & & & \\
\hline $1 \mathrm{a}$. & $\begin{array}{l}\text { Determine if Generic Boundaries } \\
\text { Exist }\end{array}$ & 5 & 2 & $\star$ \\
\hline 1b. & Review P\&IDs, E-Prints, etc. & 5 & 5 & * \\
\hline $1 c$. & Identify Alternate Lineup & 3 & 1 & \\
\hline ld. & Identify Conflicts in Tagging & 5 & 3 & * \\
\hline 2. & Fill out Maintenance Request Sheet & & & \\
\hline $2 a$. & $\begin{array}{l}\text { Fill in Information on Maintenance } \\
\text { Request Sheet }\end{array}$ & 5 & 4 & * \\
\hline $2 \mathrm{~b}$ & $\begin{array}{l}\text { Check Any Special Condition Box/ } \\
\text { Line }\end{array}$ & 1 & 1 & \\
\hline 3. & $\begin{array}{l}\text { Complete Jumper and Lifted Lead } \\
\text { Forms }\end{array}$ & 5 & 2 & $\star$ \\
\hline 4. & Fil1 Out Tags & 4 & 1 & \\
\hline 5. & Check Technical Specifications & 5 & 3 & * \\
\hline 6. & Check Isolation Boundaries & 5 & 4 & $\star$ \\
\hline 7. & $\begin{array}{l}\text { Identify Any Locked Valves in } \\
\text { Isolation Boundaries }\end{array}$ & 5 & 2 & * \\
\hline 8. & $\begin{array}{l}\text { Verify Operability of Redundant } \\
\text { System }\end{array}$ & 5 & 3 & $\star$ \\
\hline 9. & $\begin{array}{l}\text { Coordinate With Other Shift } \\
\text { Supervisors (Multiple-Unit Plants } \\
\text { Only) }\end{array}$ & 4 & 2 & $\star$ \\
\hline 10 & $\begin{array}{l}\text { Determine and Note Need For Checklist } \\
\text { For Change in Alignment }\end{array}$ & 3 & 1 & \\
\hline
\end{tabular}


11. Independently Verify Isolation

Boundary

12. Check Tags vs Request Sheet ing of Jumper and Lifted Leads

14. Sign Jumper and Lifted Lead Sheets

15. Obtain Signature on Request Sheet and Tags to Authorize Removal of Component

16. Determine and Tell Operator Correct Isolation/Deenergization Sequence

17. File Maintenance Request Sheet

18. Update Status Board (if applicable)

19. Update Station Log

20. Update Tagging Log Book

21. Record Changes in Valve Lineups in Master Valve/Breaker Lineup Book

22. Log Manual Locked Valve Manipulations

23. Check Tag vs Equipment

24. Install Tags in Plant

25. Install Tags in Control Room

26. Independently Verify Installation of Tags

27. Isolate Equipment By Manipulating Valves, etc.

28. Authorize Start of Work

Maintaining Status

29. Check Accuracy and Validity of Tags on a Periodic Basis (Monthly, Yearly)
5

4

4

\section{4}

1

1

1

1

32

4

5

4

5

2

2

44

4

4

5

4

4

3

4

1 

RATING

29a. Check Tag vs Request Sheet

29b. Verify that Tag is on Right Equipment

29c. Verify Equipment is in Right Status

30. Reissue Missing/Damaged Tags

31. Review Plant Status With Oncoming Shift

32. Document Partial Release on Maintenance Request Sheet

33. Record Temporary Restoration of Equipment Out For Maintenance

Returning Equipment to Service

34. Indicate Correct Post-Maintenance System Alignment

35. Determine and Tell Operator Correct Realignment Order

36. Change Alignment Back to Desired Status

37. Remove Jumpers and Reinstall Lifted Leads

38. Independently Verify Alignment

39. Perform Double Verification of Realignment of Locked Manual Valves

40. Verify Realignment in Control Room

41. Remove Tags in Plant

42. Remove Tags in Control Room

43. Verify that System is Operable

44. Check (Count) Tags Removed

45. Update Logs and Status Boards
3

4

4

4

4

5

4

5

5

5

4

4

43

4

3

3

5

3

5

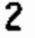

3

3

3

2

4

3

4

2

3

4

2

3

3

2

1

1

1

1

4 
TASK

IMPORTANCE HUMAN ERROR HIGH

NO

TASK DESCRIPTION

RATING

RATING

PRIORITY

46. Inform Other Unit Shift Supervisor that Equipment is Back on Line

(Multiple-Unit Plants Only)

47. Report Completion

4

1

48. Determine System Status During All Modes of Operation
5

5
2

2

*


APPENDIX B

DATA FLOW DIAGRAM AND DESCRIPTION OF EACH FUNCTION 
DATA FLOW DIAGRAM AND DESCRIPTION OF EACH FUNCTION

A data flow diagram has been derived that shows the major decompostion of functions and the interfaces among the functions. A data flow diagram portrays a situation from the perspective of what happens to information during a process.

Four symbols are used in a data flow diagram. These are:

- the named vector (called a data flow), which portrays a data path

- the bubble (called a process), which portrays transformation of data

- the straight line which portrays a file or data base

- the box (called a source or sink), which portrays a net originator or receiver of data--typically a person or an organization outside the domain of our study.

The data flow diagrams for safety system status monitoring are displayed in Figures B.1 through B.5. Following the diagrams is a description of each process and a list of the tasks that are related to each process. 


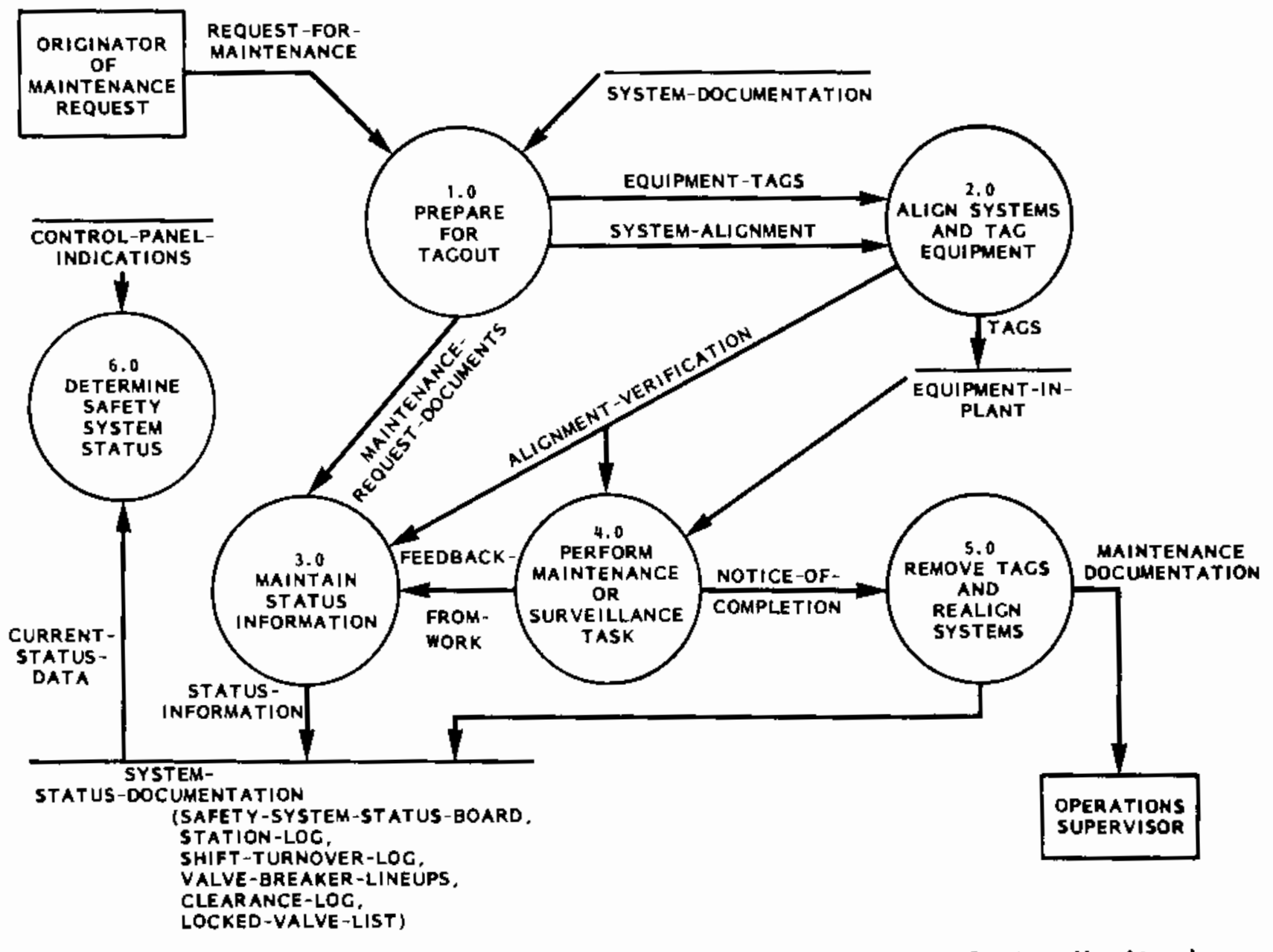

FIGURE B.1. Top-Level Data Flow Diagram for Safety System Status Monitoring 


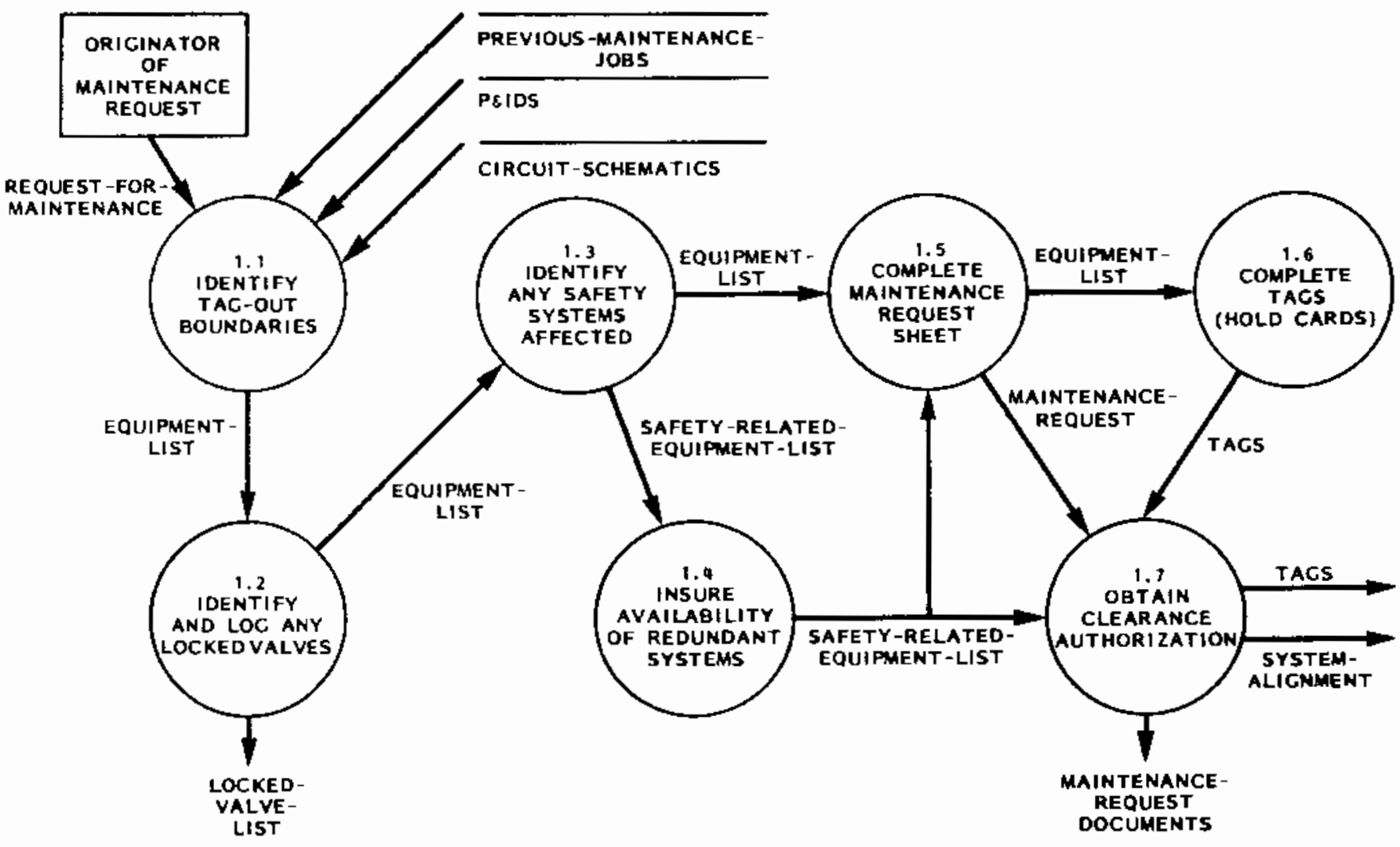

FIGURE B.2. Data Flow for 1.0 - Prepare for Tagout 


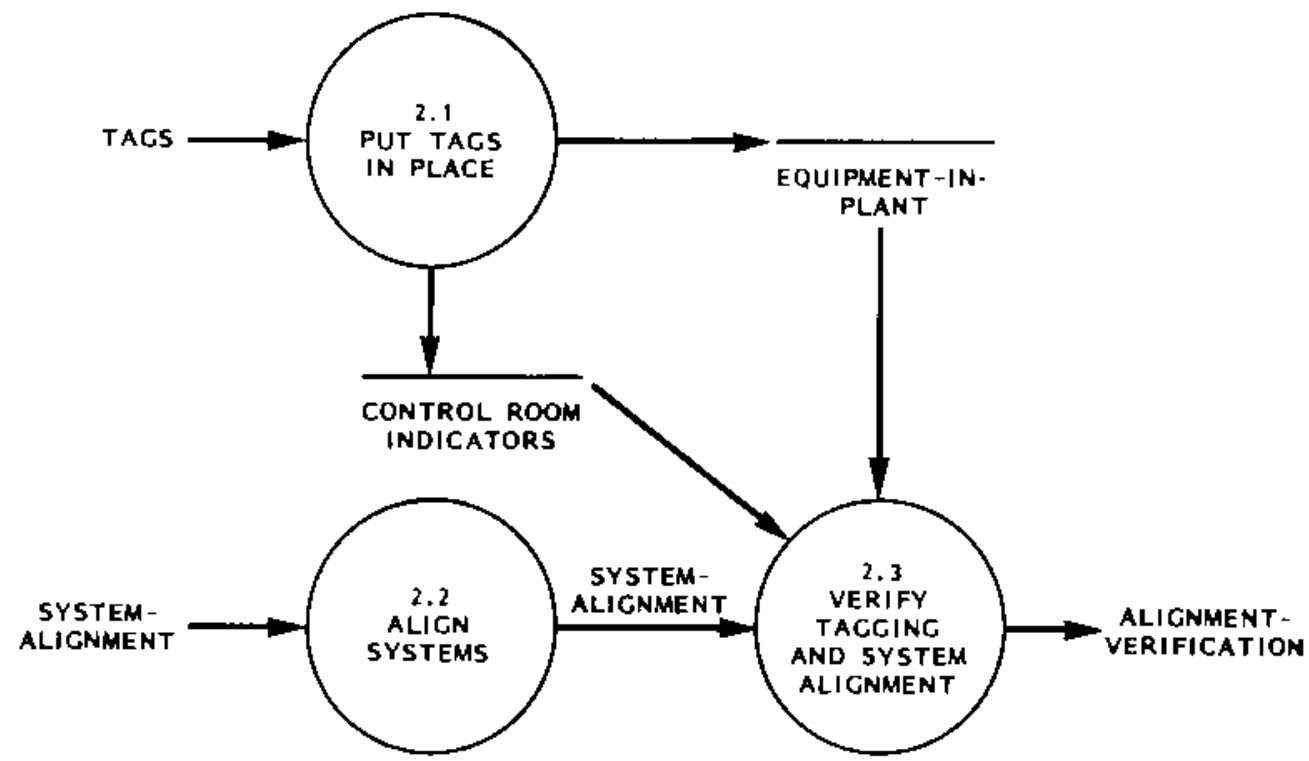

FIGURE B.3. Data Flow for 2.0 - Align Systems and Tag Equipment

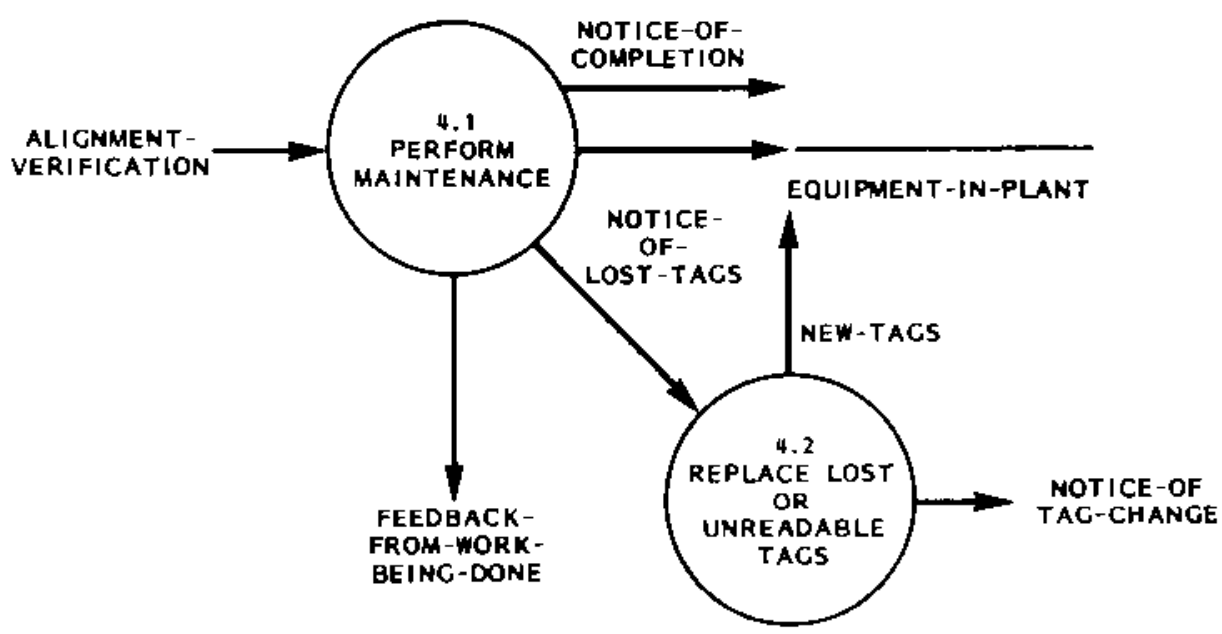

FIGURE B.4. Data Flow for 4.0 - Perform Maintenance Task 


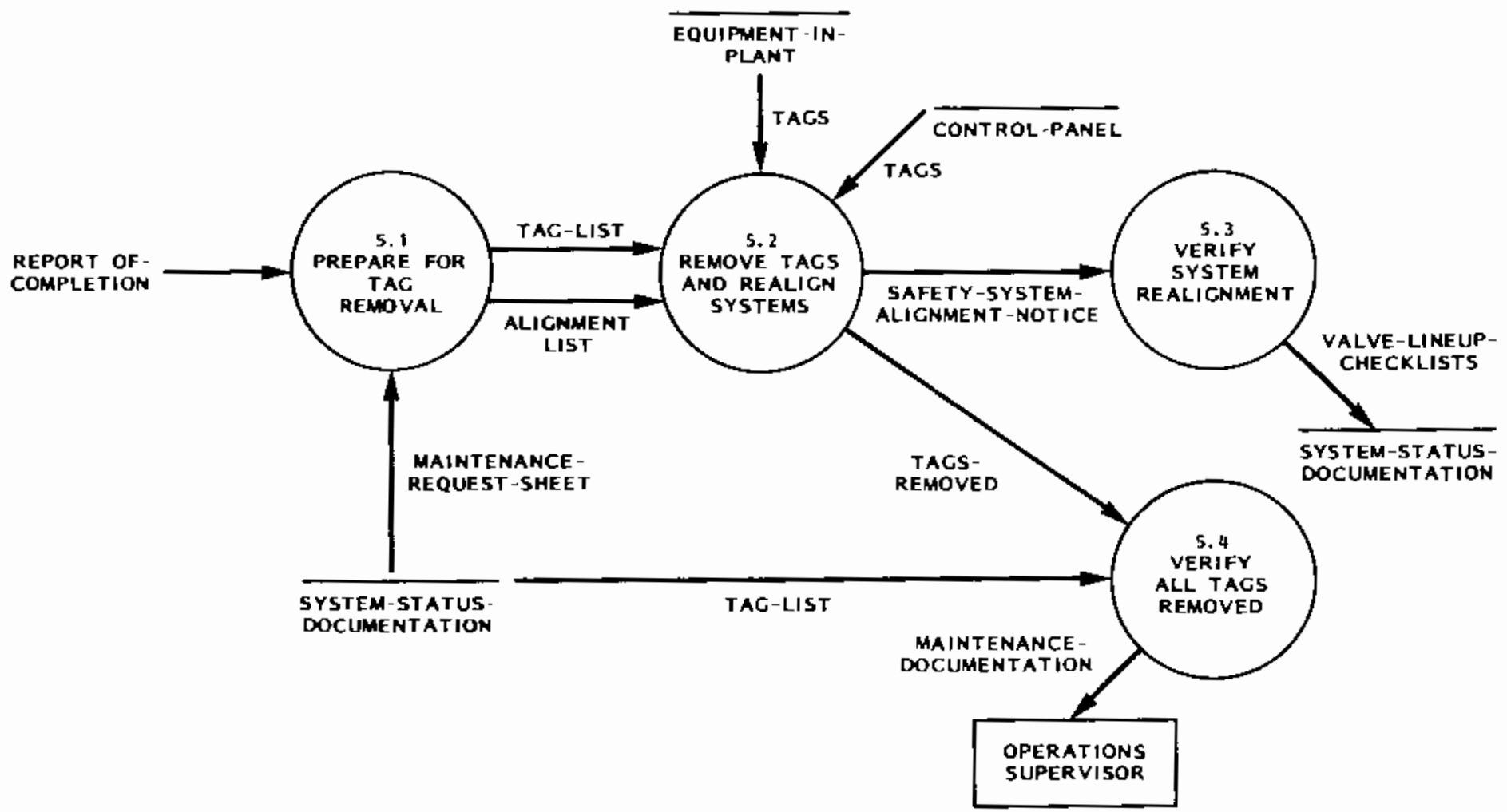

FIGURE B.5. Data Flow for 5.0 - Remove Tags and Realign Systems 
1.0 PREPARE FOR TAGOUT

1.1 IDENTIFY TAGOUT BOUNDARIES

A. Tasks to be Performed

This process includes initiating the hold card request and defining the tagout or isolation boundaries. The request for tagout may be initiated by a technician or the planning and scheduling department, but in all cases the request for tagout requires identification of the components to be tagged out in order to isolate the component requiring maintenance. This will include such items as suction, discharge, and recirculation valves and electrical power supply. The maintenance requester or control room operator will then review system diagrams (P\&IDs) and circuit schematics (E-Prints) to determine the placement of tags for complete isolation of the system, piping, or circuit to be worked on and/or to prevent operation of a system or component from all stations that could exercise control. A check is made to ensure that the equipment to be isolated is not a part of a previous isolation boundary that would result in a conflict in tagging. For repetitive maintenance and inspection work this information could be obtained from the files. In this case the information from the files will be verified and appropriate additional information added to reflect existing plant conditions. The operator is also responsible for identifying an alternate lineup if necessary.

B. Task Codes

- 1 Define boundaries.

- la Determine if generic boundaries exist.

- Ib Review P\&IDs, E-Prints, etc.

- lc Identify alternate 1 ineup.

- Id Identify conflicts in tagging.

\subsection{IDENTIFY AND LOG LOCKED VALVES}

A. Tasks to be Performed

The shift supervisor must ensure that any locked valves that are manipulated are identified and logged. A lockedvalve $\log$ sheet is provided for this purpose. Each time a locked valve is removed from or returned to its required locked position, an entry is to be made in this $\log$. It is 
the responsibility of the operator to verify the shift supervisor's approval of any locked-valve manipulation and log all such manipulations.

B. Task Codes

- 7 Identify any locked valves in isolation boundaries.

- 22 Log manual locked-valve manpulations.

\subsection{IDENTIFY ANY SAFETY SYSTEMS AFFECTED}

A. Tasks to be Performed

The shift supervisor must determine if any safety systems are affected by the tagout or isolation boundaries. If a safety system is involved, the shift supervisor will take action as specified by the appropriate Technical Specification limiting condition for operation (Tech Spec $\mathrm{LCO}$ ) before removing the system or component from service.

B. Task Codes

- 5 Check technical specifications.

\subsection{ENSURE AVAILABILITY OF REDUNDANT SYSTEMS}

A. Tasks to be Performed

In the event that the maintenance or testing activity is associated with a safety system, redundant subsystems or components will be verified to be operable. Upon discovery of inoperable components, or before initiating maintenance on components required by Tech Spec LCOs, their redundant counterpart must be verified as operable.

B. Task Codes

- 8 Verify operability of the redundant system.

\subsection{COMPLETE MAINTENANCE REQUEST SHEET}

A. Tasks to be Performed

After reaching agreement with the necessary isolation boundary requirements, it is the operator's responsibility to fill out the request sheet. If maintenance and design 
change activites have been planned and coordinated by the Planning and Scheduling Group, the request sheet may be completed by an individual in the Planning and Scheduling Group before the activity. If jumpers and lifted leads are involved, the appropriate forms are completed. The actual paper work to be completed will vary, depending upon the plant. An example of the process from one plant is provided here.

The specific items being tagged (i.e., valves, breakers, control switches, fuse holders, etc.) are listed by their unique names (or alpha-numerical designators). Valves to be closed are indicated in the CLOSED section; valves and breakers to be opened are indicated in the OPEN section. Unique positions are described (where sufficient space exists in the SYSTEM ALIGNMENT section of the HOLD Card Request Sheet) for controllers, fuse holders, and the like which are not in their normal position. At the option of the shift supervisor, such controller position changes, fuse removals, blank flange insertion, etc., as well as installation of jumpers and lifting of leads can be annotated on the Jumper and Lifted Lead Log Sheets rather than on the Hold Card Request Sheet. If such an option is chosen, the use of the other forms are annotated at the top of the HOLD Card Request Sheet on the "Special Conditions Required" line, and a check is placed in the YES box under the box provided to record the number of continuation sheets used. When sufficient space is not provided in the SYSTEM ALIGNMENT Section to identify necessary boundary isolation requirements, a HOLD Card Request Continuation sheet is used. The number of sheets so used is reflected in the box under the SYSTEM ALIGNMENT section of the HOLD Card Request Sheet.

B. Task Codes

- 2 Fill out maintenance request sheet.

- $2 a$ Fill in information on maintenance request sheet.

- 2b Check any special condition box line.

- 3 Complete jumper and lifted lead forms. 


\subsection{COMPLETE TAGS}

A. Tasks to be Performed

It is the responsibility of the operator to fill out the tags.

B. Task Codes

- 4 Fill out tags.

\subsection{OBTAIN CLEARANCE AUTHORIZATION}

A. Tasks to be Performed

The shift supervisor is responsible for authorizing the clearance for maintenance. Several tasks must be completed before the final authorization is given. The shift supervisor must ensure that Tech Spec LCOs are not violated as a result of isolating and tagging systems and components. The shift supervisor must ensure that the installation boundaries selected for systems and components are satisfactory and that safe working conditions are established. The shift supervisor must approve any lockedvalve manipulation. The shift supervisor will check the tag coverage for adequacy, and the tags and record sheet for completeness and accuracy. The shift supervisor will authorize the clearance by signing the appropriate location on the request sheet. His signature reflects his concurrence with the accuracy and completeness of the isolation required and his authorization to proceed with the removal of the system or component from service and the installation of tags. In multiple-unit plants the shift supervisor must coordinate the clearance with the supervisor of the other unit(s) if those units are affected.

B. Task Codes

- 5 Check technical specifications.

- 6 Check isolation boundaries.

- 9 Coordinate with other shift supervisors.

- 10 Determine and note need for checklist in realignment.

- 11 Independently verify the isolation boundary. 
- 12 Check tags against request sheet.

- 13 Obtain authorization for repositioning of jumper and lifted leads.

- 14 Sign jumper and lifted lead sheets.

- 15 Obtain signature on request sheet and tags to authorize removal of component. 


\subsection{ALIGN SYSTEMS AND TAG EQUIPMENT}

\subsection{PUT TAGS IN PLACE}

A. Tasks to be Performed

The process of tagging the equipment in the plant involves identifying the appropriate equipment and hanging the tag on the equipment. This is usually performed by an auxiliary operator. The control room operator places the tags on the appropriate control panel indicators.

B. Task Codes

- 23 Check tag against equipment.

- 24 Install tags in plant.

- 25 Install tags in control room.

\subsection{ALIGN SYSTEM}

A. Tasks to be Performed

If appropriate, the shift supervisor will identify (for the operator who will perform that function) the order in which isolation and de-energization will be conducted. An operator will then remove the equipment from service and align components as required.

B. Task Codes

- 16 Determine and tell operator correct isolation/ de-energization sequence.

- 27 Isolate equipment by manipulating valves, etc.

\subsection{VERIFY TAGGING AND SYSTEM ALIGNMENT}

A. Tasks to be Performed

The clearance requester will independently verify the installation of tags and realignment of systems to establish that isolation and required system conditions are attained before work is commenced.

8. Task Codes

- 26 Independently verify installation of tags. 


\subsection{MAINTAIN STATUS INFORMATION}

\section{A. Tasks to be Performed}

The details of the process of maintaining the status of the safety systems varjes with each plant. All plants maintain the following records in some form:

1. Maintenance Request Sheets: For each request for maintenance, the request sheet is stored in the control room until the maintenance has been completed. At one plant, if the maintenance is being performed on any components that affect the safety system, a special clearance form is completed and these are maintained in a separate location in the control room.

2. Master Valve/Breaker Lineup Logs: The system lineup sheets that reflect system configuration are maintained in the control room. If any changes have been made to the lineup, exception sheets are maintained with the lineup logs. In most cases these are stored in front of the lineup sheets in the same log book.

3. Station Log: Following system realignment and installation of tags, the operator makes an entry in the station $\log$ as appropriate.

4. Shift Turnover Log: Typically this log will be a record of safety system alignment at shift change and of maintenance requests that affect safety systems.

5. Safety System Status Board: Some plants maintain a safety system status board that contains entries for change of status of safety systems and for associated Technical Specification limitations and action requi rements.

At some plants the accuracy and validity of outstanding maintenance tags are checked monthly. 
B. Task Codes

- 17 File maintenance request sheet.

- 18 Update status board (if applicable).

- 19 Update station 109.

- 20 Update tagging $\log$ book.

- 21 Record changes in valve lineups in master valve/breaker lineup book.

- 29 Check accuracy and validity of tags periodically (yearly, monthly).

- 29a Check tag against request sheet.

- 29b Verify that the tag is on the right equipment.

- 29c Verify that equipment is in the right status.

- 31 Review plant status with oncoming shift.

- 32 Document partial release on maintenance request sheet.

- 33 Record temporary restoration of equipment out for maintenance. 
4.0 PERFORM MAINTENANCE OR SURVEILLANCE TASK

4.1 PERFORM MAINTENANCE

A. Tasks to be Performed

The shift supervisor will provide a copy of the request sheet to the individual assigned to the job and authorize commencement of work by signing the Job Order Form. Mafntenance will be performed on the equipment. This task is not the responsibility of the operators.

4.2 REPLACE LOST OR UNREAOABLE TAGS

A. Tasks to be Performed

This task description is specific to one plant.

A missing or unreadable card will be reissued by indicating on the applicable sheet that the card was missing or unreadable and a replacement issued. A new card will be issued using the next number on the applicable record sheet. Individuals discovering this condition will notify the shift supervisor, who will authorize the replacement card and so indicate by initialling the missing card entry and the entry for the replacement card. The entry for the missing card will then be lined out.

B. Task Codes

- 30 Reissue missing or damaged tags. 


\subsection{REMOVE TAGS AND REALIGN SYSTEMS}

5.1 PREPARE FOR TAG REMOVAL

A. Tasks to be Performed

The shift supervisor will authorize removal of tags by signing and dating in the appropriate location on the request sheet. He will also check off in the blocks provided if system realignment should be done upon removal of the tags and provide special instructions to the operator, where appropriate, regarding the order in which valves, breakers, etc. shall be realigned. If realignment of the system is to be accomplished and the realignment requirements are extensive or complex, he will indicate the iineup checklists to be used. If jumpers or lifted leads are to be removed/repositioned and were recorded in the Jumper and Lifted Lead Log Sheets, he will authorize such changes in accordance with the requirements specified in "Jumper and Lifted Lead Control." For multiple-unit plants, if the clearance was issued for equipment common to both units or if the clearance affected the opposite unit, the shift supervisor will obtain the concurrence from the opposite shift supervisor to proceed with tag removal and system restoration.

B. Task Codes

- 34 Indicate correct postmaintenance system alignment.

- 35 Determine and tell operator correct realignment order.

\subsection{REMOVE TAGS AND REALIGN SYSTEMS}

A. Tasks to be Performed

As directed by the shift supervisor, it is the responsibility of the operator to remove designated tags from equipment in the plant and the control panel indicators and controls. As directed by the shift supervisor, the operator will realign system valving, power supplies, etc., as required.

B. Task Codes

- 36 Change aijignment back to desired status.

- 37 Remove jumpers and reinstall lifted leads. 
- 41 Remove tags in plant.

- 42 Remove tags in control room.

- 46 Inform other unit shift supervisor that equipment is back on line (multiple-unit plants only).

\subsection{VERIFY SYSTEM REALIGNMENT}

A. Tasks to be Performed

The shift supervisor will ensure that any locked valves are reverified, repositioned and locked in their required position after maintenance is completed and the tagout is released. As directed by the shift supervisor, the operator will independently verify system realignment following removal of the tags and system restoration and then double verify the realignment and locked status of any locked valves. An independent verification of system restoration will be made for safety systems if system restoration was directed to be done.

B. Task Codes

- 38 Independently verify alignment.

- 39 Perform double verification of realignment of locked manual valves.

- 40 Verify realignment in control room.

- 43 Verify that the system is operable.

\subsection{VERIFY ALL TAGS REMOVED}

A. Tasks to be Performed

The operator will check all the tags removed, following restoration of clearances, to ensure that there are the correct number of tags and that all tags have been removed. This is performed by checking the tags against the listing provided on the request sheet.

B. Task Codes

- 44 Check (count) tags removed. 


\subsection{DETERMINE SAFETY SYSTEM STATUS}

A. Tasks to be Performed

The operator must determine the status of the safety system by using information from all of the documents maintained in the control room as defined in process 3 and integrate this with control panel indications.

B. Task Codes

- 48 Determine system status during all modes of operation. 
APPENDIX C

EFFECTIVENESS DF STATUS MONITORING SYSTEMS IN REDUCING THE LIKELIHOOD OF ERRORS IN HIGH-PRIORITY TASKS 


\section{APPENDIX C}

EFFECTIVENESS OF STATUS MONITORING SYSTEMS IN REDUCING THE LIKELIHOOD OF ERRORS IN HIGH-PRIORITY TASKS

Table C.1 relists six classes of status monitoring systems as described in Section 2.2.1.4 of this report. Table C.2 lists 38 status monitoring tasks (selected as having high priority) and five kinds of errors that might be associated with these tasks:

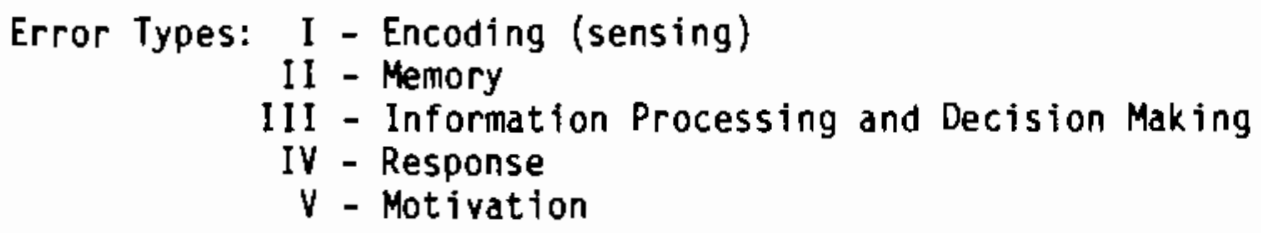

The table is a matrix relating the high-priority tasks, error types, and the status monitoring systems. An " $x$ " in the column of a particular status monitoring system indicates that the system was judged to be potentially effective in reducing the likelihood of errors in the respective high-priority tasks.

Section 3.0 describes these evaluations in more detail. Appendix A presents a complete list of the status monitoring tasks, including the highpriority tasks, and ratings of both task importance and potential for human error. 
TABLE C.1. C1asses of Status Monitoring Systems

and Their Characteristics

I. Push-Button Status Panel

- No readings from instrumented components

- Manual input capability

- Selected number of components on the display

II. Conventional Control Panel

- Displays consist of only the normal control panel display of each component.

- These displays may or may not be grouped by safety system.

III. Control Panel Indicator Lights Specifically for Safety Systems

- Display is grouped by safety system.

- Lights give status of safety system components once the system has been activated.

- Only a selected number of system components are displayed.

- Some systems of this type have a limited capability to change component status indication if equipment is out of service, thus giving limited preoperational status.

IV. Computer-Based System A

- Obtains input only from instrumented components

- No capability for manual input.

- Displays systen and component status on a CRT

- Limited graphic diagram of systems

V. Computer-Based System B

- Obtains input from instrumented components

- Capability for manual input

- Displays system and component status on CRT capabilities

- Hypothetical capabilities

- No graphics capabilities for PIDs for system mimics

VI. Computer-Based System C

- Does not obtain input from instrumented components

- Capability for manual input

- Positive identification of equipment by bar code reader

- Communication from balance of plant to control room

- No hypothetical capabilities

- Extensive P\&ID graphic displays with real-time updating of data 


\section{TARLE C.2. Task Matrix}

\begin{tabular}{|c|c|c|c|c|c|c|}
\hline & & & $\begin{array}{l}\text { PUSH- } \\
\text { BUTTON } \\
\text { STATUS }\end{array}$ & $\begin{array}{l}\text { CONVENTIONAL } \\
\text { CONTROL }\end{array}$ & $\begin{array}{l}\text { SAFETY } \\
\text { SYSTEM } \\
\text { CONTROL }\end{array}$ & $\begin{array}{c}\text { COMPUTER- } \\
\text { BASED } \\
\text { SYSTEMS }\end{array}$ \\
\hline & TASK DESCRIPTION & ERROR TYPE & PANEL & PANEL & PANEL & \\
\hline
\end{tabular}

PREPARE FOR TAGOUT

1. Define Boundaries

1a. Determine if Generic Boundaries Exist

1b. Review P\&ID'S, E-Prints, etc.

1d. Identify Conflicts in Tagging

2. Fill Out Maintenance Request Sheet

2a. Fill in Information on Maintenance Request Sheet

3. Complete Jumper and Lifted Lead Forms I , I I , IV

5. Check Technical Specifications

I , II, III

6. Check Isolation Boundaries

7. Ident ify Any Locked Valves in Isolation Boundaries

8. Verify if Redundant

System is Operable I, I I, I I 
TABLE C.2. (Contd)

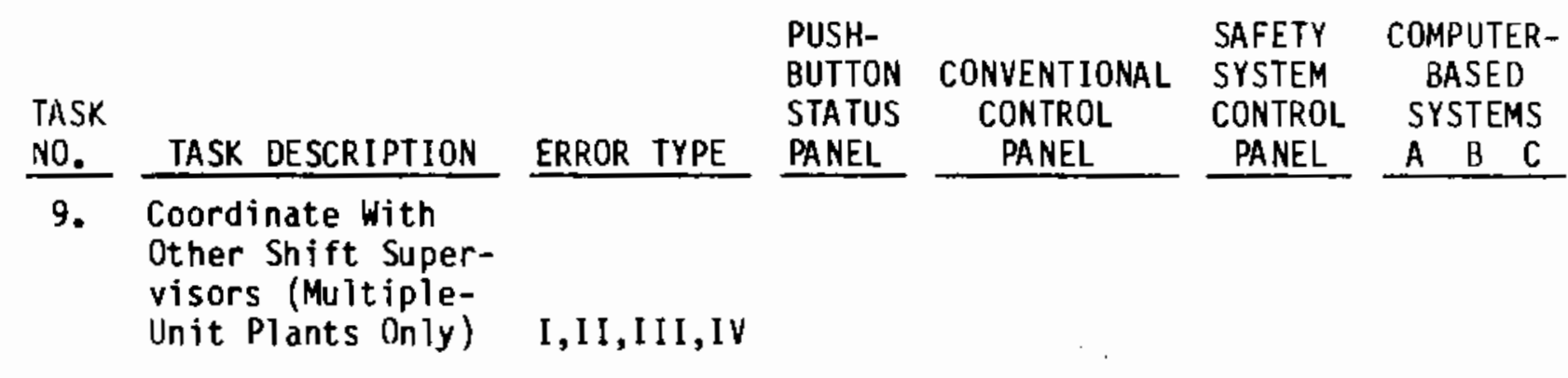

11. Independently

Verify Isolation

Boundary I, II, III

$X$

17. File Maintenance

Request Sheet I, IV

18. Update Status

Board (If Applicable)

I, II, III, IV

$x$

19. Update Station Log I, II,III,IV

20. Update Tagging Log

Book

I, I I , II I, IV

22. Log Manual Locked

Valve Manipulations I, II, IV

23. Check Tag vs

Equipment

I, II, III IV

$x$

24. Install Tags in

Plant

I, I I, IV

25. Install Tags in

Control Room I, II, III

26. Independentiy

Verify Installa-

tion of Tags

I , II, III,V

$x$

27. 1solate Equipment

By Manipulating

Valves, etc.

I, II, I II, IV

$x$

$x \quad x \quad x$ 
TABLE C.2. (Contd)

\begin{tabular}{|c|c|c|c|c|c|c|}
\hline $\begin{array}{l}\text { TASK } \\
\text { NO. }\end{array}$ & & & $\begin{array}{l}\text { PUSH- } \\
\text { BUTTON } \\
\text { STATUS } \\
\text { PANEL }\end{array}$ & $\begin{array}{l}\text { CONVENTIONAL } \\
\text { CONTROL } \\
\text { PANEL }\end{array}$ & $\begin{array}{l}\text { SAFETY } \\
\text { SYSTEM } \\
\text { CONTROL } \\
\text { PANEL }\end{array}$ & $\begin{array}{c}\text { COMPUTER- } \\
\text { BASED } \\
\text { SYSTEMS } \\
A\end{array}$ \\
\hline NO. & TASK DESCRIPTION & ERROR TYPE & PANEL & PANEL & PANEL & A B C \\
\hline
\end{tabular}

MAINTAINING STATUS

29. Check Accuracy and

Validity of Tags

on a Periodic

Basis (Monthly,

Yearly)

29b. Verify Tag is on

Right Equipment $1, I I, I I I, V \quad x$

29c. Verify Equipment

is in Right Status $I, I I, I I I, V \quad x \quad x \quad x \quad x \quad x$

30. Reissue Missing/

Damaged Tags I, II, II

31. Review Plant

Status With

Oncoming Shift

I, II, III,IV X

$x$

$x \quad x \quad x \quad x$

32. Document Partial

Release on Mainte-

nance Request

Sheet

I, I I, I II, IV

33. Record Temporary

Restoration of

Equipment Out For

Maintenance

I, I I I I I, IV

$x$

RETURNING EQUIPMENT TO SERVICE

34. Indicate Correct

Post-Maintenance

System Alignment

I , I I, I I I

$x \times$

35. Determine and Tell

Operator Correct

Realignment Order I, I I, III, IV

36. Change Alignment

Back to Desired

Status

I, II , I I I, IV

$x$

$x$

$x \quad x$ 
TABLE C.2. (Contd)

\begin{tabular}{|c|c|c|c|c|c|c|c|}
\hline $\begin{array}{l}\text { TASK } \\
\text { NO. }\end{array}$ & TASK DESCRIPTION & ERROR TYPE & $\begin{array}{l}\text { PUSH- } \\
\text { BUTTON } \\
\text { STA TUS } \\
\text { PANEL } \\
\end{array}$ & $\begin{array}{l}\text { CONVENTIONAL } \\
\text { CONTROL } \\
\text { PANEL } \\
\end{array}$ & $\begin{array}{l}\text { SAFETY } \\
\text { SYSTEM } \\
\text { CONTROL } \\
\text { PANEL } \\
\end{array}$ & $\begin{array}{r}\text { COMPUTE } \\
\text { BASED } \\
\text { SYSTEM } \\
\mathrm{A} \quad \mathrm{B} \\
\end{array}$ & $\begin{array}{l}\text { ER- } \\
\text { D } \\
\text { MS } \\
C\end{array}$ \\
\hline 37. & $\begin{array}{l}\text { Remove Jumpers and } \\
\text { Reinstall Lifted } \\
\text { Leads }\end{array}$ & $I, I I, I I I, I V$ & & & & $x$ & $x$ \\
\hline 38. & $\begin{array}{l}\text { Independent ly } \\
\text { Verify Alignment }\end{array}$ & $I, I I I, V$ & & & & & $x$ \\
\hline 39. & $\begin{array}{l}\text { Perform Double } \\
\text { Verification of } \\
\text { Realignment of } \\
\text { Locked Manual } \\
\text { Valves }\end{array}$ & I, III,V & & & & & $x$ \\
\hline 40. & $\begin{array}{l}\text { Verify Realignment } \\
\text { in Control Room }\end{array}$ & $\mathrm{I}, \mathrm{I} \mathrm{I}, \mathrm{III}$ & & $x$ & $x$ & & \\
\hline 43. & $\begin{array}{l}\text { Verify that System } \\
\text { is Operable }\end{array}$ & $I, I I, I I I, I V$ & & $x$ & $x$ & & \\
\hline 45. & $\begin{array}{l}\text { Update Logs and } \\
\text { Status Boards }\end{array}$ & I, II III, IV & & & & & \\
\hline 46. & $\begin{array}{l}\text { Inform Other Unit } \\
\text { Shift Supervisor } \\
\text { that Equipment is } \\
\text { Back on Line } \\
\text { (Multiple-Unit } \\
\text { Plants Only) }\end{array}$ & $\mathrm{I}, \mathrm{II}, \mathrm{IV}$ & & & & & \\
\hline
\end{tabular}

48. Determine System

Status During All

Modes of Operation I, II, II,V X X 


\section{APPENDIX D}

EFFECTIVENESS OF PROCEDURES IN REDUCING THE LIKELIHOOD OF ERRORS IN HIGH-PRIORITY TASKS 
APPENDIX D

EFFECTIVENESS OF PROCEDURES IN REDUCING THE LIKELIHOOD OF ERRORS IN HIGH-PRIORITY TASKS

The following table rates the effectiveness of procedures in reducing the likelihood of errors in 38 status monitoring tasks selected as having high priority. The rating codes are as follows:

Blank - Error type not associated with this taks

0 - Use of procedures would not significantly reduce error type

1 - Good procedures would reduce the error type but procedures don't exist or are not adequate as written.

2 - Good procedures would reduce the error type and existing procedures are adequate as written.

A full discussion of these evaluations can be found in Section 3.0 of this report. Appendix A presents a complete list of the status monitoring tasks, including these high-priority tasks, and ratings of both task importance and potential for human error. 
IABLE D.1. Procedures Effectiveness Ratings

\begin{tabular}{|c|c|c|c|c|c|c|}
\hline $\begin{array}{l}\text { TASK } \\
\text { NO. }\end{array}$ & TASK DESCRIPTION & $\begin{array}{c}I \\
\text { ENCODING } \\
\end{array}$ & $\begin{array}{c}\text { II } \\
\text { MEMORY }\end{array}$ & $\begin{array}{c}\text { ERROR } \\
\text { TYPES } \\
\text { III } \\
\text { PROCESSING } \\
\end{array}$ & $\begin{array}{c}\text { IV } \\
\text { RESPONSE }\end{array}$ & $\begin{array}{c}V \\
\text { MOTIVATION } \\
\end{array}$ \\
\hline \multicolumn{7}{|c|}{ PREPARE FOR TAGOUT } \\
\hline 1. & Define Boundaries & & & & & \\
\hline la. & $\begin{array}{l}\text { Determine if Generic } \\
\text { Boundaries Exist }\end{array}$ & 0 & 2 & 0 & & \\
\hline $1 b$. & $\begin{array}{l}\text { Review P\&ID'S, } \\
\text { E-Prints, etc. }\end{array}$ & 0 & 0 & 0 & & \\
\hline ld. & $\begin{array}{l}\text { Identify Conflicts in } \\
\text { Tagging }\end{array}$ & 0 & 1 & 1 & & \\
\hline 2. & $\begin{array}{l}\text { Fill Out Maintenance } \\
\text { Request Sheet }\end{array}$ & & & & & \\
\hline $2 a$. & $\begin{array}{l}\text { Fill in Information } \\
\text { on Maintenance } \\
\text { Request Sheet }\end{array}$ & 2 & 1 & & 0 & \\
\hline 3. & $\begin{array}{l}\text { Complete Jumper and } \\
\text { Lifted Lead Forms }\end{array}$ & 2 & 1 & & 0 & \\
\hline 5. & $\begin{array}{l}\text { Check Technical } \\
\text { Specifications }\end{array}$ & 0 & 1 & 0 & & \\
\hline 6. & $\begin{array}{l}\text { Check Isolation } \\
\text { Boundaries }\end{array}$ & 0 & 1 & 0 & & \\
\hline 7. & $\begin{array}{l}\text { Identify Any Locked } \\
\text { Valves in Isolation } \\
\text { Boundaries }\end{array}$ & 1 & 1 & 1 & & \\
\hline 8. & $\begin{array}{l}\text { Verify if Redundant } \\
\text { System is Operable }\end{array}$ & 1 & 1 & 0 & & \\
\hline 9. & $\begin{array}{l}\text { Coordinate With Other } \\
\text { Shift Supervisors } \\
\text { (Multiple-Unit Plants } \\
\text { Only) }\end{array}$ & 0 & 1 & 0 & 0 & \\
\hline 11. & $\begin{array}{l}\text { Independentiy Verify } \\
\text { Isolation Boundary }\end{array}$ & 0 & 1 & 0 & & \\
\hline
\end{tabular}


TABLE 0.1. (Contd)

\begin{tabular}{|c|c|c|c|c|c|c|}
\hline \multirow[b]{2}{*}{$\begin{array}{l}\text { TASK } \\
\text { NO. }\end{array}$} & \multirow[b]{2}{*}{ TASK DESCRIPTION } & \multirow[b]{2}{*}{$\begin{array}{c}\text { I } \\
\text { ENCOOING } \\
\end{array}$} & \multirow[b]{2}{*}{$\begin{array}{c}\text { II } \\
\text { MEMORY } \\
\end{array}$} & \multirow{2}{*}{$\begin{array}{c}\text { ERROR } \\
\text { TYPES } \\
\text { III } \\
\text { PROCESSING } \\
\end{array}$} & \multirow[b]{2}{*}{$\begin{array}{c}\text { IV } \\
\text { RESPONSE } \\
\end{array}$} & \multirow[b]{2}{*}{$\begin{array}{c}V \\
\text { MOTIVATION }\end{array}$} \\
\hline & & & & & & \\
\hline 17. & $\begin{array}{l}\text { File Maintenance } \\
\text { Request Sheet }\end{array}$ & 0 & & & 0 & \\
\hline 18. & $\begin{array}{l}\text { Update Status Board } \\
\text { (If Applicable) }\end{array}$ & 0 & 1 & 0 & 1 & \\
\hline 19. & Update Station Log & 0 & 2 & 0 & 0 & \\
\hline 20. & $\begin{array}{l}\text { Update Tagging Log } \\
\text { Book }\end{array}$ & 0 & 2 & 0 & 0 & \\
\hline 22. & $\begin{array}{l}\text { Log Manual Locked } \\
\text { Valve Manipulations }\end{array}$ & 0 & 1 & & 0 & \\
\hline 23. & $\begin{array}{l}\text { Check Tag vs } \\
\text { Equipment }\end{array}$ & 0 & 1 & 0 & 0 & \\
\hline 24. & Install Tags in Plant & 0 & & 2 & 1 & \\
\hline 25. & $\begin{array}{l}\text { Install Tags in } \\
\text { Control Room }\end{array}$ & 0 & 2 & 0 & & \\
\hline 26. & $\begin{array}{l}\text { Independently Verify } \\
\text { Installation of Tags }\end{array}$ & 0 & 2 & 0 & & 1 \\
\hline 27. & $\begin{array}{l}\text { Isolate Equipment By } \\
\text { Manipulating Valves, } \\
\text { etc. }\end{array}$ & 0 & 1 & 0 & 1 & \\
\hline
\end{tabular}

MAINTAINING STATUS

29. Check Accuracy and

Validity of Tags on

a Periodic Basis

(Monthly, Yearly)

29b. Verify Tag is on

Right Equipment

0

0

29c. Verify Equipment is

in Right Status

$0 \quad 0$

0

0

30. Reissue Missing/

Damaged Tags

$\begin{array}{lll}0 & 1 & 0\end{array}$ 
TABLE D.1. (Contd)

\begin{tabular}{|c|c|c|c|c|c|c|}
\hline \multirow[b]{2}{*}{$\begin{array}{l}\text { TASK } \\
\text { NO. } \\
\end{array}$} & \multirow[b]{2}{*}{ TASK DESCRIPTION } & \multirow[b]{2}{*}{$\begin{array}{c}I \\
\text { ENCODING }\end{array}$} & \multirow[b]{2}{*}{$\begin{array}{c}\text { I I } \\
\text { MEMORY }\end{array}$} & \multirow{2}{*}{$\begin{array}{c}\text { ERROR } \\
\text { TYPES } \\
\text { III } \\
\text { PROCESSING }\end{array}$} & \multirow[b]{2}{*}{$\begin{array}{c}\text { IV } \\
\text { RE SPONSE }\end{array}$} & \multirow[b]{2}{*}{$\begin{array}{c}V \\
\text { MOTIVATION }\end{array}$} \\
\hline & & & & & & \\
\hline 31. & $\begin{array}{l}\text { Review Plant Status } \\
\text { With Oncoming Shift }\end{array}$ & 1 & 1 & 0 & 0 & \\
\hline 32. & $\begin{array}{l}\text { Document Partial } \\
\text { Release on Mainte- } \\
\text { nance Request Sheet }\end{array}$ & 0 & 2 & 0 & 0 & \\
\hline
\end{tabular}

33. Record Temporary

Restoration of

Equipment Out For

Maintenance

0

2

0

0

RETURNING EQUIPMENT TO SERVICE

34. Indicate Correct

Post-Maintenance

System Al ignment

020

35. Determine and Tell

Operator Correct

Realigninent Order

0

$2 \quad 1$

0

36. Change Alignment

Back to Desired

St atus

0

1

1

1

37. Remove Jumpers and

Reinstall Lifted

Leads

0

111

38. Independently Verify

A) i gnment

1

0

0

39. Perform Double Verification of Realignment of Locked Manual Valves

1

0

40. Verify Realignment in Control Room

0

1

0

43. Verify that system is Operable

$\begin{array}{llll}0 & 1 & 1 & 1\end{array}$ 
TABLE D.1. (Contd)

\begin{tabular}{|c|c|c|c|c|c|c|}
\hline \multirow[b]{2}{*}{$\begin{array}{l}\text { TASK } \\
\text { NO. }\end{array}$} & \multirow[b]{2}{*}{ TASK DESCRIPTION } & \multirow[b]{2}{*}{$\begin{array}{c}\text { I } \\
\text { ENCODING } \\
\end{array}$} & \multirow[b]{2}{*}{$\begin{array}{c}\text { II } \\
\text { MEMORY } \\
\end{array}$} & \multirow{2}{*}{$\begin{array}{c}\text { ERROR } \\
\text { TYPES } \\
\text { III } \\
\text { PROCESSING } \\
\end{array}$} & \multirow[b]{2}{*}{$\begin{array}{c}\text { IV } \\
\text { RESPONSE } \\
\end{array}$} & \multirow[b]{2}{*}{$\begin{array}{c}v \\
\text { MOTIVATION } \\
\end{array}$} \\
\hline & & & & & & \\
\hline 45. & $\begin{array}{l}\text { Update Logs and } \\
\text { Status Boards }\end{array}$ & 0 & 2 & 0 & 0 & \\
\hline 46. & $\begin{array}{l}\text { Inform Other Unit } \\
\text { Shift Supervisor tha } \\
\text { Equipment is Back on } \\
\text { Line (Multiple-Unit } \\
\text { Plants Only) }\end{array}$ & 0 & 2 & 0 & 0 & \\
\hline 48. & $\begin{array}{l}\text { Determine System } \\
\text { Status During Al1 } \\
\text { Modes of Operation }\end{array}$ & 0 & 2 & 0 & & 0 \\
\hline
\end{tabular}





\section{APPENDIX E}

GUIDELINES FOR EFFECTIVE PROCEDURES 


\section{APPENDIX E}

\section{GUIDELINES FOR EFFECTIVE PROCEDURES}

This appendix presents guidelines on those attributes of procedures that make them more effective in general and, thus, in helping control room operators remain continuously aware of the status of their safety systems. Material in this Appendix has been derived from NUREG/CR-1977, NUREG/CR-0799, and NUREG-D899.

\section{E.1 FUNDAMENTAL REQUIREMENTS}

The fundamental requirement of a procedure is that it be usable. This means that the technical information is complete and accurate and that the information is presented in such a way that the operator can find it quickly and comprehend it easily. Procedures should be complete and accurate, that is, internally consistent, technicdlly correct, and accurate in nomenclature.

\section{E.2 ACCESSIBILITY}

Up-to-date copies of procedures should be readily available in the control room. The procedures should be packaged in such a way that they can be readily located. Some distinct means shall be provided for identifying the applicable procedures. For example, the procedures may use color-coded binders. The procedures should be tabbed or should have other means to facilitate quick access to relevant sections.

\section{E.3 COMPREHENSIBILITY}

The following are the key elements that enhances comprehensibility.

- simple and familiar language

- uniforin vocabulary

- short sentences

- short paragraphs

- simple illustrations

- concrete and specific words

- simple, active, affirmative, declarative sentence structure.

\section{E.4 LEGIBILITY}

Legibility can be enhanced by using a minimum of 10-point type and using one and one-half or double spacing between lines. Black print on matte-finish white paper is recommended. Any tables or figures that are reduced in size 
shall maintain characters that are not less than 10-point size. Attention shall be given to reproduction quality so as not to significantly degrade the legibility of the material even under reduced illumination.

\section{E.5 COVER PAGE}

The cover page should indicate the number of the procedure to ensure that it is the most current revision. It should show the required reviews and approval signatures. The cover page should contain:

- Title and procedure number

- Date of original procedure

- Current revision number and date

- Number of pages

- Review and approvals.

\section{E.6 TABLE OF CONTENTS}

A table of contents is helpful if the procedure is lengthy.

\section{E.7 IDENTIFYING INFORMATION ON EACH PAGE}

Each page of the procedure should have a shortened form of its title with procedure number, revision number and date, and page right hand corner. This information should be single spaced. of in the upper

\section{E.8 CHECK-OFF PROVISIONS}

Some type of check-off may be helpful in a long procedure (generally over seven action steps) so that the operator can readily keej track of whre he is in the procedure. A small column of space with lines () should be provided between the left and right columns to check of each action step.

\section{E.9 REFERENCING PROCEDURES}

All information necessary to carry out a task or subprocedure should be consolidated in one place. Once the sequence of actions is begun, there should ordinarily be no need to refer to other parts of the procedure for information necessary to continue the task. 


\section{E.10 CONSISTENT USAGE}

If there are synonyms for a concept, object or operation, one of them

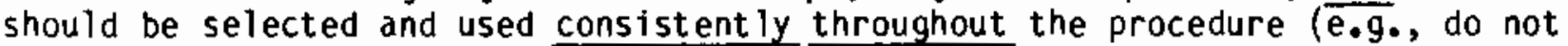
use the terms unit, assembly, equipment, and component interchangeably to refer to the same item).

\section{E.11 USE OF STANDARDIZED NOMENCLATURE AND IDIOMS}

Procedures should be written using standardized terms and idioms familiar to plant operators in the nuclear industry. Equipment nomenclature shall be identical to that on the control board.

For equipment referenced in the procedure, the official term or full name shall be used for the first reference to a hardware item at the beginning of each subprocedure, followed by a shortened name, abbreviation, or acronym in parenthesis. Thereafter, the shortened name, abbreviation, or acronym may be used.

Vague words, slang, or local jargon that might be misunderstood should be avoided. Avoid words that are ambiguous or difficult to define.

\section{E.12 WARNING, CAUTION, AND NOTE STATEMENTS}

WARNING, CAUTION, and NOTE statements should be used in procedures to attract attention to essential or critical information, and should be worded and placed in accordance with the following guidelines. Warnings, cautions, and notes should not contain action steps.

\section{E.12.1 Warnings and Cautions}

A WARNING is defined as a statement that describes those conditions, practices, or procedures which must be observed to avoid injury, loss of life, or a long-term health hazard. A CAUTION is defined as a statement that describes those conditions, practices, or procedures which must be observed to avoid damage or destruction of equipment. The use of warnings and cautions should be restricted to those situdtions which pose a recognized threat to personnel and equipment.

WARNING and CAUTION statements should contain the following information, ordinarily in the order indicated:

- the specific nature of the hazard

- the precautions necessary to avoid or minimize the hazard

- the location or source of the hazard

- the consequences of failing to heed the WARNING or CAUTION

- time considerations, when critical. 
The information should be presented in a few simple words and in clear, stigightforward sentences. It should be self-contained: the user should not be referred elsewhere. However, when the location of a hazard, its conserfumces, and remedial actions are clearly implied by the type of hazard, a: " $y$ anpeared elsewhere on the same page, such information may be onitted.

$\therefore$ an

A note is a statement that describes information of special importance or interest or that aids in job performance. This is information that should enhance the understanding of the procedure, will facilitate decisions, and would otherwise be difficult to find and incorporate in the procedure. For exarnple, locations of controls and displays should be placed in Notes, and not included in the action steps. Notes depend upon the material being presented and therefore do not have special content requirements.

\section{E.13 PLACEMENT OF WARNING, CAUTION, AND NOTE STATEMENTS}

In writing these statements, the following guidelines should be considered:

- WARNING and CAUTION statements should always precede the task or action steps to which they apply.

- Any WARNING or CAUTION that is general enough to apply to the entire procedure should be placed before the first action step in the procedure.

- WARNING or CAUTION statements should be placed in a box that extends from margin to margin.

- The word WARNING and CAUTION should be typed in all capital letters arid centered inside the top of the box.

- When a WARNING or CAUTIDN consists of two or more paragraphs, the heading should not be repeated above each paragraph.

- If it is necessary to precede an action step by both a WARNING and a CAUTION, they should appear in separate boxes with the WARNING preceding the CAUTION.

\section{E.14 FIGURES AND TABLES}

Text and related figures and tables should be arranged so they can be viewed at the same time. If this is not possible, the figure should be placed as close to its first callout as possible. 
Each figure and table should contain only that information directly relevant to a specific task or step. The intent is to provide several small,

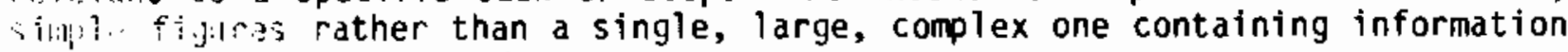
not relevant to the immediate task.

\section{E.15 TITLES OF FIGURES AND TABLES}

Each figure or table should be referenced in the text by Arabic number (e.g., Figure 1, Table 2), and each should have a title. The title should distinguish the contents or purpose of its figure or table from others in the procedure. Each title should identify the variables represented in its figure or table. Table titles should be centered above the table. Figure titles should be centered below the figure.

\section{E.16 FIGURE FORMAT}

For flow diagrams, all inputs and outputs should be clearly identified, with inputs at the left or top, and outputs on the right or bottom, respectively. The direction of flow should be indicated by arrows; signal or pressure flow should be from left to right or top to bottom and feedback or return flow from right to left or bottom to top.

Line graphs should depict a maximum of four relationships between the axis variables. Lines depicting relationships should be coded for easy discrimination. Graph scales may be linear or nonlinear as required for comprehension or use. The axes should be labeled to indicate the variables and units of measurement.

The number of grid lines used should be such that the user can read values to the required degree of accuracy. The grid lines should be no less than 0.1 inch apart. Grid lines should be easily distinguished from the graph lines, and shall not obscure detail necessary for the proper use of the graph.

\section{E.17 TABLE FORMAT}

To avoid clutter, at least 25 percent of the area within the table should be clear space between columns and groups of rows. Entries should be aligned with columns as follows:

- For decimal data, decimal points should be aligned.

- For scientific notation, multiplication signs should be aligned.

- All other numeric data should be aligned flush right.

- Alphabetic or alphanumeric data should be aligned flush left.

Units of measurement should be specified in row or column headings, as appropriate. Interpolations should be minimized by expanding the table or by presenting the data in a graph. 



\section{APPENDIX $F$}

GUIDELINES ON LABELS AND PLACARDS 


\section{APPENDIX F}

\section{GUIDELINES ON LABELS AND PLACARDS}

The following guidelines should be followed for the design of labels:

- where the ambient jlluminance will be above 10 lux $(0.9 \mathrm{ft}-\mathrm{c})$, black characters should be provided on a light background.

- The width of letters should be $3 / 5$ of the height, except for "M" and " 2 ," which should be $4 / 5$ of the height, and " $I$," which should be one stroke wide.

- The width of numerals shalt preferably be $3 / 5$ of the height, except for the "4," which should be one stroke width wider, and the "1" which should be one stroke wide.

- Where conditions indicate the use of wider characters, as on a curved surface, the basic height-to-width ratio may be increased to $1: 1$.

- For black characters on a white (or light) background, the stroke width should be $1 / 6$ to $1 / 7$ of the height.

- Where dark adaptation is required or legibility at night is a critical factor, and white characters are specified on a black background, the stroke width of the characters should be from $1 / 7$ to $1 / 8$ of the height (i.e., narrower than specified for normal daytime vision). The stroke width should be the same for all letters and numerals of equal height.

- The minimum space between characters should be one stroke width.

- The minimum space between words should be the width of one character.

- The minimum space between lines should be one-half character height.

- The height of letters and numerals should be determined by the required reading distance and luminance.

- To reduce confusion and operator search time, labels should be graduated in size. The characters in group labels should be larger than those used to identify individual controls and displays. The characters identifying controls and displays should be larger than the characters identifying control positions. With the smallest 
characters determined by viewing conditions, the dimensions of each character should be at least 25 percent larger than those of the next smaller label.

- Labels should be printed in all capitals; periods should not be used after abbreviations. Legends should be printed in all capitals; periods or commas should not be used. Instructional material placards may employ capitals and lower case when the amount of material consists of several lines; however, for short, instructional material, all-capitals are preferred. All-capital material, consisting of larger caps for the initial letter in a paragraph, line of instruction, or procedural step, may be used.

- Color combinations of printing and background should maximize

legibility. The best color combinations in desceriding order are:

blue on white

black on yellow

green on white

black on white

green on red

red on yellow

If color coding of labels and signs is necessary, select colors on the basis of recognizable differences. The following colors are considered ideal for surface coding because they are easily recognizable by both nomal and color deficient observers:

$\begin{array}{lr}\text { Color } & \text { FED-STD } 595 \text { Code No. } \\ \text { black } & 37038 \\ \text { white } & 27875 \\ \text { yellow } & 23655\end{array}$


NUREG/CR-3621

PNL-4832

IS, 95

\section{DISTRIBUTION}

No. of

Copies

OFFSITE

G. W. Lapinsky

M/S 135

U.S. Nuclear Regulatory Commission

Division of Human Factors Safety

Office of Nuclear Reactor Regulation

Washington, D.C. 20555

U.S. Nuclear Regulatory Commission

Division of Technical

Information and Document Control

7920 Norfolk Avenue

Bethesda, MD 20014

D. G. Cain

Nuclear Safety Analysis Center

$3412 \mathrm{Hillview}$ Avenue

P.0. Box 10412

Palo Alto, CA 94303
No. of

Copies

Paul Dietz

Institute of Nuclear Power Operations

1820 Water Place

Atlanta, GA 30339

ONSITE

Pacific Northwest Laboratory

R. V. Badalamente

P. J. Cowley

V. L. Crow

J. R. Lewis (20)

R. D. Widrig

Publishing Coordination (5)

Technical Information (2)

Battelle-Human Affairs Research

Centers

M. H. Morgenstern

W. R. Rankin

T. B. Rideout 



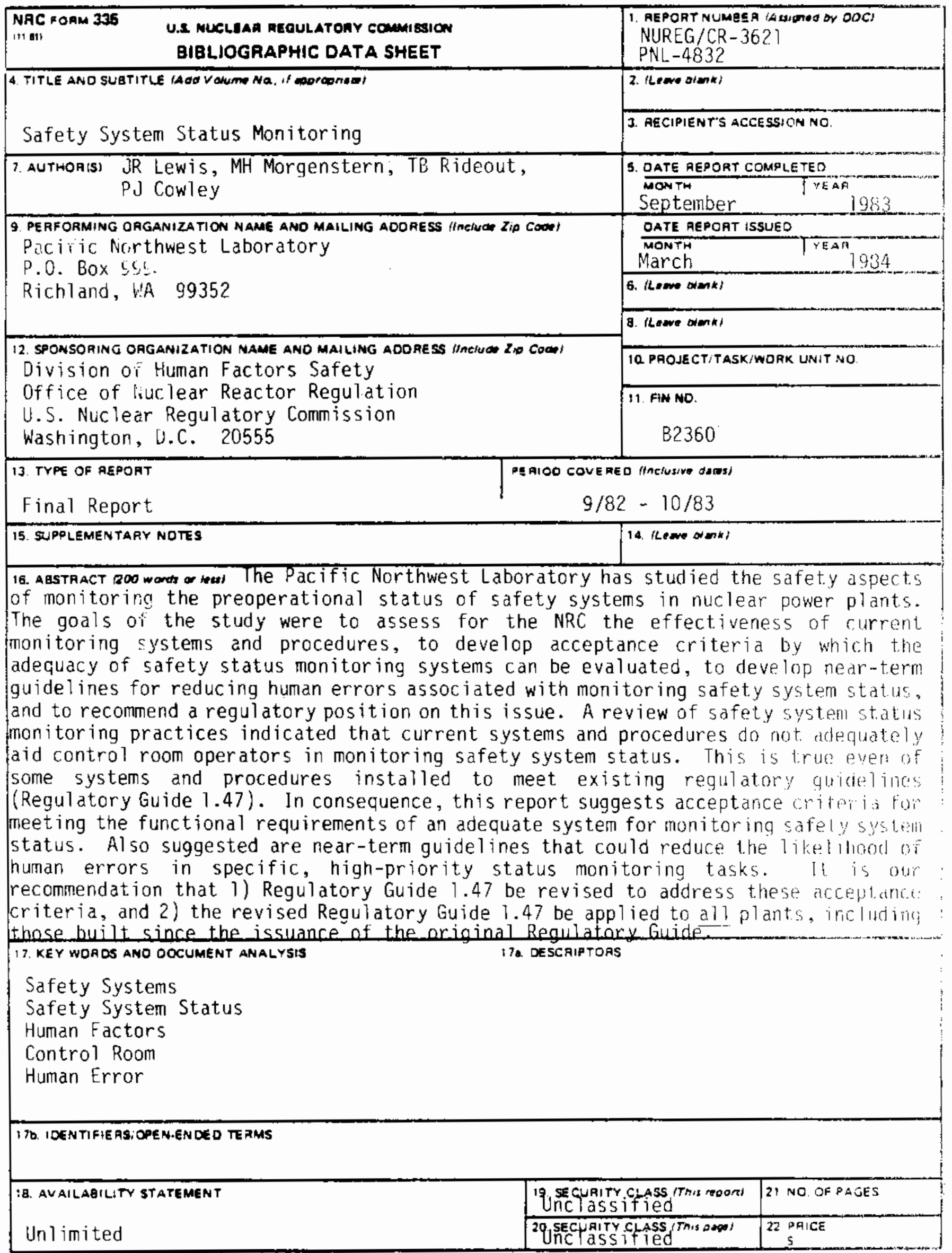

NAC FOAM 33 i11.ms

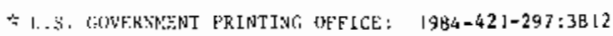


